\title{
The development, diffusion and evaluation of a fall hazard safety training program for residential construction workers utilizing instructor led and new media delivery
}

\author{
Mark D. Fullen \\ West Virginia University
}

Follow this and additional works at: https://researchrepository.wvu.edu/etd

\section{Recommended Citation}

Fullen, Mark D., "The development, diffusion and evaluation of a fall hazard safety training program for residential construction workers utilizing instructor led and new media delivery" (2009). Graduate Theses, Dissertations, and Problem Reports. 2876.

https://researchrepository.wvu.edu/etd/2876

This Dissertation is protected by copyright and/or related rights. It has been brought to you by the The Research Repository @ WVU with permission from the rights-holder(s). You are free to use this Dissertation in any way that is permitted by the copyright and related rights legislation that applies to your use. For other uses you must obtain permission from the rights-holder(s) directly, unless additional rights are indicated by a Creative Commons license in the record and/ or on the work itself. This Dissertation has been accepted for inclusion in WVU Graduate Theses, Dissertations, and Problem Reports collection by an authorized administrator of The Research Repository @ WVU.

For more information, please contact researchrepository@mail.wvu.edu. 
The Development, Diffusion and Evaluation of a Fall Hazard Safety Training Program for

Residential Construction Workers Utilizing Instructor Led and New Media Delivery

Mark D. Fullen

Dissertation submitted to the College of Human Resources and Education

at West Virginia University in partial fulfillment of the requirements

for the degree of

Doctor of Education

in

Technology Education

R. Neal Shambaugh, Ph.D., Chair

Paul E. Becker, Sc.D.

Sebastian R. Díaz, Ph.D., J.D.

Daniel Hartley, Ed.D.

Jacqueline Webb-Dempsey, Ph.D.

Department of Technology, Learning, and Culture

Morgantown, West Virginia

2009

Keywords: Developmental Research, Residential Construction, Fall Protection, Fall Hazards, Safety Training, Task Based Safety Training, DVD, OSHA Susan Harwood Training Grant

(C) 2009 Mark D. Fullen 


\begin{abstract}
The Development, Diffusion and Evaluation of a Fall Hazard Safety Training Program for Residential Construction Workers Utilizing Instructor Led and New Media Delivery
\end{abstract}

Mark D. Fullen

The numbers of workers in the residential construction industry are on the rise. Falls have continually been the largest contributor to residential construction worker deaths and injuries. These workers are largely self-employed or working for small companies. These individuals are difficult to reach through traditional methods. This research proposed to use the Internet to reach this group and engage them in the curriculum development cycle.

An instructional design research method known as Type I Developmental Research was utilized to study the methodology, product, implementation, and outcomes for this program throughout the design, implementation, and evaluation stages. Five complete cycles of design, implementation, and evaluation were evaluated. These cycles occurred organically as the analysis of the data collected resulted in a need to revise the training material, delivery method or evaluation method. Type I developmental research treats the design-development-evaluation process as a form of inquiry and does so by embedding traditional research methods into the development project and utilizes the case study method (Richey, Klein \& Nelson, 2004).

The research questions were: (1) Does the training program addressing residential fall hazards and safety bring about individual or group behaviors that may reduce the likelihood of falls from heights on residential construction sites? (2) Does the technology-based availability and delivery of this training material increase trainee interest? (3) Does including residential construction worker, supervisor, and expert feedback into the developmental cycle of training development impact the relevance and acceptability of the residential fall protection training material?

The results of the study were that the newly developed material has brought about increased knowledge and fall protection usage. The availability of the training material on the Internet led to a broad diffusion and use of the training material, although most seekers of this material were trainers and safety professionals rather than workers. Finally, including workers and others in the training development cycle has impacted the relevance and acceptance of the material. 


\section{DEDICATION}

This dissertation is dedicated to my Grandfather, George Kincaid. He taught me that I could do anything I wanted to if I put my mind to it. My natural curiosity and my thirst for knowledge came from having the honor of spending my childhood working at his side. 


\section{ACKNOWLEDGMENTS}

I would like to acknowledge the many people who have contributed to the completion of this dissertation. I would like to offer sincere gratitude to my dissertation advisor, Dr. Neal Shambaugh, for his consistent support and encouragement throughout this process. His feedback to my questions and work in progress provided me the confidence to keep going; to Dr. Paul Becker for his mentorship to me over the past decade. He believed in me, and considered me a peer long before I deserved it; to Dr. Sebastian Diaz for his support and candor on the realities of this process as well as his amazing talent of making statistics come alive; to Dr. Daniel Hartley for inspiring me as a Technology Education doctorate alumnus making valuable contributions to the field of occupational safety and health; and to Dr. Jacqueline Webb-Dempsey for introducing me to qualitative research. She provided me with a set of tools that I will use for the rest of my career.

I would like to sincerely thank my peers at WVU Safety \& Health Extension that contributed to the training material that is the core of this research. In particular I would like to thank Brandon Takacs, Kyle Johnson, Bob Moore, Jan Della-Giustina, Missy Stewart and Sergio Caporali for assisting in the development and delivery of the residential fall protection training material. I would also like to acknowledge that the basis of this research comes from initial and continued funding from the OSHA Susan Harwood training grant program.

Thanks to my parents, Dan and Ina Fullen for making education a priority in our home, even when times were tough. Their belief in me molded me into the person I am today. To my siblings Robin, Jane, and Dan for always looking out for me. Most importantly, endless thanks to my wife Jennifer. She has always believed in me and continues to encourage me in everything that I do. Without her in my life this would not have been possible. 


\section{TABLE OF CONTENTS}

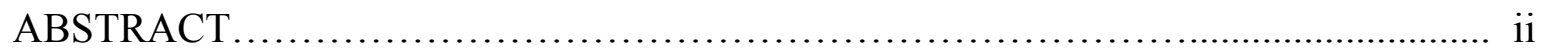

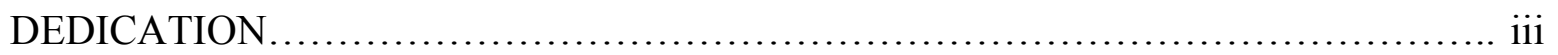

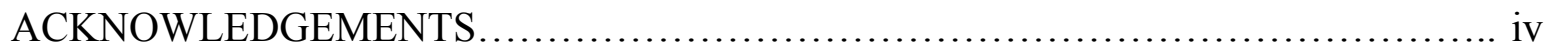

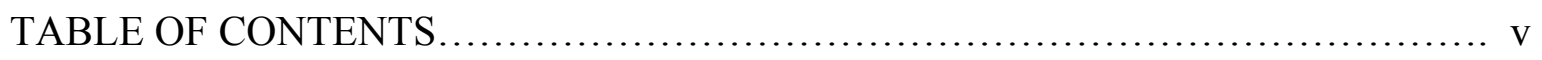

LIST OF TABLES......................................................... xiii

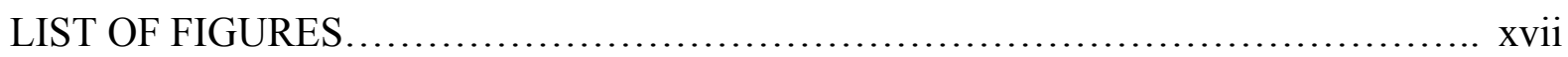

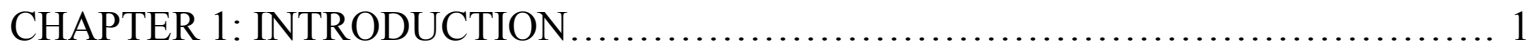

The Problem with Falls in Construction..................................... 1

Need for the Study................................................. 2

Transient Nature of Construction and Construction

Workers / Changing Workforce.................................. 3

Residential Construction Worker Characteristics........................ 3

Problem Statement...................................................... 4

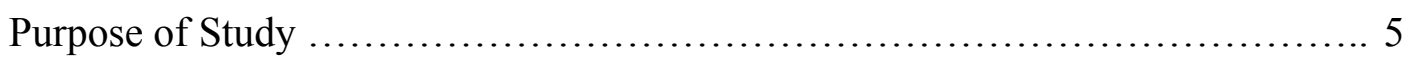

Research Questions.................................................... 7

CHAPTER 2: LITERATURE REVIEW ...................................... 9

Review of Topics.................................................... 9

Literature Related to Safety Training Program Effectiveness................9

Literature Related to Available Residential Fall Protection

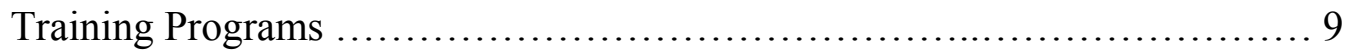

Literature Related to Safety Training Interventions.............................. 11

Literature Related to Similar Type I Developmental Research............... 18 
Intended audience (industrial workers) ............................. 19

Training content versus classroom teaching curriculum..................20

Train-the-trainer and technology based content......................... 20

Problem-based instruction. ..................................... 21

Evaluation methods. ........................................... 21

Summary of Literature Reviewed................................................ 21

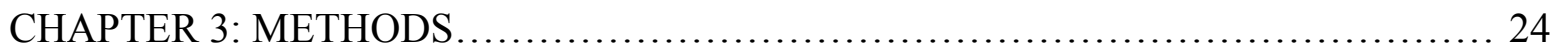

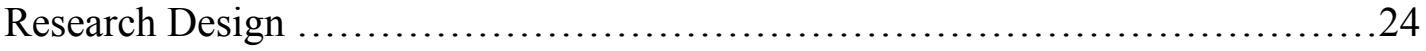

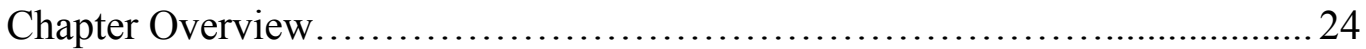

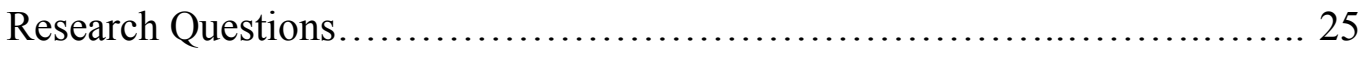

Chapter Sections...................................................... 26

Program Overview................................................. 26

Training material development grant work plan.......................27

Organize a focus group to establish industry needs. ................... 27

Analyze four residential work sites concurrently. ................... 28

Videotape and photograph residential construction processes during

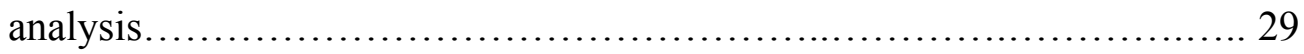

Market the program. .............................................. 29

Produce, author and distribute DVD for self guided or group training....... 29

Develop downloadable training materials (handbooks,

train-the-trainer guidelines, PowerPoint slides). ..................... 32

Develop questionnaires and pre and posttests for the instructor led training and questionnaire for the interactive DVD delivery $\ldots \ldots \ldots \ldots \ldots \ldots 32$ 
Conduct regional classes for supervisors and workers. ................ 33

Track downloads and collect online, completed questionnaires............33

Evaluate the training effectiveness by analyzing pre and posttests, questionnaire data and the student evaluations of instructors

and course content.............................................. 34

Developmental Research Design..................................... 34

Researcher's Role and Background............................................ 39

Participant Selection................................................ 41

Data Collection Methodology..............................................43

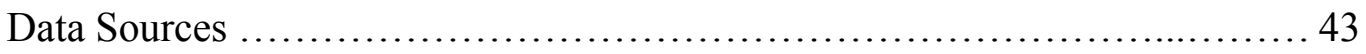

Design Phase.......................................................... 44

Implementation Phase.............................................. 44

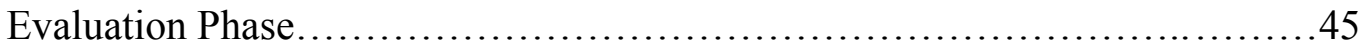

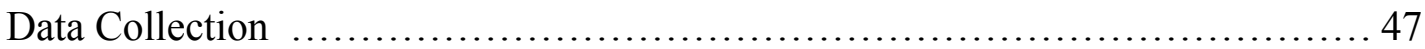

Historical and current documents.................................. 47

Pre and post tests................................................4 47

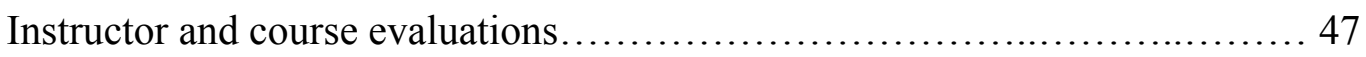

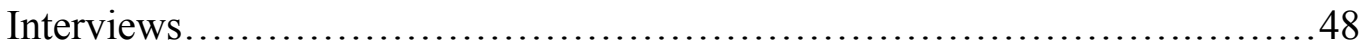

Questionnaires.................................................... 49

Number of downloads. ............................................49

Number of DVD order requests. .................................. 49

Number trained in instructor led courses. ............................... 49

Work site observations. ........................................... 49 


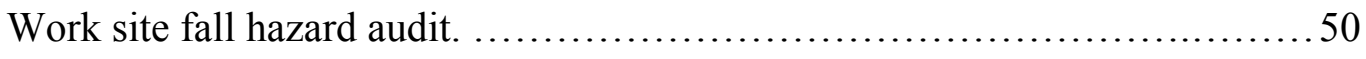

Data Analysis....................................................... 51

Historical Documents............................................ 51

Pre and Posttests...................................................... 52

Course and Instructor Evaluations................................... 53

Expert, Instructor and Student Interview Transcripts.......................55

Expert, Instructor and Student Questionnaire Results ....................... 55

Work Site Observations......................................... 55

Work Site Fall Hazard Audit Results................................... 56

Triangulation of Data............................................. 56

CHAPTER 4: RESULTS .............................................................. 60

Development of Instructor Led and Self-guided DVD Training Curriculum........60

Developmental Cycle I of PowerPoint and Interactive DVD Training Material.... 62

Cycle I Development..............................................62

Cycle I Delivery and Evaluation of the Instructor Led Training............. 64

Class 1, February 19, 2007, Morgantown, WV ..................... 65

Class 2, February 27, 2007, Martinsburg, WV ..................... 72

Cycle I Delivery of DVD Training Material and downloadable PowerPoints... 79

Cycle I Evaluation of DVD Training Material.......................... 82

Summary of Cycle I Instructor Led Training \& DVD Distribution.............88

Developmental Cycle II of PowerPoint Training Material...................... 91

Cycle II Development............................................ 91

Cycle II Delivery and Evaluation.................................. 91 
Class 3, May 19, 2007, Chesapeake, VA.......................... 91

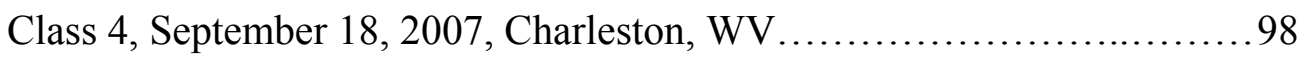

Class 5, September 24, 2007, Morgantown, WV...................... 104

Class 6, September 28, 2007, Washington DC......................... 109

Class 7: October 9, 2007, Harrisburg, PA............................ 113

Summary of Cycle II.............................................. 118

Developmental Cycle III of PowerPoint Training Material..................... 119

Cycle III Development.............................................. 119

Cycle III Delivery and Evaluation..................................... 120

Class 8, 9, 10 \& 11 December 19, 2007 and

January 25, 2008, Uniontown, PA............................... 120

Class 12, Morgantown, WV, February 7, 2008..................... 122

Summary of Cycle III............................................. 129

Developmental Cycle IV of PowerPoint Training Material..................... 130

Cycle IV Development............................................ 130

Cycle IV Delivery and Evaluation.................................. 132

Class 13, August 4, 2008, Roanoke, VA............................. 132

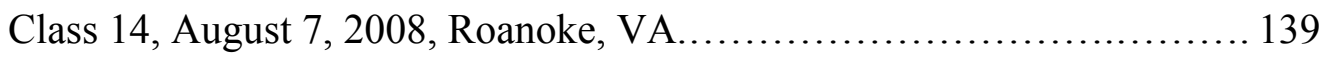

Summary of Cycle IV ............................................. 145

Developmental Cycle V of PowerPoint Training Material

and Interactive DVD............................................... 147

Cycle V Developmental Changes to the DVD and PowerPoint................ 147

Cycle V Delivery and Evaluation of DVD and PowerPoints................. 149 
DVD version 2.0 delivery and evaluation............................ 149

Class 15, March 2, 2009, Morgantown, WV. .......................... 156

Summary of Cycle V.............................................. 162

Summary of All Developmental Cycles...................................... 164

CHAPTER 5: CONCLUSIONS................................................ 171

Research Questions................................................... 171

Research Question 1............................................... 171

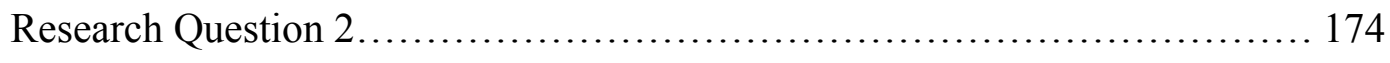

Research Question 3.............................................. 177

Implications for Training Material Development............................... 180

Use of Work Specific Content by Phase of Work............................ 180

Use of DVD Video for Interactive Training................................. 181

Use of Developmental Cycles for Training Programs......................... 182

Guidelines on Use of Developmental Cycles for Safety Trainers................ 183

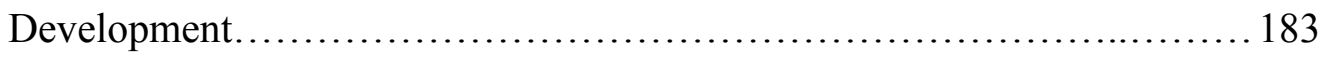

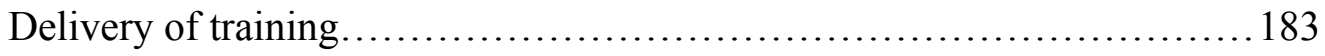

Evaluation......................................................... 184

Implications for Those Attempting to Reach Workers Through the Internet........ 184

Implications for the Residential Construction Industry.......................... 185

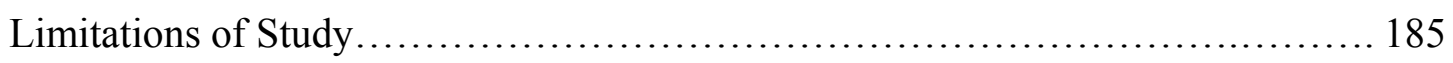

Data Collection Varied by Course.......................................... 185

Variability of Participants............................................. 186 
Limited Feedback for Post-post Exams and Post Interviews

from Construction Industry.......................................... 186

Limitation of Students Control Over Workplace Fall Hazard Conditions........ 186

No Feedback from Industry Experts................................... 187

Future Research.................................................... 187

Evaluate the Effectiveness of the Addition of Hands-on

Training to the Training Curriculum..................................... 187

Further Improvements of the DVD as a Delivery Medium.................. 187

Exploration of Other, More Current Delivery Mediums to More

Effectively Reach Workers........................................ 188

Development of a Train-the-Trainer Program and a Field Based

Developmental Cycle Toolkit......................................... 188

Public Safety Outreach............................................ 189

Development of More Effective Post Training Evaluation Tool.................189

Long-term Research to Measure Injury Rates and Site

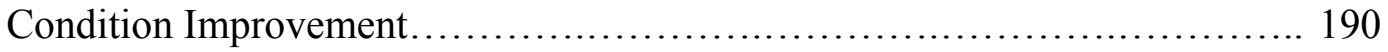

An Evaluation of Cultural Barriers that Impact Worker Injures and Fatalities... 190

REFERENCES........................................................... 191

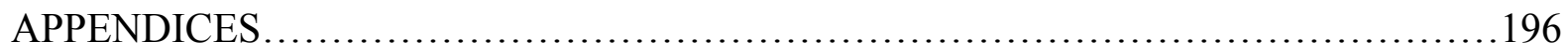

Appendix A: Residential Fall Protection DVD Menu System......................... 197

Appendix B: Human Subjects Approval Letter...................................... 199

Appendix C: Pre Test Cycle I (Instructor Led Classes).............................201

Appendix D: Post Test Cycle I.............................................. 204 
Appendix E: Pre Test Cycle III........................................... 207

Appendix F: Post Test Cycle III............................................ 209

Appendix G: Pre Test Cycle V........................................... 211

Appendix H: Post Test Cycle V........................................... 213

Appendix I: WVU Safety \& Health Extension Instructor / Course Evaluation........... 215

Appendix J: Residential Fall Protection Training Participant Interview Protocol........... 217

Appendix K: Residential Fall Protection Training Material Development

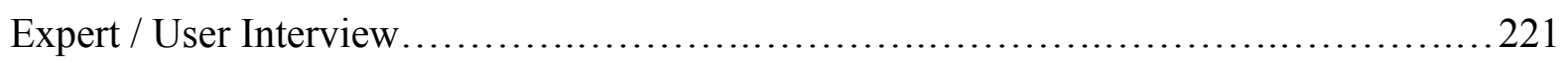

Appendix L: Residential Fall Protection Training Material Development

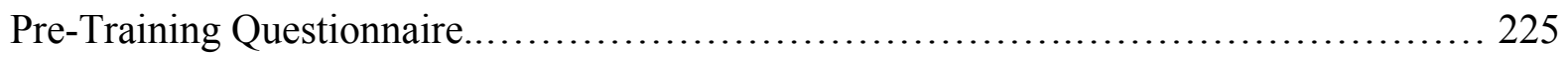

Appendix M: Residential Fall Protection Training Material Development

Post-Training Questionnaire ............................................... 230

Appendix N: Web Requested Residential Fall Protection Training

Material Development Questionnaire......................................... 233

Appendix O: Worksite Fall Hazards Audit Reports................................. 238 


\section{LIST OF TABLES}

Table 1: Number of Residential Contractors in OSHA Region III................... 42

Table 2: Number of Residential Employees in OSHA Region III...................... 43

Table 3: Data Sources by Developmental Phases Across All Cycles.................. 46

Table 4: Relationship Between Data Sources and Research Questions................... 58

Table 5: Cycle 1 Class 1 Pre Questionnaire - Demographics......................... 66

Table 6: Cycle I Class 1 Pre Questionnaire Fall Injury and Fall Protection Related Data... 67

Table 7: Cycle 1 Class 1 Pre Questionnaire - Technology \& Training..................... 68

Table 8: Cycle I Class 1 Post Training Questionnaire / Evaluation..................... 70

Table 9: Cycle 1 Class 1 Pre/Post Paired T-Test Statistics............................. 71

Table 10: Cycle 1 Class 2 Pre Questionnaire Demographic and Injury Data............... 74

Table 11: Cycle I Class 2 Pre Questionnaire Fall Injury and

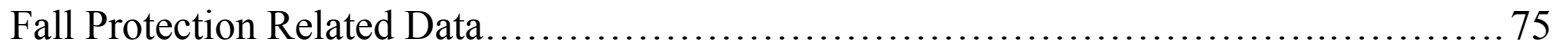

Table 12: Cycle I Class 2 Pre Questionnaire - Technology (DVD) ................... 76

Table 13: Cycle I Class 2 Pre Questionnaire - Technology

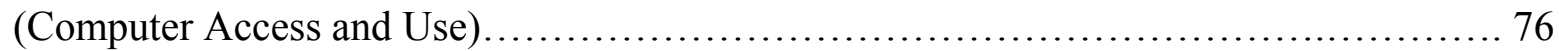

Table 14: Cycle I Class 2 Pre Questionnaire - Training............................ 77

Table 15: Cycle I Class 2 Post Training Questionnaire - Evaluation

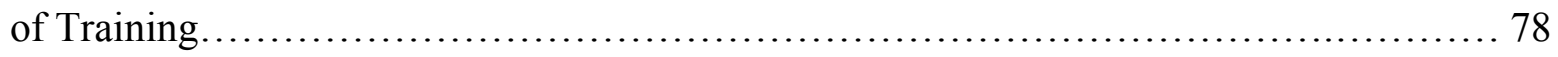

Table 16: Cycle I Class 2 Pre/Post Test Paired T-Test Statistics....................... 79

Table 17: Website Page Hits Between 10/1/06 - 9/30/08......................... 80

Table 18: Cycle I DVD Recipient Demographic Data............................ 83

Table 19: Cycle I DVD Recipient Training Material Evaluation.................... 85 
Table 20: Cycle I DVD Recipient Fall Hazards and Injury Data........................ 86

Table 21: Cycle I DVD Recipient Technology and DVD Data........................87

Table 22: Summary of Cycle I Design Decisions, Implementation and Revisions.......... 90

Table 23: Cycle II Class 3 Pre Questionnaire Demographic and Injury Data............... 93

Table 24: Cycle II Class 3 Pre Questionnaire Fall Injury and

Fall Protection Related Data.................................................. 94

Table 25: Cycle II Class 3 Pre Questionnaire - Technology (DVD)........................ 94

Table 26: Cycle II Class 3 Pre Questionnaire - Technology

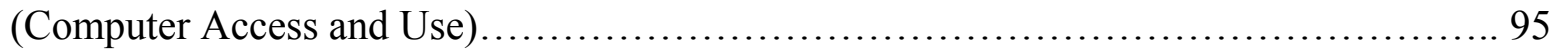

Table 27: Cycle II Class 3 Pre Questionnaire - Training......................... 95

Table 28: Cycle II Class 3 Post Training Questionnaire............................. 96

Table 29: Cycle II Class 4 Post Training Instructor Evaluation........................ 98

Table 30: Cycle II Class 4 Pretest to Posttest Paired T Test.......................... 99

Table 31: Cycle II Class 4 Posttest to Post Posttest Paired T-Test...................... 100

Table 32. Cycle II Class 5 Pre Questionnaire Demographic and Injury Data.............. 104

Table 33. Cycle II Class 5 Pre Questionnaire Fall Injury and

Fall Protection Related Data................................................... 105

Table 34. Cycle II Class 5 Pre Questionnaire - Technology \& Training................... 106

Table 35. Cycle II Class 5 Post Training Questionnaire............................. 108

Table 36. Cycle II Class 5 Pretest to Posttest Paired T Test............................. 109

Table 37. Cycle II Class 6 Post Training Instructor Evaluation.........................110

Table 38. Cycle II Class 6 Pretest to Posttest Paired T Test........................... 111

Table 39. Cycle II Class 7 Pre Questionnaire Demographic and Injury Data............... 114 
Table 40. Cycle II Class 7 Pre Questionnaire Fall Injury and

Fall Protection Related Data............................................... 115

Table 41. Cycle II Class 7 Pre Questionnaire - Technology \& Training................. 115

Table 42. Cycle II Class 7 Post Training Questionnaire.............................. 117

Table 43. Cycle II Class 7 Pretest to Posttest Paired T Test............................. 118

Table 44. Summary of Cycle II Design Decisions, Implementation and Revisions......... 119

Table 45. Cycle III Class 12 Pre Questionnaire Demographic and Injury Data............ 123

Table 46. Cycle III Class 12 Pre Questionnaire Fall Injury and

Fall Protection Related Data................................................ 124

Table 47. Cycle III Class 12 Pre Questionnaire - Technology \& Training................. 125

Table 48. Cycle III Class 12 Post Training Questionnaire............................ 127

Table 49. Cycle III Class 12 Pretest to Posttest Paired T-Test......................... 128

Table 50. Summary of Cycle III Design Decisions, Implementation and Revisions........ 130

Table 51. Cycle IV Class 13 Pre Questionnaire Demographic and Injury Data.............133

Table 52. Cycle IV Class 13 Pre Questionnaire Fall Injury and

Fall Protection Related Data................................................ 134

Table 53. Cycle IV Class 13 Pre Questionnaire - Technology \& Training..................135

Table 54. Cycle IV Class 13 Post Training Questionnaire............................. 137

Table 55. Cycle IV Class 13 Pretest to Posttest Paired T Test.......................... 138

Table 56. Cycle IV Class 14 Pre Questionnaire Demographic and Injury Data.............139

Table 57. Cycle IV Class 14 Pre Questionnaire Fall Injury and

Fall Protection Related Data.............................................. 140 
Table 58. Cycle IV Class 14 Pre Questionnaire - Technology \& Training..................141

Table 59. Cycle IV Class 14 Post Training Questionnaire............................ 143

Table 60. Cycle IV Class 14 Pretest to Posttest Paired T Test.......................... 145

Table 61. Summary of Cycle IV Design Decisions, Implementation and Revisions........ 146

Table 62. Cycle V DVD Recipient Demographic Data.............................. 150

Table 63. Cycle V DVD Recipient Training Material Evaluation....................... 152

Table 64. Cycle V DVD Recipient Fall Hazards and Injury Data...................... 154

Table 65. Cycle V DVD Recipient Technology and DVD Data...................... 154

Table 66. Cycle V Class 15 Pre Questionnaire Demographic and Injury Data............ 157

Table 67. Cycle V Class 15 Pre Questionnaire Fall Injury and

Fall Protection Related Data................................................ 158

Table 68. Cycle V Class 15 Pre Questionnaire - Technology \& Training................. 159

Table 69. Cycle V Class 15 Post Training Questionnaire................................. 161

Table 70. Cycle V Class 15 Pretest to Posttest Paired T-Test........................... 162

Table 71. Summary of Cycle V Design Decisions, Implementation and Revisions......... 163

Table 72. Training Classes by Developmental Cycle............................. 165

Table 73. Summary of All Cycles I through V Design Decisions,

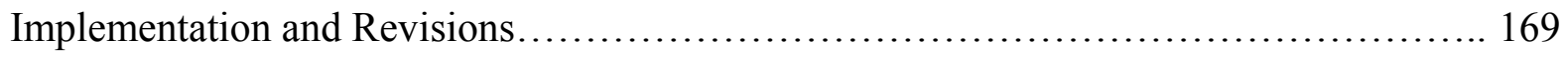

Table 74. All Cycles Pretest to Posttest Paired T-Test............................... 172

Table 75. Technology Comparison of Instructor Led Students and DVD Recipients........175

Table 76. Differences Among Test Scores by Developmental Cycle.....................179 


\section{LIST OF FIGURES}

Figure 1: Residential Fall Protection DVD Flow Chart.............................. 31

Figure 2: Developmental Research Model...................................... 34

Figure 3: Embedded Single Case Adapted from Yin, 2003.......................... 35

Figure 4: Research Methods Flow Chart..................................... 59 


\section{Chapter 1}

Introduction

\section{The Problem of Fall Related Fatalities and Injuries in Residential Construction}

The total number of fatalities in residential construction increased from 84 in 1992 to 117 in 2003 (Dong, 2005). A query of the 2003 Bureau of Labor Statistics (BLS) data identified 63 fall fatalities in 2003 (“Census of,” 2005). Dong (2005) reports, based on Census of Fatal Occupational Injury (CFOI) data, deaths due to falls in residential construction have increased from $33.3 \%$ off all fatalities in 1992 to $53.8 \%$ in 2003 . This is a $20.5 \%$ increase in residential construction as compared to a 7\% increase in all construction. Based on 2003 BLS data, fall fatalities represent nearly $48 \%$ of all fatalities in residential construction ("Census of," 2005). An interesting and troublesome fact is $35.1 \%$ of all of the residential construction fatalities were among the self-employed. This percentage is nearly twice that of all construction (Dong, 2005). Further analysis of current data by Dong (2005) identifies that $86 \%$ of fatalities in residential construction occurred in companies with less than 20 employees. This is disproportionately high when taking into account that only $64 \%$ of workers were employed by companies with less than 20 employees (Dong, 2005).

Hispanic fatalities in residential construction have been on the rise with an increase from 5 in 1992 to 26 in 2003 (Dong, 2005). Hispanics are experiencing a higher rate of fatalities in construction than any other ethnic group in the United States (Brunette, 2005). Of the fatalities that occurred to Hispanic construction workers between 1995 and 2000, 37\% were documented as falls to a lower level (Brunette, 2005). A review of non-fatal injuries in residential construction through a BLS query shows a decrease in non-fatal injuries from 1992 to 2003 of nearly 5,000 ("Nonfatal cases," 2005). Even with this decline in non-fatal injuries, falls are still 
the leading injurer of residential construction workers ("Nonfatal cases," 2005). It could be assumed that a larger number of non-fatal injuries are not being reported due to the high percentage of small and self-employed contractors. A fatality could not be overlooked as far as reporting is concerned, but a non-fatal injury may occur to an employee and not be reported to a supervisor. Optionally, it could be reported to the employer but not documented by the employer on an injury log due to the lack of formal safety and health programs and education in small construction companies (Wojcik, Kidd, Parshall, \& Struttman, 2003). The BLS data that shows a decrease in non-fatal injuries in the U.S. are in opposing correlation with the same data from Ontario, Canada (Dong, Men, \& Haile, 2005).

Overall, the number of workers in the residential construction industry are on the rise. Falls have continually been the largest contributor to residential construction worker deaths and non-fatal injuries. Residential construction workers that are self-employed or working for small companies have a higher risk of being seriously injured or killed than those working for large organizations. More Hispanics are working in construction and proportionally, more of them are being injured and killed in construction.

\section{Need for the Study}

The number of workers in residential construction has steadily increased from 708,000 in 1998 to 894,000 in 2004 (Dong, 2005; see also Methner, McKernan, \& Dennison, 2000). Residential construction workers account for only $12.8 \%$ of employment in all construction during 2003. Excluding agriculture, construction has the highest percentage of Hispanic workers at $17 \%$ (Brunette, 2005). Since 1995, Hispanic workers in construction have increased from $10.3 \%$ to $15.1 \%$ in 1999 (Brunette). The rise in the number of Hispanic workers increases the problem of educating the work force due to the language barrier. 
Transient Nature of Construction and Construction Workers / Changing Workforce

Residential construction, like all construction is generally transient. This means the workforce is transient and sometimes difficult to stop and take the time to train. The majority of residential construction is non-union and workers typically move from company to company as projects come to an end. Goldenhar, Moran, and Colligan (2001) surveyed non-union construction companies and identified several reasons why non-union contractors did not conduct safety training. These included; employees leave too soon, lack of knowledge of safety, they have no one to conduct the training, the workers are too dispersed geographically, and there is no place to conduct training (Goldenhar et al. 2001).

\section{Residential Construction Worker Characteristics}

According to The Construction Chartbook (2007), in 2005 the union construction worker was more likely to have a high school diploma than a non-union construction worker. Approximately $45 \%$ of non-union construction workers had high school diplomas. This percentage has not changed from the previous edition of the Chartbook that evaluated educational attainment of construction workers in 2000 (“Construction Chartbook," 2002). Thirty-three percent of non-union construction workers have less than a high school diploma and only 4 percent have a bachelor's degree or higher. Over half (55\%) of non-union Hispanic construction workers have less than a high school diploma, while only $30 \%$ have a high school diploma (“Construction Chartbook," 2007).

Based on the 2000 Census, the Construction Chartbook (2002) identified that in 2000, $52 \%$ of construction workers had a computer at home while only $39 \%$ of them used the Internet on a computer or television (WebTV). The 2003 Census data showed an increase in construction 
workers who had computers at home to $57.1 \%$ and Internet use at home to $48.9 \%$ ("Presence of," 2005). This increase shows great promise in reaching construction workers through the Internet. In comparison, $66.1 \%$ of all of the working census population over 18 years of age in 2003 had a computer at home and 58.9\% had Internet access at home. Approximately $66 \%$ of union construction workers in 2003 had computer and Internet access at home compared to $57 \%$ of non-union construction workers ("Construction Chartbook," 2007). The difference between the general population and construction is relatively small ("Presence of," 2005). Much of the literature makes recommendations for continued efforts in the areas of safety training effectiveness, residential construction safety interventions, and fall injury and fatality interventions. All of the problems described herein reinforce the needs identified by the research community to develop a training program for residential construction workers that is designed to impact safe work practices and also be able to be used by small construction companies with limited resources and limited understanding of safety and health training.

\section{Problem Statement}

Falls from heights are the leading cause of fatalities and serious injuries in residential construction. Training construction workers in fall protection is required by OSHA regulations. The goal of delivering safety training in this area is to reduce the number of fatalities and injuries caused by falls. Although measuring a reduction in injuries and fatalities is difficult to measure in smaller studies, safety training has been shown to increase worker awareness and knowledge and also to reduce the number of fall hazards identified on construction sites. No literature has been identified that measures the effectiveness of training for residential construction workers specifically. This is due in part because the residential construction worker population is difficult to reach to train. This is due to several factors including the transient nature of the work, high 
turnover of the workforce, and the low percentage of organized labor and apprenticeship training programs in residential construction. Also, the majority of residential construction workers are employed by companies with ten or less employees and these companies do not typically have a formalized safety and health training program or employ a person solely responsible for safety and health program implementation or training. Finally, current fall hazard safety training programs available are broad in nature and do not apply specifically to residential construction activities or hazards.

\section{Purpose of the Study}

This study proposes to conduct Type I developmental research on training material that was developed in the last two years by West Virginia University Safety \& Health Extension (WVUSHE) through a grant funded by the Occupational Safety \& Health Administration (OSHA) Susan Harwood Training Material Development Grant Program. The grant required the development of training materials to be made available for no cost to the public through instructor led training and through a website. Through this funding, WVUSHE developed training material addressing fall hazards in residential construction. The training material was developed using residential construction work site video footage and photographs and was presented in a unique format, especially when compared to the typical construction safety training material currently available.

An important and defining feature is that the training material was categorized by phase of construction (i.e., site preparation, foundation work, flooring, framing, etc). This differs from existing training materials in that other training is non-specific in that it presents to the construction worker the OSHA regulatory requirements and does not adapt the regulation to the actual work site conditions. This training developed by WVUSHE presents real hazards with real 
workers. Specifically, the training material demonstrates hazardous situations with no safe controls, and then provides to the student several safe alternatives to choose from to complete the same task safely. The training material has been developed on DVD-video with English and Spanish narration and the same material is available on PowerPoint with speaker notes in English and Spanish. Audio tracks in English and Spanish are included on an optional PowerPoint slide show for contractors who are not comfortable with public speaking or training. WVUSHE has committed to train 250 individuals using this material beginning January 2006. WVUSHE will also provide the material on the Internet for 2 years and track the number of downloads and online training of all the material made available. The evaluation plan within the grant proposal called for the development of pre and post exams as well as evaluation questionnaires. This study will use additional instruments to measure the effectiveness of this training program.

This study is Type I developmental research where the training methodology, product, implementation and outcomes are studied and evaluated for this specific program throughout the design-implementation-evaluation stages (Richey, Klein \& Nelson, 2004). As typically found in Type I developmental research, this research will utilize the case study method as the basis for evaluation and reporting the final results. The research will collect and analyze data through several design-implementation-evaluation cycles of the training program. The number of cycles will be dependent on the need to redevelop the material based on the data collected through each cycle. Type I developmental research treats the design-development-evaluation process as a form of inquiry and does so by embedding traditional research methods into the development project (Richey, et al., 2004). There is also a Type II developmental research process. Where Type I developmental research is described as "the combination of doing and studying in the process of discovering superior procedures", Type II often does not start with the actual 
development of a product or program but rather focuses on the instructional design processes offering implications on any program or project. (Richey, et al.).

The case study will be mixed method, which will include qualitative and quantitative measures nested within the broader case study and will be evaluated within each measure and also between the various measures. The collected data includes results of document and media content analysis, pre and posttests, instructor and course evaluations, interviews, questionnaires, and site observations (qualitative and quantitative). An additional measure will then be comparing the data collected in the first cycle to the data from the second cycle. This study is mixed method in that the research questions, the data collection and the analysis will use both qualitative and quantitative principles and will result in findings that are arrived at through triangulation of all data.

\section{Research Questions}

A global view of this research would show a case study utilized to conduct Type I developmental research that will include both qualitative and quantitative data from five complete design-implementation-evaluation cycles. This research design and all data collected will also be connected to and will seek to help answer three research questions. These research questions are as follows:

1. Does the training program addressing residential fall hazards and safety bring about individual or group behaviors that may reduce the likelihood of falls from heights on residential construction sites?

More specifically, will the training material developed and its organization of information (hazards and controls demonstrated by phase of construction) increase learner knowledge 
and have a real impact on how work is completed on the jobsite and how falls are controlled?

2. Does the technology-based availability and delivery of this training material increase trainee interest?

More specifically, does the utilization of new technologies (interactive DVD, material made available through the Internet) for safety training in residential construction to deliver the training material increase the trainee's interest in the program and in turn have the potential to reach and impact more of the impacted population?

3. Does including residential construction worker, supervisor and expert feedback into the developmental cycle of training development impact the relevance and acceptability of the residential fall protection training material?

More specifically, does the developmental research model of multiple iterations of development, implementation and evaluation, result in a training program with more relevance and residential construction community (worker, supervisor, owners, experts) acceptability? In particular, will the feedback after each cycle of the training impact the quality of the final training product of the following cycle of training? 
Chapter 2

Literature Review

Review of Topics

Literature Related to Safety Training Program Effectiveness

A review of the literature related to safety training in residential construction and small construction companies revealed limited data. The studies located have identified a lack of quality in training and a lack of training in general. Focus groups with union residential construction carpenters as part of an injury surveillance project concluded that fall protection taught in apprenticeship school did not always result in safe work practices on the job site (Lipscomb, et al., 2003). Apprentices in the focus groups explained that the senior craftsmen (journeymen) at the work site were careless and too comfortable in completing their work in a hazardous manor. The young workers that had just completed fall protection training felt that they did not have the authority to make changes and began following the work practices of the senior craftsmen (Lipscomb, et al.). Kinn (2000) found that 38\% of injured plumbers and pipefitters did not receive any health and safety training or safety orientation. A study of the adequacy of health and safety training provided to young Latino construction workers identified that $68 \%$ to $72 \%$ of those in the study received some type of safety training, while only $24 \%$ of those received any written material. In addition the median training time was only 1 hour (O’Connor, Loomis, Runyan, dal Santo \& Schulman, 2005).

\section{Literature Related to Available Residential Fall Protection Training Programs}

It was difficult to locate available training programs specifically for fall protection in residential construction, while training is widely available in fall protection for construction, in general. In conducting searches for residential fall protection training programs, several state 
organizations were located that provide fall protection training and/or training material specifically for residential construction. For example, Michigan Occupational Safety \& Health Administration provides a $2 \frac{1}{2} 2$ hour course entitled Fall Protection for Residential Construction. This program is provided upon request and is designed for managers, employees, and business owners. The training flyer states that the training will review the safety standards for fall protection including the latest OSHA and MIOSHA interpretation. Examination of recent fatal falls in construction and discussion of the latest fall protection techniques for construction will be covered ("Fall Protection," 2005). Washington State Department of Labor and Industries provides downloadable training videos addressing safety hazards including fall protection related to specific work tasks in residential construction. These residential construction videos are Siding Safety, Framing Safety, and Roofing Safety. Additionally, Power Point slides addressing general fall protection safety for all construction with speaker notes and teaching suggestions are available for download. One of these available PowerPoint presentations utilizes fall fatality investigations conducted in Washington state to emphasize the reality of the risks of falling during construction ("Washington State," 2005). Kentucky Department of Labor also offers a free day long Residential Construction Training Course that includes Fall Protection as a part of the curriculum (“Kentucky Department," 2005).

The National Association of Home Builders developed training material addressing the hazards in construction that are responsible for the majority of deaths and serious injuries. One of these four is falls from height. The training, named "Big-Four", requires that potential trainers attend a six-hour seminar that includes material on teaching techniques. The trainers are required to be fluent in English and Spanish. Once completed, these trainers will then conduct the "BigFour" courses in classroom setting for workers in English and Spanish ("OSHA Awards," 2002). 
The Occupational Safety and Health Administration Fall Protection standard (Occupational Safety and Health Administration [OSHA], 2005) has a requirement within the regulation for training. Specifically, the standard requires that "The employer shall provide a training program for each employee who might be exposed to fall hazards. The program shall enable each employee to recognize the hazards of falling and shall train each employee in the procedures to be followed in order to minimize these hazards." In addition, there are specific training requirements based on the types of exposures the employee are exposed too. There is no description of what methods are to be used to deliver the training. The standard only requires that the training is documented and that the employee' signs a record of training. Retraining is required if an employee does not have the knowledge or skill required or if the workplace or the personal fall arrest system changes (OSHA, 2005).

\section{Literature Related to Safety Training Interventions}

The review of the literature identified very few education or training interventions that were specific to fall protection in residential construction or that taught the content in alternative ways. The studies identified involve either fall protection or residential construction. In these studies some include small construction companies (less than or equal to 10 employees) that include residential construction or they include other training content in addition to falls.

This author was involved in a study of an organizational intervention with the intent to reduce falls in small construction companies. Multiple elements of the intervention had educational components (worker and supervisor fall protection training and feedback from quarterly work site and management audits). The conclusions of the study were that the intervention contractors that received the management program, training, site audits, feedback and consultation better controlled fall hazards on the work site and more consistently managed 
and implemented the fall hazard management program than the control group of contractors (Becker, Fullen, Akladios, \& Hobbs, 2001).

A second study focused on small construction companies with less than 10 employees and tested fall and back injury training (Wojcik, Kidd, Parshall, \& Struttmann, 2003). The authors identified back and fall-related injuries in Kentucky as generating a high number of lost time work days (Wojcik, et al., 2003). The education component of this study was the translation of injury data into what the authors called "interactive narrative simulation exercises." The authors described "Narrative thinking theory" is that knowing and understanding is increased through stories told, heard and lived. The narrative simulations in this project were based on real life scenarios and were translated into "powerful and memorable mental images that allow the participant to experience a work situation or dilemma." The simulations included situations where productivity is chosen over safety.

Although this study only evaluated the performance and effectiveness of the training simulations as measured by the participants, the study was a two-group quasi-experimental design with a control group. The intervention included two cycles of implementation consisting of three simulations in year one and three in year two. The companies were recruited by invitation through the mail. This program was conducted by the state Workers Compensation Commission and as an incentive for companies to participate, a 10\% insurance premium discount was provided at the next policy renewal. Once a company agreed, intervention packets were sent to owners, supervisors, and employees. The intervention packets included applicable human subject's forms, instructions for completion of the simulations, a pre-test of safety climate, demographic information, three simulation exercises with evaluation questionnaires and an immediate post-test safety climate questionnaire. The materials were sent directly back to the 
researcher. Four months later the participants were mailed a delayed post test.

The simulations were in a booklet and included line drawings to supplement the training. Answers and additional explanations were in a separate answer booklet. The answers were printed in invisible ink and when the student chose an answer with a provided invisible ink pen, the invisible ink was developed and the student received immediate feedback on their answers. The questions were integrated into a larger story and would lead the student to a next portion of the story with additional questions. There were often more than one correct answer, but once the student used the pen all answers for that particular question were revealed.

The results of this paper suggest that the evaluations of the simulations were favorable. Owners and employees found the simulation realistic but not particularly applicable to their work. The fall simulations were presented as a generic simulation that did not identify the trade. The results suggest that this may lead to a lower level of perceived applicability to the field from the employees. Finally, the results suggested that the simulations were perceived as effective by the learners and they were perceived as being realistic and of high quality but lacked applicability to the work site. A recommendation from the author to increase applicability would be to develop specific scenarios to specific trades rather than making the material generic. The conclusions of this study suggest that including worker and supervisor feedback into the design of training material helps with the applicability and acceptability of the training.

A third study was identified that focused on falls as well as other high injury hazards in the residential construction industry. This intervention program, called HomeSafe, was developed by the Home Builder's Association of Denver and OSHA Region VIII in Colorado after a decade of high fatality and injury rates in residential construction in the state (Gilkey, Hautaluoma, Ahmed, Keefe, Herron, \& Bigelow, 2004). 
This was a long term intervention program that included as one of its components, fall hazards safety training. In addition, membership in the program included access to additional training programs and safety toolbox talks for use on the worksite. The participating work sites were audited and worker behavior based on 10 key items (including falls). The training consisted of a 3 hour training and orientation program. This training was not mandatory for all employees. Some companies sent safety personnel or others to collect the training information and they were expected to train the employees. In addition other educational material included a pocket sized booklet on the program and access to an OSHA 10 Hour Construction safety course that had been tailored to the residential construction industry. Companies that participated in the program received less stringent inspections from OSHA in return for participation and the companies, if cited by OSHA would receive the largest penalty reductions allowed. The companies were also eligible for a 5\% discount on their workers' compensation premiums. The program required companies to submit injury logs and man hours.

The injury incidence rates of the HomeSafe companies saw a significant drop (Darragh, Stallones, Bigelow, \& Keefe, 2004). Although upon further analysis the Poisson regression results showed no decrease in injury incidence rates after the HomeSafe intervention (Darragh, et al., 2004). The authors attribute these results to the limitation of the program and methods.

Gilkey, et al. (2004) reevaluated the HomeSafe program by evaluating ongoing jobsite audits of the companies in the HomeSafe program for $2 \frac{1}{2}$ years. This evaluation of the study included a control group. The audit tool used in this portion of the study measured compliance with the HomeSafe 10 point list using 87 questions. This would correlate the audit tool back to the training in the Home Safe 10 point list. The results of this study concluded that the HomeSafe (intervention) contractors improved significantly in audit scores over the $2 \frac{1}{2}$ years and that they 
improved more than the control contractors.

Falls were specifically discussed in Gilkey's (2004) research. Fall protection audit ratings included personal fall arrest systems, scaffolding, and ladder use. These three categories received the highest audit scores of all on the 10 point list. The author suggests that this program appeared to have improved the safe work practices and conditions that will lead to the reduction of falls.

The combined results of these two articles regarding the HomeSafe program demonstrate that an educational intervention offered within a program offering the small companies' financial benefits can result in reduced injuries and improved work site safety performance (including falls). Additionally, the act of following up with jobsite audits is an adequate measure of training effectiveness.

A fourth study identified, describes the development of construction safety training material targeting Hispanic Workers (Brunette, 2005). This article described the process of design, implementation and evaluation of a training program targeting Hispanic construction workers. Although the author does not cite or describe this as Type I development research, in reviewing the article it does meet the definition and intent of this type of research. The author first describes the high injury and fatality rates in construction that have been well established and then further describes the high propensity of Hispanic workers in this workforce. A review of construction safety training materials in Spanish highlights the small amount available and also the low quality of the translation. The training material developed for this project included an OSHA 10 Hour construction safety training program and accompanying educational materials. Fall hazard related subjects were Fall Protection, Scaffolds and Stairways and Ladders. The training material included video, a Spanish - English dictionary, fact sheets, pamphlets and posters. All training courses begin with the showing of a 15 minute video that 
shows Hispanic construction workers talking about the hazards they face on a daily basis. The training developers chose to require the showing of this video at the opening of the training session to immediately engage the workers in the learning experience. The author and codevelopers identified specific training methodologies that have been identified as important to developing quality training for Hispanic workers. They include the following (Brunette, 2005):

Design materials that are linguistically and culturally appropriate

Use a language that is familiar to the workers

Avoid straight translation from English materials

Use native-speaking Spanish translator who has in-depth knowledge of construction Keep material at a limited literacy level

Use plenty of clear and realistic illustrations, graphics, or photographs

Use standard Spanish to provide equivalent Spanish version of a given word or term Conduct pilot tests with a subset of Hispanic workers

Have native Hispanic speakers conduct the training Include basic information on workers' rights

Deliver material in a learner centered environment

Training program should be culturally sensitive

Establish a continuous evaluation process

In addition to these guidelines, the author discusses the importance of the translation process. For this project a process called decentering was used, where the training materials are developed in English, then translated into Spanish. Once translated that material is reviewed by Hispanic and English speaking construction workers. If the Spanish translation is incorrect it is corrected. Once correct, the final Spanish material is translated back into English for a new 
English version.

The developers also engaged the Hispanic community by recruiting Hispanic construction workers for focus groups. The groups were told that this is their project and that they will guide the development. The decision was made to use exclusively Hispanic workers in the photographs and videos. The focus group suggested the development of a Hispanic cartoon construction worker. This worker was developed and was shown throughout the training, performing construction tasks. The instruction design model that the developers used was called Instructional System Design and it included analysis, design, development, implementation and evaluation throughout the process. The material was disseminated through a website for other trainers to utilize. A local campaign of flyers and posters were distributed among the Hispanic community though churches, grocery stores, and community groups. Also, T-shirts and stickers with the cartoon character and a project theme were distributed. Postcards were also mailed to surrounding areas.

Some challenges in the program included involving and engaging the hard-to-reach workers. The conclusions are mainly that it is vital to involve the audience in the development and validation of a training program, which applies to this research, specifically to research question 3.

An additional training intervention study was identified that measured worker activities before and after safety training. This study was conducted with members of the International Chemical Workers Union and did not involve construction workers or falls. The research collected data from the trainees prior to and 14 to 18 months after training. The data collected included trainees interest and involvement in safety and health, use of information resources, training activities at work and their attempts at improving safety at work. The study concluded 
that workers were more likely to make changes to worksite safety conditions following training than before they were trained (Becker \& Morawetz, 2004).

\section{Literature Related to Similar Type I Developmental Research}

A review of literature identified no studies related to Type I developmental research involving construction workers and development of technology based fall protection training delivery. In fact, there were no studies identified that involved construction or fall protection, with the exception of the article discussed in the previous section (Brunette, 2005). There were, however literature identified that had some similarities to this study. The similarities include the following:

Intended audience (industrial workers)

Training content versus classroom teaching curriculum

Train-the-trainer and technology based content

Evaluation methods

Inclusion of stakeholders in design and evaluation

Typically all Type I developmental research studies identified included the designimplementation-evaluation cycles in some form. McKenney and van den Akker (2005) describe four prototype revision cycles and a fifth final version cycle of a computer based program to develop, implement, and evaluate science and math curriculum in Africa. This study was conducted over four years with 108 measurement instruments. Similarly a long term developmental research study was conducted using an instructional design college level course that was conducted over 5 years and six iterations of the class (Shambaugh \& Magliaro, 2001). Through each delivery of the course a complete design-implementation-evaluation cycle was completed and the content was revised throughout the study (Shambaugh \& Magliaro, 2001). 
These studies represent ideal situations where data and time are available to conduct long term studies. Other studies involving industrial workers seem to use less instruments and cycles and shorter durations. These will be discussed in the following sections related to their similarities to this study.

Intended audience (industrial workers). Two developmental research studies were identified that involved the development of training material designed for industrial workers. Buch (1989) completed a study that involved the systematic development of computer based industrial training for moving counselors employed by Allied Van Lines. The training program was developed using a traditional systems model for designing instruction. Modifications were made throughout the process in the instructional analysis and the instructional strategies. So, in this study the cyclical nature of the developmental research took place only in the design phase. The training effectiveness was measured by comparing learner outcomes of the intervention group with a control group. The study concluded that there was a significant difference in the knowledge gained of the intervention group compared to control group.

A second study identified measured industrial worker achievement through the systematic design of instruction, using an Instructional Systems Design Model (Kress, 1990). Similar to the Buch (1989) study the research compared the results of two courses. One course had been designed and developed using an instructional systems design model, and the other was non-systematically designed and developed. The measurement instruments used were a written test and a performance test, both completed after the course. Attitude measures were administered at the beginning of the class. Although, the results of the study indicated no significant difference between the two courses in predicting overall achievement in the two courses, the use of post written tests for measurements apply to this study. Additionally, the 
systematic planned design of an industrial training course does also have relevance to this author's study.

Training content versus classroom teaching curriculum. These studies are pertinent to this study, in that they involve the development of training versus classroom teaching curriculum. The majority of Type I Developmental Research studies identified by Richey, Klein and Nelson (2004) were for either K-12 or postsecondary schools. Only eleven studies were identified that were classified as either for business or industry or employee training. Within those eleven several were designed for college or school teacher professional development, which does not necessarily apply to construction worker training.

Train-the-trainer and technology based content. One developmental research study was identified that involved the development of train-the-trainer content. One element of this author's study that is similar is the providing of the developed residential fall protection training content for other safety and health instructors to use to train. This study tested the effectiveness of an instructional systems design model through the design, development and validation of a Trainthe-Trainer instructional program (Forsyth, 1997). The study resulted in the development of an instructional design model for train the trainer instruction and a train the trainer program with agendas, assessment tools, evaluation tools and processes and a participant manual. The results revealed that both the instructional design model and the train the trainer program were effective in a community-based setting (Forsyth, 1997).

Although no studies were identified that used DVD-video as the delivery medium, several studies used some form of multi-media or computer based technology for delivery. Minnesota Extension Service conducted a study using computers installed in elementary and secondary schools for a distance education project that used a satellite delivery of content (Coyle 
$\&$ Spitzer, 1992). Although the study describes only the implementation and use of the technology with no clear results, it does demonstrate a case of developmental research utilizing technology, within an Extension Service group within a university as in this author's study.

Other studies previously discussed include technological components. McKenney and van den Akker (2005) describe the prototyping and development of a computer based program to assist in the design, development and evaluation of curriculum in science and math in Africa. The use of a computer for industrial training delivery was also studied by Buch (1989).

Problem-based instruction. Dabbagh, Jonassen, Yueh and Samouilova (2000) conducted a case study that examined the application of problem-based learning in teaching an introductory instructional design class. The results suggested that instructional design is a dynamic process and that the instruction of this course should use more problem solving. Similarly, Ross (1998) conducted developmental research blending course content with employees real work activities and situations evolving and adapting the course as to continually relate the training to the real work situations. The results being the process of adaptation is the key to making a course like this work.

Evaluation methods. Forsyth (1997) evaluated the effectiveness of the developed trainthe-trainer program by measuring the knowledge gained and also the skill acquisition. The knowledge gains were measured through testing around training but the skill acquisition was measured through evaluation of on the job behaviors and transfer of the training to the work site.

\section{Summary of Literature Reviewed}

Residential construction workers are underrepresented in training and other interventions with the goal to reduce injuries and fatalities in the literature. Much of the training is conducted by construction companies to meet the minimum OSHA requirements, which require signatures 
from those trained, and re-training if an employee lacks proficiency. No training content was found available for residential construction workers on DVD. There were downloadable PowerPoint's identified in one location on the Internet.

Residential fall protection training material has been taught previously although there are not many measurable evaluations of the effectiveness. The literature review identified programs that came as near as possible to the content described here. The first study used simulations to train employees of small construction companies and identified the use of real life style stories taken directly from the industry group that is being trained increases the impact on the student. Also, it is important to make the content trade specific. This study did not take into consideration the low education rate in construction and did not provide a backup training program in the case that a worker could not read or speak Spanish (Wojcik, Kidd, Parshall, \& Struttmann, 2003).

The "HomeSafe" program showed a higher control of hazards for those contractors that participated in a training program than those who did not. This was measured through the use of a job site audit tool. Also, the results showed that as the program provides additional support the results will be more positive (Gilkey, 2004).

The article describing the development of an OSHA 10 Hour training program for Hispanic construction workers described in great detail the methods to consider when developing training material for Spanish speaking workers and an instructional design methodology that included assessment of the training material throughout the development process as well as continuous evaluation and improvement once complete and in use. The article also described marketing and diffusion recommendations (Brunette, 2005).

Documenting this process of designing, implementing and evaluating the residential fall protection training program benefits from the results of other similar Type I Developmental 
Research that was identified. Although no other studies were identified with the same audience, topic, or delivery medium there were aspects that were similar. These included similar intended audiences (industrial workers), training content versus classroom teaching curriculum, train-thetrainer curriculum development, technology based content delivery and similar evaluation methods. The results from all of the studies provided insight into how to document the efforts involved and how to report them. Additionally, the developmental research literature lends support to this author's work plan.

In conclusion, the lack of literature overall in this area of residential construction, fall hazard safety training, and developmental research within these groups means that there is a need for developmental research and intervention research in these areas. Some limitations to this study include difficulty in reaching the audience and an uncertainty of whether or not they will be accepting of the intervention. 


\section{Chapter 3}

Methods

\section{Research Design}

\section{Chapter Overview}

This research evaluates the effectiveness of a recently developed safety training curriculum addressing falls hazards in residential construction and will follow the principles of Type I developmental research. Type I developmental research is where the methodology, product, implementation and outcomes are studied and evaluated for a specific program throughout the design-implementation-evaluation stages (Richey, Klein \& Nelson, 2004). In this study, there will be five complete cycles of design, implementation, and evaluation. Pertinent data will be collected to study and evaluate each stage and cycle. The data that will be and that has been collected is described in detail in this Chapter. The developmental research methodology calls for the data generated from cycle 1 to provide feedback and input used to improve the program development, implementation and evaluation in cycle 2 and so on through cycle 5 .

In addition to studying the instructional design process, this author poses three research questions as part of this study, that will also be elaborated upon with the use of the same collected data. Thus the data collected is meeting three needs. First, it is providing feedback for the improvement of the training program through five design-implementation-evaluation cycles. Second, the information is being utilized to document the design-implementation-evaluation process as required by the developmental research methodology. Third, the data sources collected provides evidence to respond to the three research questions. Finally, the complete process, including all described above will be presented in the form of a case study. 


\section{Research Questions}

A global view of this research would show a case study utilized to conduct Type I developmental research that will include both qualitative and quantitative data from five complete design-implementation-evaluation cycles. This research design and all data collected will also be connected to and will seek to help answer three research questions. These research questions are as follows:

1. Does the training program addressing residential fall hazards and safety bring about individual or group behaviors that may reduce the likelihood of falls from heights on residential construction sites?

More specifically, will the training material developed and its organization of information (hazards and controls demonstrated by phase of construction) increase learner knowledge and have a real impact on how work is completed on the jobsite and how falls are controlled?

2. Does the technology-based availability and delivery of this training material increase trainee interest?

More specifically, does the utilization of new technologies (interactive DVD, material made available through the Internet) for safety training in residential construction to deliver the training material increase the trainee's interest in the program and in turn have the potential to reach and impact more of the impacted population?

3. Does including residential construction worker, supervisor and expert feedback into the developmental cycle of training development impact the relevance and acceptability of the residential fall protection training material? 
More specifically, does the developmental research model of multiple iterations of development, implementation and evaluation, result in a training program with more relevance and residential construction community (worker, supervisor, owners, experts) acceptability? In particular, will the feedback after each cycle of the training impact the quality of the final training product of the following cycle of training?

\section{Chapter Sections}

This chapter includes a detailed overview of the proposed instructional design and content of the original training material that was created, implemented and evaluated as Developmental Cycle I. This includes a program overview and the detailed work plan that was proposed in the original grant that funded the development.

The next chapter section describes the developmental research design that will be employed during the development, delivery and evaluation of this training program throughout all cycles. This next section is the researcher's role and background as related to this study, followed by description of the participant selection followed by the data collection methodology. The final section describes the data analysis that will be completed throughout the developmental cycles as well as to respond to the three research questions.

\section{Program Overview}

The following describes the original training material development program work plan and is the starting point for this research and is what the design phase of cycle I is based upon. The goal of the original training program was to develop, deliver and make available training material for residential construction workers, supervisors, owners, and trainers in the area of fall protection. The approach is to offer multiple avenues of outreach to the residential construction community at large. The training material developed will be offered for use as a downloadable 
training package (PowerPoint, worker and supervisor manuals, and train-the-trainer guide), a web-based interactive training course, an interactive DVD and finally by traditional instructor lead training.

Training material development grant work plan. The original training material development grant was begun as West Virginia University Safety \& Health Extension (WVUSHE) was awarded a grant by the Occupational Safety and Health Administration (OSHA) through a training material development grant program. The following outlines the goals of the original training grant program. For the purposes of this dissertation research the original grant goals represent the first cycle of the design and implementation phases of the Type I developmental research (Richey, Klein \& Nelson, 2004). Some evaluation elements from the original work plan apply to this dissertation research, but additional evaluation measures are included for the purposes of this study that go beyond those in the grant program goals.

Organize a focus group to establish industry needs. An effective training program has many key elements. One of the most important of these is to know the audience. The first activity was to organize a focus group to establish the needs of the community that will be receiving the training material. The focus group was established and met early in the grant timeline and discussed the training concepts and content proposed. The comments and suggestions from the group were considered during the initial training design and development stage (cycle 1).

The original focus group was recruited from a number of sources. This included individual contractors, contractor associations, government (OSHA, NIOSH), worker organizations, and technology and marketing specialists. The group held the first meeting approximately one month into the project. The focus group will be contacted throughout the rest 
of the process through email and phone and will participate in expert interviews or questionnaires as available.

Analyze four residential work sites concurrently. WVUSHE analyzed safety hazards on four separate residential home construction sites. Since residential construction design varies a great deal, WVUSHE strived to analyze a variety of different home designs. The analysis of the four works sites were planned to collect data from different phases of the house building process so as to gather a wide variety of fall hazards in a short amount of time. Stages of construction that were planned to be assessed included:

1. Site Preparation, excavation for basement and footer

2. Construction of foundation walls

3. Flooring and framing at the first level

4. Flooring and framing from the second level and any additional levels

5. Framing and sheeting the roof

6. Application of shingles or tile and other waterproofing material

7. Electrical wiring

8. Plumbing and other mechanical work

9. Siding and/or bricking the home

10. Hanging and finishing drywall

The hazard assessment employed video taping the work process and the performance of a preliminary job safety analysis (JSA). Following the site visit the field person completed a final Job Safety Analysis for each installation. This was performed by WVU faculty using the video collected at the jobsites along with standard job safety analysis techniques. Results of this analysis were used to develop the original training material. The training developed was task 
based by phase of construction, rather than hazard based.

Videotape and photograph residential construction processes during analysis. The video and photographs collected during the four analyses also served as material that was used in the development of the training material. WVU used appropriate portions of the video and photographs collected during analysis in training material. The video and photographs were used in the interactive DVD, online training and in the downloadable training material (PowerPoint slides and manuals).

Market the program. WVUSHE personnel with responsibilities for marketing developed a marketing plan designed to reach the desired audience. The goal of this plan was to schedule training locations and identify potential employees, employers, industry associations, and labor unions that will agree to attend the free training sessions made available upon completion of the training material.

Produce, author and distribute DVD for self guided or group training. WVUSHE produced, authored and began distribution of an interactive DVD for use by residential construction employers and employee's. The DVD offers an interactive training section that is based on the phases of residential construction, job tasks, hazards and appropriate safe controls identified through research and during the work site job safety analyses (Appendix A). The training material is divided into training modules by work task. The (student) user will have the ability to choose the order in which he or she learns. They can choose to concentrate on construction phases that they participate in more often or on tasks that are less familiar and they need to learn.

The curriculum design approach is to make the DVD training an interactive experience for the learner. The content is presented in a way that will prompt the student to choose first from 
what phase of construction to review, then to choose from a selection of potential fall hazards and then finally from a selection of safe alternatives to the selected hazards (Figure 1). This makes the training unique and customized based on each student's selections. An additional advantage to this structure is that the training is not repetitive. The same training module could be used as refresher training for the same audience and the student would gain new information based on the path chosen.

The DVD training demonstrates with primarily video and some photos the proper techniques to use fall protection in residential construction. Additionally the training will have an optional bilingual (English and Spanish) audio track that will include a narration of the text on the screen. The narrator will also describe the activity in the photos or video. This allows the training to reach Hispanic residential construction workers and workers who have trouble reading. The text will also be translated into Spanish.

The advantage of the DVD is that there are fewer limitations on the quality and amount of video to be used. The DVD training will prompt the user(s) to make a decision (selection) to progress through the training material. This will allow the DVD training to be customized to the level of knowledge of the user(s).

The DVD produced is playable in all stand-alone consumer model DVD players and DVD-ROM drives in PC's. That advantage is that there is no requirement to have access to the Internet or to have a PC. Since its introduction in 1997, the home DVD player has been the most successful consumer electronics device in the history of that market. In the first three months of 2003, 4.4 million DVD players were sold in the United States. That brings the total since introduced to 61 million players in 43 million homes (Fenton, 2003). The likelihood of a residential construction employee or employer having and using a consumer DVD player at 
home is more likely than them having or using a PC. WVUSHE will produce 500 DVD's for distribution by request through the website, distribution through conferences and expos and while conducting related training.

Figure 1. Residential Fall Protection DVD Flow Chart

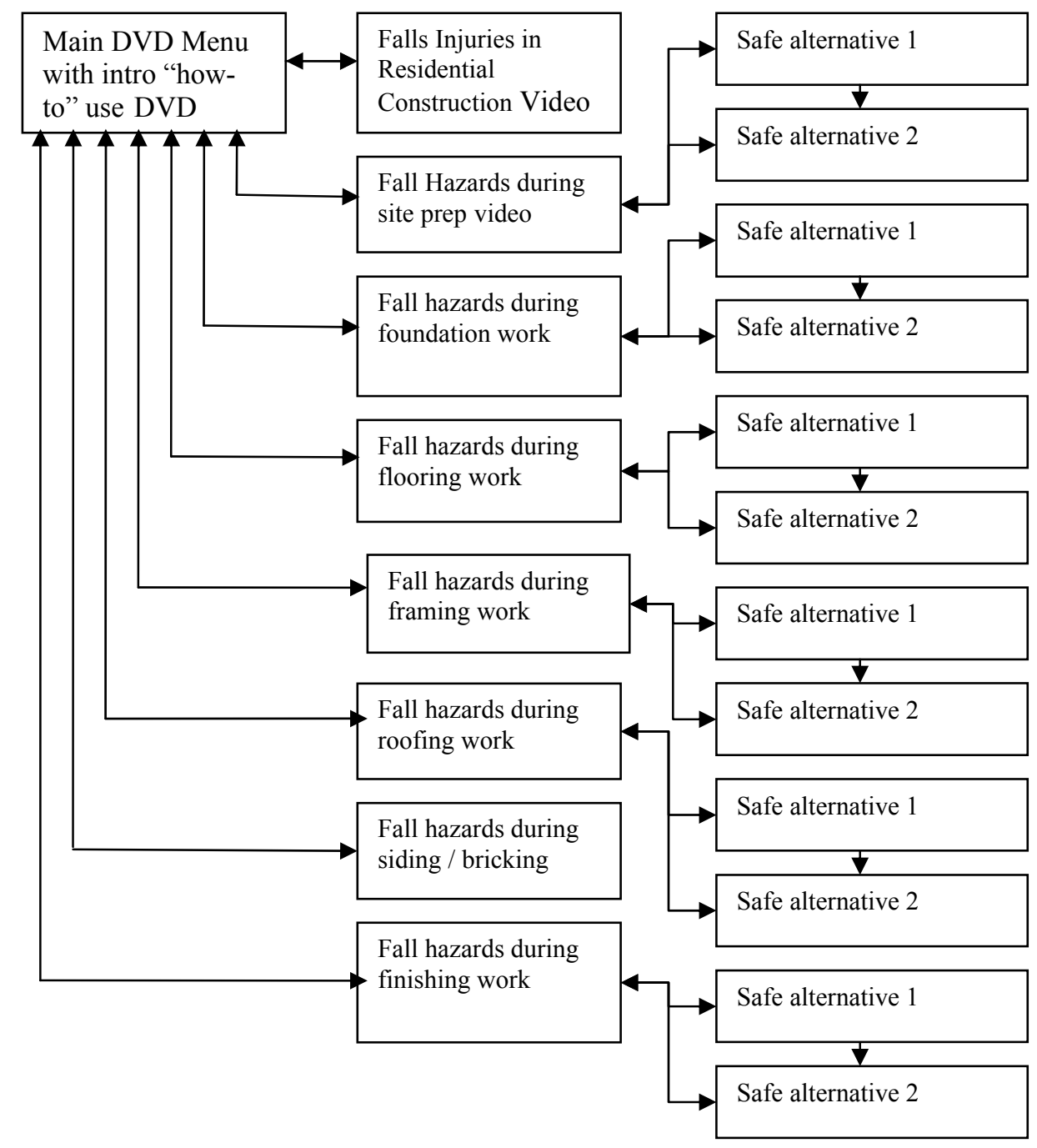

Develop downloadable training materials (handbooks, train-the-trainer guidelines,

PowerPoint slides). WVU developed training material that is downloadable from a website. The 
training material will include PowerPoint slides, trainers Guide, pre and post tests, and course and instructor evaluations. The material is available for download from www.residentialfallsafe.org website. The text documents will be available as a PDF document or in a Microsoft Word. The PowerPoint slides will be available to view on the website and to download for use with Microsoft PowerPoint. The slides will be developed for use with all versions of PowerPoint. They will be backwards compatible with older versions of the software.

The content on the Power Point slides mirror the content on the DVD differing only in that the slides contain still images of the video clips included on the DVD. The exact same English and Spanish narration used on the DVD is included in the notes portion of the slides for the instructors that download the material to use. There is also a version of the slides available for download that includes audio narration in English and Spanish. This was included in the training material for those with PowerPoint but that are not comfortable with public speaking. This will allow the slide show to be presented with narration for an audience. The Spanish version text and instructor notes have also been translated. These slides are available for download and are also included on the interactive DVD.

\section{Develop questionnaires and pre and post tests for the instructor led training and} questionnaire for the interactive DVD delivery. WVUSHE will develop questionnaires to evaluate the effectiveness of the training. The downloadable training material will have an online questionnaire that the user can complete while online or the questionnaire will be emailed to the downloader. When instructor led training is being conducted by WVUSHE faculty, questionnaires will be completed in the classroom. The interactive DVD will be evaluated with questionnaires as well. The means of receiving the DVD training questionnaires will depend on the method of distribution (On-line request, personal interaction, phone request, etc.). 
The questionnaires will be developed separately for each training medium. Some of the information will be common to all of the forms while some will be specific to the type of training (i.e., online, interactive DVD, etc.) The questionnaires will allow WVU to evaluate the effectiveness of the training and to conduct a comparative analysis of the different types of training approaches.

Pre and post tests will also be developed and provided for each training medium. The pre test will be administered prior to training and post tests will be administered immediately following the training. The student information will be gathered during the training and the student will be contacted several months later and will be given the post test a second time. The pre and post tests will be administered for all instructor led courses. The pre and post tests will be offered for online training and for the DVD but will be at the discretion of the user to return or complete.

Conduct regional classes for supervisors and workers. WVUSHE proposed to conduct ten regional training classes. WVUSHE proposed to conduct training in the following cities: (Morgantown, WV, Charleston, WV, Martinsburg, WV, Beckley, WV, Pittsburgh, PA, Philadelphia, PA, Harrisburg, PA, Richmond, VA, Bluefield, VA and Washington DC). Track downloads and collect online, completed questionnaires. The Website developer incorporated a counter into the download portion of the website to track visitors and the number of downloads. The website will also track and collect the questionnaire's that have been completed online.

Evaluate the training effectiveness by analyzing pre and post tests, questionnaire data and the student evaluations of instructors and course content. The evaluation plan for this 
project will access both the process and outcome measures to meet the grant requirements. The process evaluation will determine whether WVUSHE have effectively carried out the functions planned for this project. The outcome measures will determine if the project has been effective in changing individual or group behaviors in ways that are likely to decrease falls from heights on residential construction sites.

\section{Developmental Research Design}

This study is Type I developmental research where the training methodology, product, implementation and outcomes are studied and evaluated for this specific program throughout the design-implementation-evaluation stages as shown in Figure 2 (Richey, Klein \& Nelson, 2004). As typically found in Type I developmental research this research will utilize the case study method as the basis for evaluation and reporting the final results.

Figure 2. Developmental Research Model

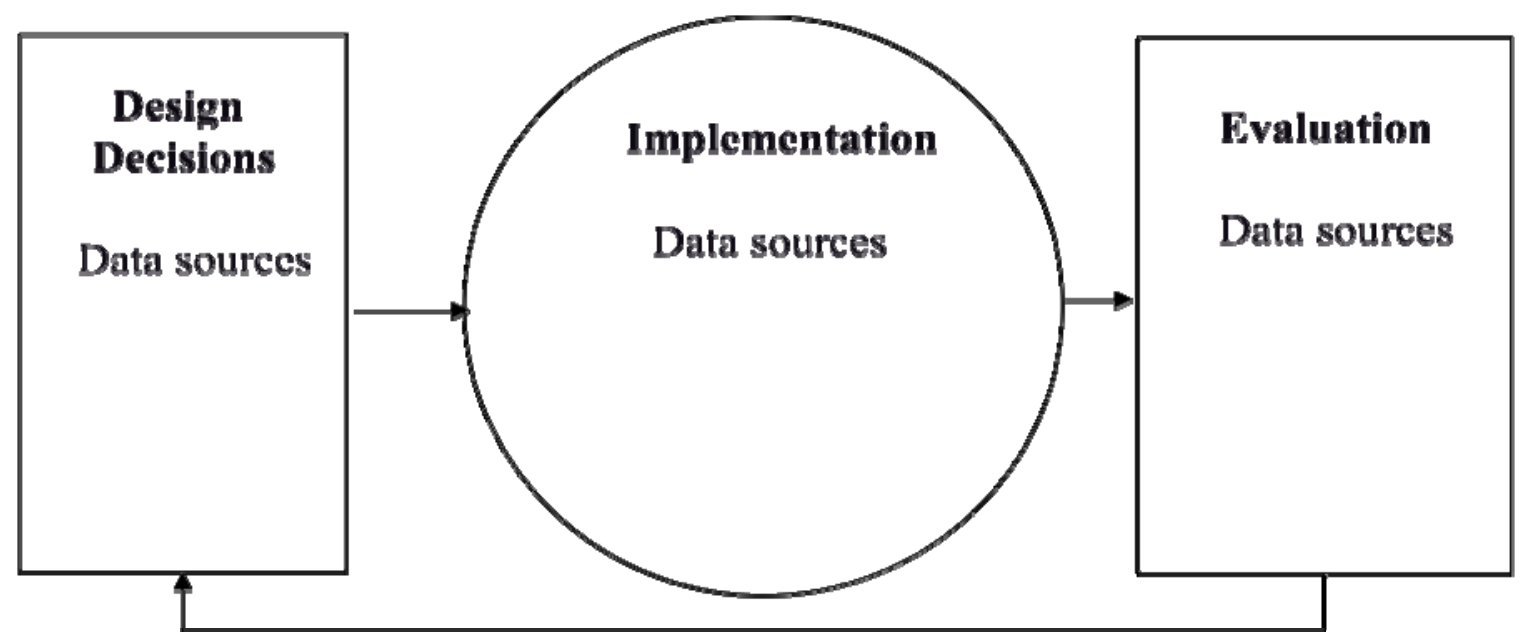

Yin (2003) defines a case study as "an empirical inquiry that investigates a contemporary phenomenon within its real-life context, especially when the boundaries between phenomenon and context are not clearly evident." A case study, then by this definition attempts to capture contextual data that the researcher believes to be pertinent to the resulting outcomes of the 
product developed. Yin (2003) goes on to describe case study inquiry as having the ability to cope with a technically specific situation where there are many more variables that are important to collect than just data points. More specifically this developmental research will be an embedded single case design (Figure 3).

Figure 3. Embedded Single Case Adapted from Yin, 2003

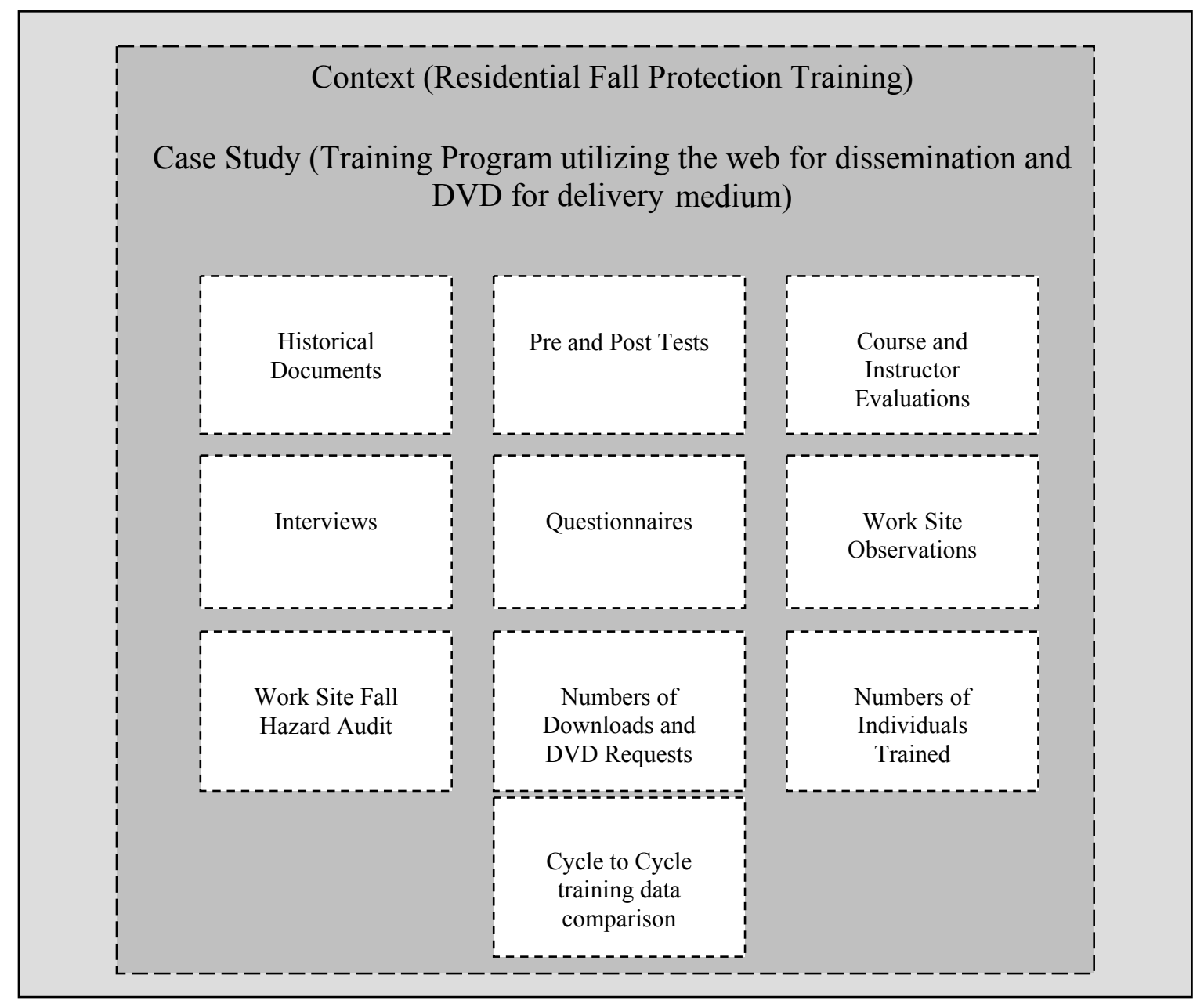

An embedded single case study involves more than one unit of analysis, as in this study (Yin, 2003). The case study findings will be discovered based on a number of qualitative and quantitative data sources that will combine to make up the case study context. The rationale for selecting a single case study methodology for this research is that first, this training program is a unique case within the field of residential construction safety and health and second, that this is a 
longitudinal study that will be observed throughout two cycles of implementation (Yin, 2003). The data collected will be independently analyzed. These analyses will be described in greater detail within this Chapter. Once collected, all data will be assembled and organized into a case record, which will be the source file that will provide the researcher all pertinent data to conduct parallel mixed analysis also known as triangulation of data and to report findings and conclusions (Tashakkori \& Teddlie, 1998; Merriam, 1998). The findings and conclusions will provide the descriptive results about the case, providing all the information necessary to understand the uniqueness of the case (Merriam, 1998).

The research will collect and analyze data through five design-implementation-evaluation cycles of the training program. Originally, the plan was to deliver the training through 2 cycles. The first cycle being the design, implementation and evaluation of the completed and approved training material meeting the grantee requirements with the second cycle being the design, implementation and evaluation of the training material based on the data collected from cycle I.

The actual training program concluded with 5 developmental cycles. These cycles occurred organically, as the data was collected and the needs for revisions became apparent to this author. Cycle I included two publically held training classes in Morgantown and Martinsburg, WV where the class was delivered with the interactive DVD as the primary delivery medium. Cycle I also included the distribution through the website of the interactive DVD for self-guided learning.

Cycle II included 5 classes held for the public and for individual companies in Charleston, WV, Morgantown, WV, Chesapeake, VA, Washington DC, and Harrisburg, PA. The training material in this cycle was delivered with the PowerPoint presentations as the primary delivery medium. 
Cycle III included 5 classes held in Uniontown, PA and Morgantown, WV. Four classes were held in Uniontown, PA for an individual company and one class in Morgantown, WV was held specifically for a non-profit group training youth ages 16 to 21 in the construction trade. Cycle III was a transitional cycle that evolved the training material to address some issues that had been identified in previous cycles as missing or not well explained.

Cycle IV included two classes in Roanoke, VA and were delivered to vocational instructors that teach high school students construction trades skills including the construction of residential homes. This cycle marked the first time that someone other than the curriculum developer taught the course.

Cycle V included 1 class held in Morgantown, WV delivered to the same non-profit group taught in Cycle III with a different group of students. Cycle V also marked the revision and distribution of the interactive DVD that included all revisions made throughout cycles 2 through 4. The delay in DVD redevelopment was due to the amount time, effort, and resources to produce, edit and distribute the DVD video.

Type I developmental research treats the design-development-evaluation process as a form of inquiry and does so by embedding traditional research methods into the development project (Richey, Klein and Nelson, 2004). As previously stated the development phase of the first cycle of this program has been completed prior to this research but will still be documented and evaluated historically.

This case study will be mixed method, which will include qualitative and quantitative measures, which will be nested within the broader case study and will be evaluated within each measure and also between the various measures. The collected data includes results of document and media content analysis, pre and posttests, instructor and course evaluations, interviews, 
questionnaires, and site observations (qualitative and quantitative). An additional measure will then be comparing the data collected in the first cycle to the data from the second cycle and so on. This study is mixed methods in that the research questions, the data collection and the analysis will use both qualitative and quantitative principles and will result in findings that are arrived at through triangulation of all data.

A global view of this research would show a case study utilized to conduct Type I developmental research that will include both qualitative and quantitative data from five complete design-implementation-evaluation cycles. This research design and all data collected will also be connected to and will seek to help answer three research questions. These research questions are as follows:

1. Does the training program addressing residential fall hazards and safety bring about individual or group behaviors that may reduce the likelihood of falls from heights on residential construction sites?

More specifically, will the training material developed and its organization of information (hazards and controls demonstrated by phase of construction) increase learner knowledge and have a real impact on how work is completed on the jobsite and how falls are controlled?

2. Does the technology-based availability and delivery of this training material increase trainee interest?

More specifically, does the utilization of new technologies (interactive DVD, material made available through the Internet) for safety training in residential construction to deliver the training material increase the trainee's interest in the program and in turn have the potential to reach and impact more of the impacted population? 
3. Does including residential construction worker, supervisor and expert feedback into the developmental cycle of training development impact the relevance and acceptability of the residential fall protection training material?

More specifically, does the developmental research model of multiple iterations of development, implementation and evaluation, result in a training program with more relevance and residential construction community (worker, supervisor, owners, experts) acceptability? In particular, will the feedback after each cycle of the training impact the quality of the final training product of the following cycle of training?

\section{Researcher's Role and Background}

This researcher's role in this project is one of a person wearing all of the hats. My connection to this project began as the primary grant writer on the initial application to the Occupational Safety \& Health Administration that resulted in the award of the grant to WVUSHE. I am the principal investigator on the project, the primary curriculum developer, video and audio editor, DVD producer and author, and I am one of three instructors of the material. Additionally, I am one of two evaluators of the effectiveness of the project as required by the funding agent.

Specifically related to my role in this dissertation it is all encompassing. I developed the research design and methodology used and the measuring instruments, presented and instructed the training material, conducted the interviews and the site observations, evaluated the data and performed the analysis of all data collected and performed the triangulation yet to be discussed.

I believe it is important to discuss my background and experience in the content area of fall hazards and protection in construction as well as in related research conducted in this area prior to this study. Prior to beginning my career at the university as an Extension faculty member 
I was employed for 4 years as a safety and health professional in the construction industry. This included a variety of experiences including gaining an understanding of the complexities of fall hazards in construction and determining safe alternatives to protect the construction workers. This also included developing and conducting training on the subjects relating to falls in construction. This experience increased my understating of the complexities of the construction industry and the many work situations where fall protection needed to be implemented. Once I began working at WVUSHE I worked primarily on a long term intervention project that had the aim to assist contractors and construction workers in reducing falls from heights. The project was called "Fall-Safe.' My role on the project was to conduct fall hazard worker and supervisor training, conduct onsite fall hazard site condition and management audits, and provide consultation and assistance to the contractors and workers and to publish and disseminate the findings of the research. This project allowed me to take the skills I had gained in the private sector and apply them to intervention research.

The Fall-Safe project led to several other studies and projects that were related to falls in the construction industry and also to on site data collection of hazards. The first of which was a case study of four work sites that involved the installation of modular homes. The study identified the safety hazards that were specific to this activity and that were not specifically regulated by OSHA. The genesis of this study came about while I was conducting fall protection training for a local company that installed modular homes. During this study I developed protocol for and conducted site observations and developed and analyzed survey questionnaires.

An additional project was related to the technology transfer of the PDA based audit tool that was developed as a research tool for the Fall-Safe project. This lead to a NIOSH Small Business Innovation Research grant to conduct research and development of the audit tool for 
potential commercialization. Again, one of the main focuses of the audit tool was fall hazards on construction sites in addition to other serious hazards on construction sites.

I am also an OSHA training instructor through the OSHA Training Institute, which WVUSHE is a training center. I typically instruct on fall protection related issues including the OSHA standard on fall protection, residential fall protection guidelines, scaffolding hazards, steel erection fall hazards and safe use of ladders and stairways. In addition to training within the OSHA training center I also provide fall protection consultation and custom training curriculum to clients of WVUSHE. My experiences in the areas of construction safety, fall hazards, safety training, and intervention research has given me a greater understanding of the issues relating to the problem with fall fatalities and injuries in construction and in curriculum development, delivery and evaluation.

\section{Participant Selection}

The unit of analysis in this study is the developed residential fall protection training program. However the participants in the study provide a large amount of the data that is to be collected to evaluate the program and to respond to the research questions.

This training material development targets owners, supervisors, workers and experts in residential construction. The project will make special efforts to market to the needs of smaller contractors and especially those with less than 10 employees in West Virginia and OSHA Region III (West Virginia, Virginia, Maryland, Pennsylvania, Delaware and Washington DC). The sample of those utilizing the training material will be a convenience sample and will include employees, employers, instructors, and experts.

The geographic scope of this program for the instructor led training will be OSHA Region III, which WVUSHE provides with OSHA outreach training. Therefore a market base as 
well as name recognition is present in this area. The geographic scope of the web-based training and distribution of the DVD is unlimited. I would suspect that this will include the United States.

The project intends to reach a minimum of 250 employees through a four hour residential fall protection instructor led course. In addition to the 250 employees provided with direct training, the downloadable, online and DVD training material offered through the website will reach an unknown audience size and population type. Tables 1 and 2 were generated with information from the Bureau of Labor Statistics' webpage. It includes the number of residential building contractor's establishments and employees, NAICS 2361 by geographic location. The states given in the table are those that are designated as part of the OSHA Region III.

Table 1. Number of Residential Contractors in OSHA Region III

\begin{tabular}{ll}
\hline State & \# of Residential Contractors \\
\hline Delaware & 664 \\
\hline Maryland & 4494 \\
\hline Pennsylvania & 9157 \\
\hline Virginia & 5409 \\
\hline West Virginia & 1710 \\
\hline Washington, D.C. & 102 \\
\hline TOTAL & $\mathbf{2 1 , 5 3 6}$
\end{tabular}

Table 2. Number of Residential Employees in OSHA Region III

\begin{tabular}{ll}
\hline State & \# of Residential Employees \\
\hline Delaware & 3310 \\
\hline Maryland & 22651
\end{tabular}




\begin{tabular}{lc}
\hline Pennsylvania & 34461 \\
\hline Virginia & 25439 \\
\hline West Virginia & 5229 \\
\hline Washington, D.C. & 824 \\
\hline TOTAL & $\mathbf{9 1 , 9 1 4}$
\end{tabular}

\section{Data Collection Methodology}

\section{Data Sources}

As a Type I developmental research study the development, implementation and evaluation stages of the training program will be documented, and analyzed throughout all cycles of implementation. This study includes five complete cycles (Figure 2). Cycle 1 includes the design, implementation and evaluation of the original training program product developed as required by a training material development grant received. The remaining cycles 2 through 5 will take into account all of the pertinent data collected during cycle I and each previous cycle. That data will be utilized to re-develop or refine the program, then the revised program will be re-implemented and re-evaluated. Cycles 2 through 5 will also be documented and evaluated throughout the process.

Data will be collected throughout this program design, implementation and evaluation. The data sources described below are categorized by the phase of the project (design, implementation and evaluation). The data sources provide information that relates to more than one of the phases of the project and for all training cycles. The following presents the data sources in terms of the phases of the program.

\section{Design Phase}


The origin of this training material development project began with the award of a grant from OSHA. The request for proposal document as well as the completed and accepted grant proposal will be collected and reviewed for document analysis. The initial design of the training program was based on the goals and objectives of the initial grant proposal and once accepted the program developers were committed to that development plan. The original work plan called for a focus group to convene and determine what elements needed to be addressed in the training. These documents will be analyzed along with other historical documents such as quarterly reports, emails, and meeting minutes. This of course applies to the development of the first version of the training material known as cycle 1.

Data that applies to the re-design (cycles 2 through 5) of the material after the first cycle is completed includes all previous cycles' instructor and course evaluations, student and instructor questionnaires, expert, student and instructor interviews, residential construction worksite post training observations and work site fall hazard audit results.

\section{Implementation Phase}

For all cycles the training material will be made available in a variety of formats and delivery methods. One type of implementation will be the act of making the material available to the general public through a website as required by the grant. Once that training material is available for mail order or download, individuals seeking training or potential trainers seeking material to use during training could obtain the training material and use it how they would see

fit. Data sources collected for this implementation phase will be the number of downloads and DVD order requests received during each cycle, content and usability questionnaires and evaluations completed by those who received and used the training material.

The other type of implementation that is part of this training program is the actual 
instructor led training. The data collected during this implementation phase includes instructor and course content and usability evaluations, pre and post test results, and interview and questionnaire data collected from students, instructors, and experts. The course evaluations will differ somewhat based on the delivery medium and method.

Finally, work site observations and fall hazard audit data will be collected from a sample of those workers and companies that received the instructor led training. This will occur following training implementation within each cycle.

\section{Evaluation Phase}

While there will be intermediate evaluations occurring throughout the program design and implementation, a final overall evaluation will be completed to answer 3 research questions. The data collected for evaluation during each cycle and as a final evaluation includes all of the data described above and additionally the qualitative data generated as all of the individual data sources analyzed utilizing triangulation. This will include all available historical documents, interview transcripts, questionnaire resulting data, pre and post test results, instructor and course evaluations, work site observations, and work site fall hazard data (Table 3). 
Table 3. Data Sources by Developmental Phases Across All Cycles

\begin{tabular}{|c|c|c|c|}
\hline & Development & Implementation & Evaluation \\
\hline $\begin{array}{l}\text { Cycle 1: Original } \\
\text { Training Material }\end{array}$ & $\begin{array}{l}\text { Document Analysis of: } \\
\text { - Grant Request for Proposal } \\
\text { - Funded grant proposal } \\
\text { - Focus Groups Results } \\
\text { - Quarterly Reports, emails, } \\
\text { meeting minutes }\end{array}$ & $\begin{array}{l}\text { Training material made } \\
\text { available through website: } \\
\text { - Number of downloads } \\
\text { - DVD order requests } \\
\text { received } \\
\text { - Users, instructors, } \\
\text { students and expert } \\
\text { content and usability } \\
\text { questionnaires and } \\
\text { intcrvicws } \\
\text { Instructor Led Training } \\
\text { - Course and instructor } \\
\text { evaluations completed by } \\
\text { those who received and } \\
\text { used the training material } \\
\text { - Student content and } \\
\text { usability questionnaires } \\
\text { and interviews } \\
\text { - Pre and post tests } \\
\text { - Work site observations } \\
\text { - Work site Fall hazard } \\
\text { audit data } \\
\text { - Number trained in } \\
\text { classroom }\end{array}$ & $\begin{array}{l}\text {-Document analysis of } \\
\text { original grant request for } \\
\text { proposal, funded grant } \\
\text { proposal, focus group } \\
\text { results, quarterly reports, } \\
\text { emails, and meeting } \\
\text { minutes. } \\
\text { - Pre and post tests } \\
\text { - Instructor and course } \\
\text { cvaluations } \\
\text { - Expert, instructor, and } \\
\text { student questionnaires } \\
\text { and interview results } \\
\text { - Work site observational } \\
\text { data collected } \\
\text { - Work site fall hazard audit } \\
\text { results } \\
\text { - Number of downloads } \\
\text { - Number of DVD's } \\
\text { requested to ship } \\
\text { - Number trained in } \\
\text { classroom }\end{array}$ \\
\hline $\begin{array}{l}\text { Cycles } 2 \text { - 5: } \\
\text { Revised Training } \\
\text { Material }\end{array}$ & $\begin{array}{l}\text { Revisions made to cycle } 1 \\
\text { training material design will } \\
\text { be based on data collected } \\
\text { from cycle } 1 \text { dcsign, } \\
\text { implementation and } \\
\text { evaluation including: } \\
\text { - pre and post tests } \\
\text { - Instructor and course } \\
\text { evaluations } \\
\text { - Expert, instructor, and } \\
\text { student questionnaires and } \\
\text { interview results } \\
\text { - Evaluations of training } \\
\text { material } \\
\text { - Work site observational } \\
\text { data collected } \\
\text { - Work site fall hazard audit } \\
\text { results } \\
\text { - Number of downloads } \\
\text { - Number of DVD's } \\
\text { requested to ship } \\
\text { - Number trained in } \\
\text { classroom }\end{array}$ & $\begin{array}{l}\text { Revised training based on the } \\
\text { results of data collected during } \\
\text { cycle } 1 . \\
\text { Reviscd training matcrial } \\
\text { made available through } \\
\text { website: } \\
\text { - Number of downloads } \\
\text { - DVD order requests } \\
\text { - Users, instructors, } \\
\text { students and expert } \\
\text { content and usability } \\
\text { questionnaires and } \\
\text { interviews } \\
\text { - Revised Instructor Led } \\
\text { Training } \\
\text { - Course / instructor } \\
\text { evaluations } \\
\text { - Student content and } \\
\text { usability questionnaires } \\
\text { and interviews } \\
\text { - Pre and post tests } \\
\text { - Work site observations } \\
\text { - Work site Fall hazard } \\
\text { audit data } \\
\text { - Number trained }\end{array}$ & $\begin{array}{l}\text { Collect and evaluate the same } \\
\text { data as in cycle } 1 \text { evaluation. } \\
\text { In addition collect data } \\
\text { sources as follows: } \\
\text { - Differences in all data } \\
\text { collected from cycle to } \\
\text { cycle } \\
\text { - Data sources generated } \\
\text { through triangulation of all } \\
\text { data collected }\end{array}$ \\
\hline
\end{tabular}




\section{Data Collection}

This researcher is the developer of the grant program and has been involved in all phases of the design, implementation and evaluation. This access allows for full access to the data. The following describes how the data sources discussed above will be collected. All questionnaires, interview protocols, and pre and post tests were approved for exemption under the Human Subjects Policies by the WVU College of Human Resources and Education (Appendix B).

Historical and current documents. The historical and current documents will include the original grant request for proposal, the submitted and funded grant proposal, and all documents related to the project including emails, meeting minutes, focus group transcription, previous work site field notes and job safety analyses, etc. This data is controlled by and available to this researcher for analysis.

Pre and posttests. The original OSHA grant required that the developed training program have an evaluation component. One of the evaluation measures that WVUSHE provided was the development and implementation of pre and post tests (Appendix C, D, E, F, G and H). As instructor led courses are conducted by WVUSHE, the instructor will require the students to complete pre and post tests prior to and following training. The plan for delivery and collection of the post tests is to collect one post test immediately following the instructor led course and then to collect a second post test (post-post test) approximately 6 months after the training has been completed. This will be the exact same content as the post test given immediately following the training.

Instructor and course evaluations. Further requirements of the grant request for proposal included evaluations of the course and the instructors. These original evaluations were developed for the implementation of the grant and additional evaluation content was developed for this 
research (Appendix I). The course and instructor evaluations are combined into one document for the instructor led courses and will be collected from the students when WVUSHE conducts instructor led courses. Course and instructor led evaluations will be made available to those downloading training material and requesting the DVD and the results of the evaluations will be requested by WVUSHE to utilize for evaluation of the program. Course evaluations will different somewhat based upon the delivery medium. Additionally, no instructor evaluations will be collected if the student completes the course on their own (Self-guided through DVD or webbased).

Interviews. Interviews will be conducted with students, instructors, and experts related to the training program and the three research questions. The interview questions and protocol will differ for each of the three groups interviewed, based on the relation of the questions to the research questions. The interview questions developed for each group will be structured in that each person interviewed within a group (student, instructor, or expert) will be asked the same pre-designed set of questions (Appendix $\mathrm{J}$ and $\mathrm{K}$ ). This type of structured interview is appropriate for case studies where specific information is being sought (Merriam, 1998). The interviews will be audio recorded and will then transcribed. The interviews will be conducted in person and over the phone based on the availability of the interviewees. The in person interviews will take place both at the interviewees location and at WVUSHE offices based on availability and scheduling. Student interviews will take place following completion of training and can take place at WVUSHE offices or at the various training site locations. The number of interviews will

vary based upon agreement of participants to be interviewed. The goal being to interview experts from the original focus group panel and any others discovered during initial dissemination of 
training material. The number of instructors interviewed will also be based on the number of instructors that download or request the training material and then use the material to train. WVUSHE faculty trainers will also be interviewed with the exception of the author.

Questionnaires. Questionnaires will be similar in content to the interview question protocol, with the difference being that the responses will be limited and will not allow for many open ended responses The questionnaires will be completed by experts, students, and instructors. The student questionnaires will be conducted following instructor led training (Appendix L and M). Instructor and expert questionnaires will be conducted, as individuals are available.

Questionnaires will also be completed by those obtaining the DVD material through the website (Appendix N). Those completing questionnaires online may include instructors, students and experts.

Number of downloads. The OSHA grant required that WVUSHE track hits and downloads from the website. WVUSHE will track all requests for downloads of training material throughout cycle 1 and 2 of the program implementation.

Number of DVD order requests. All order requests data is being collected including the number of DVD's requested. This will be ongoing through both cycles of training material developed. Also, as intermediate changes are made in cycle 1 , the revised versions sent will be tracked as well. Demographic and contact information is also collected from those that order the DVD's. This will provide contact information for follow up data (post tests and questionnaires).

Number trained in instructor led courses. WVUSHE proposed in the original grant proposal that 250 residential construction employees, employers, and owners will be trained in instructor led training within the Mid Atlantic region known as OSHA Region III (West Virginia, Virginia, Pennsylvania, Maryland, Delaware, and Washington DC). As other data is 
collected at instructor led courses the total number trained will be collected during both cycles of training implementation.

Work site observations. Following instructor led courses of local residential construction company employees, WVUSHE will seek agreements from and make arrangements with employers to gain access to residential construction building work sites with home construction in process. Upon acceptance from employers and employees in allowing site access, the researcher will spend approximately one full work shift at each work site and collect observational data through note taking and photographs.

Work site fall hazard audit. WVUSHE and this researcher co-developed with a local software company (VeriTech, Inc.) a Pocket PC PDA (Personal Digital Assistant) based fall hazard audit tool. This audit tool was used as a data collection and reporting tool in a previous intervention research project entitled Fall-Safe (Becker, Fullen, Akladios, Carr, \& Lundstrom, 2001). This audit tool will be used while the researcher is on site completing the work site observations. This audit tool will act as a reminder for and prompt the researcher to document worker, supervisor and owner behaviors and actions to be included in the observation notes and photographs. This audit tool is designed to evaluate every fall hazard on the work site, and evaluates based on OSHA regulations, how well each fall hazard is being controlled. The resulting data results in a detailed report of the worksite that identifies all fall hazards, how well each was controlled or not controlled and generates a percentage score for each hazard, each location within the site (i.e., first floor, second floor, attic, roof, etc.), and a total work site score (Appendix O). 


\section{Data Analysis}

This Type I developmental research involves the documentation of the designimplementation-evaluation process through five complete cycles, while at the same time assessing the program as it relates to the three guiding research questions. The following will detail how the data collected will be analyzed and evaluated as related to the three research questions and also as related to the five cycles of design-implementation-evaluation. The identification of what data that is to be collected relates back to the five cycles of the training program have been identified in the data sources section. Table 4 identifies the data sources as related to which research questions they address.

\section{Historical Documents}

All documentation that relates to the initial development of the training material including the original grant request for proposal, the submitted and awarded proposal, correspondences, quarterly reports, emails, focus group results and all other documents related to the training program originally developed will be reviewed for content that may be significant to the redesign of the training material. The documents will be reviewed and any data that emerges or that pertains will be documented separately in a spreadsheet that will sort the themes and pertinent information in appropriate categories as those categories are identified then created.

The documents will also be reviewed for pertinence to answering the three research questions. The quarterly reports to the granting agent as well as email correspondence will support research question 1 in reporting on the pre and post test results, student questionnaire results, and the quantity of students taught. The quarterly reports will also document the number of DVD's requested, downloads, and online training sessions completed. This will provide pertinent data to answer research question 2 related to the effect technology has on trainee 
interest. The original grant proposal as well as the focus group transcription identified the original plan for reaching the workers and impacting safety. These documents will be used to guide the re-development of the training program along with other data collected. The grant proposal along with the quarterly reports and correspondence will help in answering research question 3 related to the use of feedback on impacting acceptability and relevance of the training program.

\section{Pre and Postests}

The pre and posttests developed for this training program were designed to measure knowledge gain from each of the modules. The design of the test included selecting one item from each of the training modules that was identified within the training as a key objective. Once identified there were two questions developed for each topic item that addressed the same basic concept. One question was placed in a pre test and the other in a post test. There are six major training modules in the final content of the first version of the training, so the initial pre and posttest has 6 questions each. The six questions are randomized and then placed into the pre and posttest. As discussed in the data collection section, the pre test will be given for all training mediums prior to training where applicable and the post test will be given first immediately following training, then again as a post-post test approximately 6 months after the initial training is completed.

The initial evaluation of this data will compare pre and post test scores completed prior to and following training (both post and post-post tests will be evaluated). The differences between the pre and post mean scores will be compared using a students $T$ Test at $p=0.05$ level of significance. Additionally, pre and post score differences from cycle 1 will be compared to pre and post score differences from cycle 2 and so on through cycle 5. 
The results of the statistical analysis during each cycle and between cycles will contribute to answering research questions 1 and 3. Question 1 asks, "Does the DVD addressing residential fall hazards and safety bring about individual or group behaviors that may reduce the likelihood of falls from heights on residential construction sites?", while question 3 asks, "Does including residential construction worker, supervisor and expert feedback into the developmental cycle of training development impact the relevance and acceptability of the residential fall protection training material?". Question 3 will be illuminated by this data when comparing the results of each cycle to the one preceding it, because the design and implementation of cycles will be impacted by the feedback collected during each previous cycle.

\section{Course and Instructor Evaluations}

WVUSHE has departmental and faculty requirements for instructor evaluation forms. This data will be collected as WVUSHE faculty instruct the courses. Through the training material development grant process, additional evaluations were developed that more specifically address the goals of the grant and this research.

The data collected in these course and instructor evaluations include data relating to quality of instruction, applicability of training to the field, ease of use of content and technology, and preparedness of instructor. The evaluations will vary slightly based on the medium of delivery of the training to gain medium specific feedback. For example, evaluation questions relating specifically to the Menu system used in the DVD will only be applicable to those who completed the training using the DVD. The course and instructor evaluation content will be contained on one form to increase likelihood of completion.

The resulting data from the evaluations will be quantified for descriptive statistical analysis. The course and instructor evaluations will be conducted during each implementation 
cycle and the data collected during each cycle will be compared for change.

The results of the statistical analysis during each cycle and between cycles will lend evidence to answer research questions 2 and 3. Question 2 asks, "Does the technology-based availability and delivery of this training material increase trainee interest?" Evaluation scores and comments sections from the course and instructor evaluations will provide data pertinent to this question. Question 3 asks, "Does including residential construction worker, supervisor and expert feedback into the developmental cycle of training development impact the relevance and acceptability of the residential fall protection training material?" As evaluations are conducted during the implementation phase of both cycle 1 and 2 training implementation, this data will be pertinent to this question. The evaluation data will also be included in the larger qualitative analysis described below.

Expert, Instructor and Student Interview Transcripts

The transcripts from the student, instructor and expert interviews will be analyzed for emerging themes. Since the interview questions for each group will be structured, the analysis of the data will involve identifying quotes and comments from the interviewees that represent resurfacing themes that relate to the three research questions or that relate to the redesign of the training material as part of the developmental research process. This researcher will read the transcripts and highlight identified themes using a color coding system. The documents will then be re-read for verification and clarification that all pertinent data and themes were identified and color coded. A second researcher will act as a code and review the transcripts two times and follow the same color coding system. A spreadsheet will record themes that emerge out of the transcripts. The quotations or a paraphrase of a comment will be copied and pasted from the electronic document transcript into the spreadsheet. This allows for the researcher to review the 
spreadsheet for a condensed and summarized version of the themes that arose out of the interviews. This also allows for cross comparison of the data with other qualitative and quantitative data collected throughout the process.

The interview following the second cycle of implementation will be vital in the analysis of the success of the redesign, because the other data sources such as student evaluations and pre and post tests may be limited due to time and available new population. The emerging themes from the second cycle interviews of students, instructors and experts will be compared to the results of the first cycle emerging themes. The interview transcripts and resulting analysis will lend evidence to all three research questions. Expert, Instructor and Student Questionnaire Results

Questionnaires will be developed based on the interview questions. The questionnaires will also include and collect demographic data. The questionnaires will be used to support the interviews. The questionnaire data will provide data that will be used to answer all three research questions and also redevelop the training material for re-implementation in cycle 2 of the process. Questionnaires collected after the second cycle will be analyzed as described above and additionally will be compared to the results of the questionnaires collected following cycle 1 implementation.

\section{Work Site Observations}

Work site observations will be conduced simultaneously as the fall hazard audit is being conducted. The observations will be documented by taking field notes of the construction work in process. Once completed all field notes will be reviewed for common themes using color coding and organization of identified themes using a spreadsheet. The documentation will include all details related to work processes that include working at heights. All details from 
worker behavior to construction processes and management control of fall hazards. Site observations are designed to provide discovery into the reasons why people do what they do and what outside factors affect their decisions. The resulting observation notes of all work sites observed will be reviewed to identify emerging and common themes. These themes will range from fall hazards to worker attitudes towards fall protection and will be identified and documented following the same process described for analysis of interview transcripts. Also, the observation notes will be used in conjunction with the fall hazard audit data reports to hopefully shed new light on the field observations as well as a verification of the validity of the quantitative field audit data (Merriam, 1998). The data that emerges from the site observations will lend evidence to all three research questions.

Work site observations will also be conducted following cycle 2 implementation. The resulting themes from this cycle of observations will be evaluated the same as above and will also be compared to the results from cycle 1 .

\section{Work Site Fall Hazard Audit Results}

The PDA based audit tool used for this data collection process results in a variety of quantitative fall hazard and control data as well as auditor observational data. The audit tool collects data on every fall hazard on the work site, and how each of those fall hazards are controlled based on OSHA regulations. A report is generated that scores each fall hazard control (Appendix). The report is organized by location names (i.e., First Floor North Side, Roof, Basement). The audit tool also collects the number of employees exposed and a variety of other work site demographic data.

This fall hazard data will provide a verification of the site observations collected from the same sites. This audit data can lend support to the observer's generalizations or assumptions and 
it can also shed some light on the field observations (Merriam, 1998). The audit data will lend evidence to all three of the research questions.

\section{Triangulation of Data}

This study is a case study analysis of a single safety training program across five cycles of development. As described above, there are many different data sources that are collected throughout the process of designing, implementing and evaluating this one program. . In order to keep the research questions in focus throughout the data collection and analysis Table 4. was developed to identify the relationship between the documentation and the research questions.

Denzin (1970) wrote about triangulation stating "the rationale for using this strategy is that the flaws of one method are often the strength of another, and by combining methods, observers can achieve the best of each while overcoming their unique deficiencies." The term "triangulation" has its roots in surveying, were a surveyor uses two points to identify and verify the location of a third point (Patton, 2002). In qualitative or mixed methods research, the researcher becomes part of the study and thus part of the results. By utilizing triangulation, I put myself in the role of the surveyor, holding the level and viewing the other points through the telescope, attempting to identify and clarify this third point. By identifying this third point I will be able to draw a better map of this research that can more easily explain the conclusions and results and show how it relates back to the guiding research questions.

Triangulation of the compiled data sources will be conducted in this study with the goal of discovering emerging themes and connections between all of these data sources (Figure 4). These connections hopefully will lend support to assumptions made in the analysis of single data sources and more importantly lend support to the three research questions. 
As Type I developmental research is an applied research approach, the results of the triangulation within the program will also be utilized to improve the training program for reimplementation and re-evaluation and this resulting data will be evaluated as well.

Table 4. Relationship Between Data Sources and Research Questions

\begin{tabular}{|c|c|c|c|c|c|c|}
\hline & $\begin{array}{l}\text { Historical } \\
\text { Documents }\end{array}$ & $\begin{array}{c}\text { Pre/Post } \\
\text { Tests }\end{array}$ & $\begin{array}{l}\text { Instructor } \\
\text { Evaluations }\end{array}$ & Interviews & $\begin{array}{l}\text { Question- } \\
\text { naires }\end{array}$ & $\begin{array}{l}\text { Worksite } \\
\text { observations } \\
\text { and audits }\end{array}$ \\
\hline \multicolumn{7}{|l|}{ Research } \\
\hline Question 1 & $\sqrt{ }$ & $\sqrt{ }$ & & $\sqrt{ }$ & $\sqrt{ }$ & $\sqrt{ }$ \\
\hline \multicolumn{7}{|l|}{ Research } \\
\hline Question 2 & $\sqrt{ }$ & & $\sqrt{ }$ & $\sqrt{ }$ & $\sqrt{ }$ & $\sqrt{ }$ \\
\hline \multicolumn{7}{|l|}{ Research } \\
\hline Question 3 & $\sqrt{ }$ & $\sqrt{ }$ & $\sqrt{ }$ & $\sqrt{ }$ & $\sqrt{ }$ & $\sqrt{ }$ \\
\hline
\end{tabular}


Figure 4. Research Methods Flow Chart

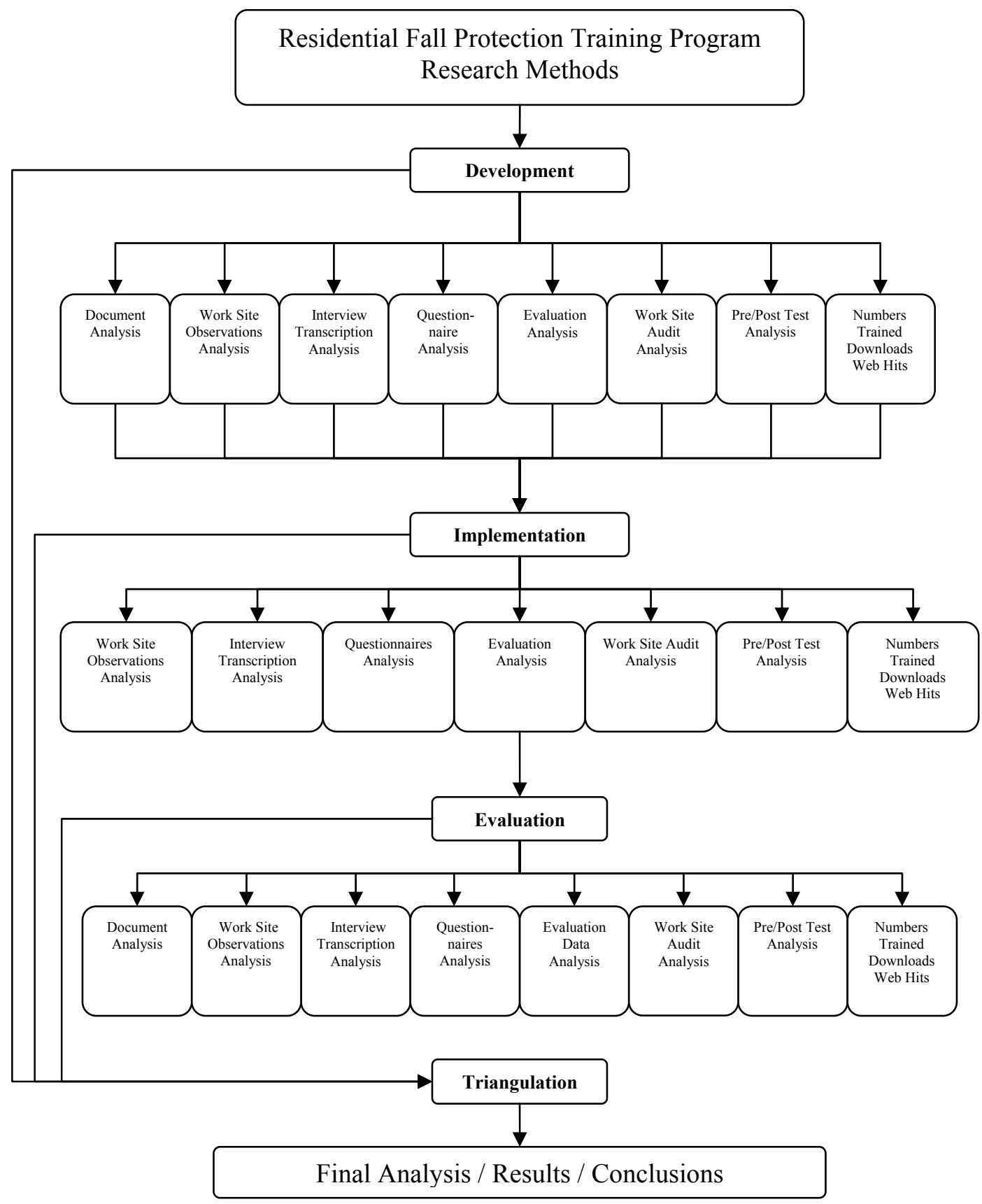




\section{Chapter 4}

Results

This chapter describes the development of the residential fall protection training material, the quantitative and qualitative data collected through five developmental cycles of the instructor led training and two developmental cycles of the development, distribution and use of the self-guided DVD via website requests and the resulting data collected. In addition this chapter describes the analysis of the data collected for continued development and to answer the three research questions.

\section{Development of Instructor Led and Self-guided DVD Training Curriculum}

WVU Safety \& Health Extension (WVUSHE) received grant funding from The Occupational Safety \& Health Administration Training Institute to develop training addressing falls from height in residential construction. WVUSHE proposed to develop training utilizing Microsoft PowerPoint for instructor led training and a self-guided interactive DVD for use either for self-guided learning or for use by other trainers for delivery. The grant work to develop the original training material began October 1, 2004 and was completed and accepted by the grantor September 2006. The intent of this grant was focused on development of the training material, not delivery. WVUSHE applied for and received a second grant from OSHA in October 2006 to utilize the previously developed training material for delivery of the training to a proposed 410 individuals. This grant began in October 2006 and was completed in September of 2008.

WVUSHE proposed to develop training customized for the audience, which was residential constriction workers, foreman, supervisors and owners. The hope being to keep the learners interest and engage the trainee by showing them scenarios that they would encounter on an actual jobsite instead of showing them photographs or video of fall protection being used on 
commercial or industrial construction sites that did not apply. WVUSHE understood the need for this training as this organization is an OSHA training center and work with the residential construction industry a great deal. WVUSHE proposed to also deliver the training with a minimum amount of text and use primarily photographs and video to demonstrate unsafe and then safe acts.

WVUSHE also proposed to develop the training modules by phase of residential construction. The intent being not to teach the residential construction fall protection through reinterpretation or regurgitation of the OSHA federal regulations, but rather to deliver the topic to the worker in a way that the worker would encounter fall hazards on the work site. WVUSHE proposed that the construction phases addressing fall hazards and providing safe alternatives by phase of construction were as follows:

Site Preparation Hazards

Foundation Hazards

Flooring Hazards

Framing Hazards

Roofing Hazards

Siding and Brickwork Hazards

Other Hazards

An additional module was proposed to be developed to introduce the topic of fall protection, which was to be entitled "The Problem." This module was to address and introduce the students to the serious problem of injuries and fatalities due to falls from height in residential construction. This module was not completed for the first developmental cycle. 


\section{Developmental Cycle I of PowerPoint and Interactive DVD Training Material}

Developmental Cycle I was the most intensive of all of the developmental cycles due to the fact that this material was all original and required the collection of a large amount of original visual material. Additionally, once collected all of this visual material was organized, edited and placed in two delivery mediums (Microsoft PowerPoint and DVD-video) with the addition of development of a script and the recording of narration in English and Spanish. Once this work was complete it had to be submitted to the granting agent for approval and corrections. Once approved WVUSHE had to teach the classes with the approved material only. If changes were made the grant officer had to approve.

\section{Cycle I Development}

A team of 3 faculty at WVUSHE began the work of collecting and organizing photographs and video material that captured work in all identified construction phases that also included fall hazards either being controlled safely or not. This team worked with local residential builders to collect video footage and photographs of residential construction work at heights, developed the curriculum and narrative needed to address the fall hazards and safe controls shown in the training material, contacted fall protection equipment manufacturers as well as other training groups to obtain permission to use video segments and photographs in addition to the footage collected in the field, edited the video, recorded narration in English and Spanish, developed the PowerPoint's, and produced a self-guided interactive DVD. All work was completed by WVUSHE with the exception of the Spanish translation. This was done by collecting approximately 20 hours of actual worksite video footage of residential construction in progress as well as hundreds of worksite photographs. Once the footage and photographs were collected they were imported into a computer, edited and categorized by phase of construction 
and type of fall hazard. The same categorization was done with manufacturer and training center photographs and video footage.

These three faculty members along with a faculty member used for English narration and a subcontractor for Spanish translation completed development of a PowerPoint training program and a self-guided DVD-video in September 2006 that were both approved by the grantor for content accuracy. The resulting DVD included video segments addressing hazards by phase of construction, then offered for the user, several" safe alternatives" to review. This allowed a selfguided user to complete the training that was appropriate for his or her trade (roofer, drywall finisher, etc.) or for the work being conducted currently (by phase of construction). The DVD also included all of the PowerPoint training in a DVD-ROM portion of the disc. The PowerPoint was provided in English and Spanish, with and without narration. This was done to address a known issue in the industry that some first line supervisors (foreman, superintendent) from the construction industry are not comfortable and have not been trained to be trainers. This addition of a narration option built into the PowerPoint allows these construction supervisors to deliver the training publically.

The narration and photographs on the PowerPoint presentations were correlated with the video content and narration on the DVD. WVUSHE also developed a website that made available the PowerPoint's for review and offered an order form for the 2 Disc DVD set. Software selected and utilized to produce this training curriculum included Microsoft PowerPoint, ULead DVD Workshop 2.0, Adobe Audition, and Sony Vegas 4.0. Hardware purchased included a camcorder, microphone, audio mixer, and material for a desktop sound booth, as well as a desktop PC with Windows XP. 
In addition to the training material, pre and post tests were developed to test the students knowledge prior to and after the training course on the major areas taught in the course that correlated with the training modules. Also developed were pre and post questionnaires that collected the demographic, injury, and training experience prior to the course, and perceptions and opinions of the training developed following the course. Interview protocols were developed for students, trainers, and experts. Finally, a questionnaire was developed to be sent to all who requested the DVD set through the website order form. The DVD questionnaire was executed through email with the online survey tool www.surveymonkey.com. Cycle I Delivery and Evaluation of the Instructor Led Training

Cycle I delivery of content includes the delivery of the content at two public courses. These were courses delivered on February 19, 2007 in Morgantown, WV and on February 22, 2007 in Martinsburg, WV. Once the grant officer approved the training material in both formats (PowerPoint \& DVD), WVUSHE scheduled a series of public courses to meet the obligations of the grant and to educate and inform the residential construction industry throughout OSHA Region III (WV, VA, PA, MD, DE \& DC). These were the first two courses delivered to the public with the approved curriculum. I acted as the primary trainer for all courses throughout the whole grant cycle with the exception of the last two classes held during the final developmental Cycle. In Cycle I, as the primary trainer and curriculum developer I made the decision to utilize the DVD-video as the primary training medium as opposed to the PowerPoint presentations. This decision was made for several reasons. First, I felt strongly that this type of delivery would hold the audience's attention better than photographs used in the PowerPoint presentations and that the freshness and uniqueness of this delivery medium to this audience could increase the attention and learning of the audience. I also believed that the video included on the DVD was 
more compelling than the photographs on the PowerPoint presentations. What follows are the results of all data collected from each of the first two classes held during Developmental Cycle I.

Class 1, February 19, 2007, Morgantown, WV. The first class was held in Morgantown, WV at the offices of WVUSHE. This class was marketed in local papers and through a University press release as well as by direct marketing of local residential builders. Data collected from this training class included various historical documents (i.e., sign-in sheets, instructor notes, class details, training material, quarterly grant report), pre and post questionnaires, pre and posttests, and post-post tests and questionnaires.

The student enrollment was 22 and was made up of 5 residential construction workers, 2 residential construction employers, and 15 "others." This group of "others" was made up of primarily college students from Fairmont State University Safety Engineering Technology program and the West Virginia University Safety Management Master's program as well as some WVU Extension Service faculty. These "others" were not the audience that was originally intended.

The training was delivered using the DVD as the primary training medium. Although the student evaluations validated their satisfaction with the class, as the instructor I believed that I was acting only as an operator of the equipment with the occasional addition of information or answering of a question. This was due to the fact that narration had been recorded for the entire DVD content so the instructor was in essence playing multiple videos. Additionally, music was added at each DVD menu and submenu levels, which caused a bit of a distraction in the classroom as the instructor would continually have to turn the system volume down to hold discussions between video segments and then turn the volume back up when the next video segment began. 
Several of my faculty peers were in the audience and the informal feedback from them after the class was that these distractions were not apparent to the audience, and the quality of content seemed to overpower the other issues that were of a concern to me.

The students completed a pre and posttest and a pre and post questionnaire. The results of these two data collection instruments in Tables 5 through 7 . This class had more females attending than the other classes due mainly to the enrollment of college students in the course. The college students also affected the questions relating to job title, and construction experience. Otherwise the difference in this class compared to the other classes was minimal. Some of this could be due to the fact that many of the students attending the course had worked construction in the summers and others had completed internships in the construction industry where they had been exposed to fall hazards. Approximately half of the students stated that they work at heights while only $26.32 \%$ reported using fall protection. A small percentage had fallen from a height or had been injured from a fall from heights.

Table 5. Cycle 1 Class 1 Pre Questionnaire - Demographics

\begin{tabular}{llc}
\hline Question & Responses & Percentage \\
\hline Sex $(\mathrm{n}=22)$ & Male & $68.18 \%$ \\
& Female & $31.82 \%$ \\
\hline Job Title $(\mathrm{n}=16)$ & Supervisor & $6.25 \%$ \\
& Employee/Skilled & $6.25 \%$ \\
& Supervisor/Foreman & $12.50 \%$ \\
& Contractor/Owner & $18.75 \%$ \\
\hline Type of Construction $(\mathrm{n}=17)$ & Others & $62.50 \%$ \\
\hline
\end{tabular}




\begin{tabular}{llc} 
& Commercial & $5.88 \%$ \\
& Heavy Construction & $5.88 \%$ \\
\hline Years Worked in Construction $(\mathrm{n}=16)$ & Other & $64.71 \%$ \\
\hline Number of Employees at your company $(\mathrm{n}=9)$ & Less than 1 year & $68.75 \%$ \\
& 1 to 5 years & $18.75 \%$ \\
& 5 to 10 years & $6.25 \%$ \\
& More than 10 years & $6.25 \%$ \\
\hline & 2 to 5 employees & $33.33 \%$ \\
& 5 to 10 employees & $11.11 \%$ \\
& 10 to 20 employees & $0.00 \%$ \\
& More than 20 & $22.22 \%$
\end{tabular}

Table 6. Cycle I Class 1 Pre Questionnaire Fall Injury and Fall Protection Related Data

\begin{tabular}{lcc}
\hline Question & Responses & Percentage \\
\hline Have you fallen from heights $(\mathrm{n}=19)$ & Yes & $15.79 \%$ \\
& No & $84.21 \%$ \\
\hline Have you been injured $(\mathrm{n}=19)$ & Yes & $5.26 \%$ \\
& No & $94.74 \%$ \\
\hline Do you work at heights $(\mathrm{n}=19)$ & Yes & $52.63 \%$ \\
\hline Do you use fall protection $(\mathrm{n}=19)$ & No & $47.37 \%$ \\
& Yes & $26.32 \%$ \\
& No & $73.68 \%$
\end{tabular}


The data related to technology also was not skewed by the increased enrollment of college students (Table 7). All of the construction industry students had at least 1 DVD player and $83.36 \%$ had accessed DVD special features. All of the students owned a computer at home and $86.36 \%$. All of the students use the computer while half had completed web based safety training.

Table 7. Cycle 1 Class 1 Pre Questionnaire - Technology \& Training

Question $\quad$ Response Percentage

\begin{tabular}{|c|c|c|}
\hline \multirow[t]{3}{*}{ Number of DVD Players owned $(n=22)$} & Own 1 & $27.27 \%$ \\
\hline & Own 2 & $36.36 \%$ \\
\hline & Own 3 or more & $36.36 \%$ \\
\hline \multirow[t]{2}{*}{ Have used Special Features on DVD $(n=22)$} & Yes & $83.36 \%$ \\
\hline & No & $13.64 \%$ \\
\hline Have Computer at Home $(n=22)$ & Yes & $100.00 \%$ \\
\hline \multirow[t]{2}{*}{ Web Access at Home $(n=22)$} & Yes & $95.45 \%$ \\
\hline & No & $4.55 \%$ \\
\hline \multirow[t]{4}{*}{ Connection Speed at Home $(n=22)$} & Dial Up & $4.55 \%$ \\
\hline & Cable & $18.18 \%$ \\
\hline & DSL & $50.00 \%$ \\
\hline & None & $27.27 \%$ \\
\hline \multirow[t]{2}{*}{ Computer at Work $(\mathrm{n}=22)$} & Yes & $86.36 \%$ \\
\hline & No & $13.64 \%$ \\
\hline \multirow[t]{2}{*}{ Web Access at Work $(n=22)$} & Yes & $81.82 \%$ \\
\hline & No & $18.18 \%$ \\
\hline
\end{tabular}




\begin{tabular}{lll} 
Do you use the computer $(\mathrm{n}=22)$ & Yes & $100.00 \%$ \\
\hline Computer Skills Self Assessment $(\mathrm{n}=22)$ & First Time User & $0.00 \%$ \\
& Beginner & $0.00 \%$ \\
& Intermediate & $68.18 \%$ \\
& Advanced & $31.82 \%$ \\
\hline Ever complete Web-Based training $(\mathrm{n}=22)$ & Yes & $50.00 \%$ \\
& No & $50.00 \%$ \\
\hline Participated in Instructor Led training $(\mathrm{n}=22)$ & Yes & $68.18 \%$ \\
& No & $31.82 \%$ \\
\hline Completed Safety Training on Other Topics $(\mathrm{n}=21)$ & Yes & $86.36 \%$ \\
& No & $13.64 \%$
\end{tabular}

The results of the post-training questionnaire were very positive in regards to applicability of the training to the industry and acceptability by the students (Table 8). The responses to the training materials' design features resulted in a $100 \%$ response of either "Excellent" or "Good". The responses to the whether or not the training addressed real world fall hazards resulted in $89.47 \%$ stating that "Always" or "Often" the hazards would be encountered on a residential construction site. In response to whether the safe alternatives offered were applicable in the field $89.47 \%$ responded "Yes." Seventy-six percent of the attendees stated that they will "Always" or "Often" make use of this training in the field. In open ended responses, two attending the class recommended that the training include video or photographs of rehabilitation, remodeling and renovation of existing structures. 
Table 8. Cycle I Class 1 Post Training Questionnaire / Evaluation

\begin{tabular}{|c|c|c|}
\hline Question & Response & Percentage \\
\hline \multirow[t]{2}{*}{ Design Features of the training delivered $(n=21)$} & Excellent & $52.38 \%$ \\
\hline & Good & $47.62 \%$ \\
\hline Did the training address fall hazards that would & Always & $36.84 \%$ \\
\hline be encountered on a residential construction site? & Often & $52.63 \%$ \\
\hline$(n=19)$ & Sometimes & $10.53 \%$ \\
\hline Were the safe alternatives applicable in the field? & Yes & $89.47 \%$ \\
\hline$(n=19)$ & No & $10.53 \%$ \\
\hline To what extent will you make use of this training & Always & $19.05 \%$ \\
\hline \multirow[t]{2}{*}{ material in the field? $(n=21)$} & Often & $52.38 \%$ \\
\hline & Sometimes & $28.57 \%$ \\
\hline \multirow[t]{4}{*}{ This training compared to others? $(n=21)$} & Excellent & $33.33 \%$ \\
\hline & Good & $52.38 \%$ \\
\hline & Satisfactory & $4.76 \%$ \\
\hline & N/A. & $9.52 \%$ \\
\hline
\end{tabular}

A pre and posttest was developed to measure the student's basic knowledge regarding major areas of residential fall protection. There were different questions developed for the pre and posttests addressing the same fall hazard categories.

A paired-samples t-test revealed significant differences in the residential fall protection skills scores before and after the training, $\mathrm{t}(20)=-5.200, \mathrm{p}<.0001$ (Table 9). This indicates that 
the mean fall protection score after the training $(\mathrm{M}=.7937)$ was significantly higher than the mean before the training $(\mathrm{M}=.5873)$.

Table 9. Cycle 1 Class 1 Pre/Post Paired T-Test Statistics

\begin{tabular}{|c|c|c|c|c|c|c|}
\hline \multicolumn{7}{|c|}{ Paired Samples Statistics } \\
\hline & & Mean & $\mathrm{N}$ & Std. Deviation & \multicolumn{2}{|c|}{ Std. Error Mean } \\
\hline \multirow[t]{2}{*}{ Pair 1} & PreTest & .5873 & 21 & .12493 & \multicolumn{2}{|c|}{.02726} \\
\hline & PostTest & .7937 & 21 & .17404 & \multicolumn{2}{|c|}{.03798} \\
\hline \multicolumn{7}{|c|}{ Paired Samples Correlations } \\
\hline & & & $\mathrm{N}$ & Correlation & \multicolumn{2}{|c|}{ Sig. } \\
\hline Pair 1 & PreTest \& & tTest & 21 & .295 & \multicolumn{2}{|c|}{.194} \\
\hline \multicolumn{7}{|c|}{ Paired Samples Test } \\
\hline & & \multicolumn{5}{|c|}{ Paired Differences } \\
\hline & & Mean & $\begin{array}{c}\text { Std. } \\
\text { Deviation }\end{array}$ & $\begin{array}{c}\text { Std. Error } \\
\text { Mean }\end{array}$ & \multicolumn{2}{|c|}{$\begin{array}{l}95 \% \text { Confidence } \\
\text { Interval of the } \\
\text { Difference }\end{array}$} \\
\hline & & & & & Lower & Upper \\
\hline Pair 1 & $\begin{array}{l}\text { PreTest - } \\
\text { PostTest }\end{array}$ & -.20635 & .18185 & .03968 & -.28913 & -.12357 \\
\hline \multicolumn{7}{|c|}{ Paired Samples Test } \\
\hline & & & $\mathrm{t}$ & $\mathrm{df}$ & \multicolumn{2}{|c|}{ Sig. (2-tailed) } \\
\hline Pair 1 & PreTest - I & Test & -5.200 & 20 & \multicolumn{2}{|c|}{.000} \\
\hline
\end{tabular}

A post-post test and a follow up questionnaire were emailed to all participants in June 2008. The post-post test was the exact posttest given in the course. Three students from Class 1 responded to the survey, although only one completed the survey. This one student could not be identified so their posttest could not be correlated with the previous tests therefore a statistical test could not be conducted. The post-post test score was $80 \%$ (4 out of 5 questions were answered correctly), which is within $1 \%$ of the original posttest average score of $79.37 \%$. 
The questionnaire portion of the survey was a follow up to determine if the training had been utilized and was effective over time. One student from this class answered, "Yes" to the question "Did this Residential Fall Protection Training Material address fall hazards that you see on your residential worksites?" and "Sometimes" to the question "To what extent have you made use of the training material on the jobsite?" The respondent then stated that he is not currently in the residential construction industry and is completing college.

Class 2, February 27, 2007, Martinsburg, WV. The same marketing campaign was used to publicize the second class, which was held as an open public course at a hotel conference room in Martinsburg, WV. Data collected from this training class included various historical documents (i.e., sign-in sheets, instructor notes, class details, training material, quarterly grant report), pre and post questionnaires and pre and posttests.

The attendees to this course were much more residential construction focused which met the original intent of the curriculum developed. The student enrollment was 9 and was made up of 6 "Supervisor/Foreman”, 2 “employee/laborer” and 1 "contractor/owner.” Although this class was small it was reaching the group intended.

Similar to the first course, I conducted the training utilizing the DVD as the main media tool, with the exception of the first module, "The Problem." This module is an introduction to the problem with falls in residential construction and was produced with a black background and white text with dramatic background music and narration to emphasize to the audience the seriousness of the problem. The production problem was that the narration identically matched the text on the screen and when played for an audience seemed to be speaking down to them. Due to this impression that I felt when teaching the first class, I chose to use the PowerPoint version of this module and to narrate the slides myself. This seemed to be more effective and 
gave me a chance to elaborate on some of the injury and fatality data in more detail. Once that section was completed I reverted back to the interactive DVD with a more responsive control of the audio between video segments. I also utilized a bit more hands-on demonstrations in this training class. This occurred because the class was smaller and more intimate which gave me the ability to interact on a more individual level.

The use of the DVD again did not result in poor evaluations or pre/post test results and I improved on the act of transitioning back and forth between modules and between my additional narration and hands-on training. Still, though, from an instructor's perspective the DVD as the primary delivery mechanism created an unevenness to the class if not for the students for the instructor. The students completed a pre and posttest and a pre and post questionnaire. The results of these two data collection instruments are included in Tables 10 through 15 .

The demographics for Class 2 are included in Table 10. This class had all males attending which is typical of residential construction. The majority of those attending were either supervisors or foreman $(66.67 \%)$ with the remaining attendees being skilled workers $(22.22 \%)$ and owners $(11.11 \%)$. Over $85 \%$ of the students had been in the construction industry for more than 10 years, with the remaining having 5 to 10 years of experience. The majority $(62.5 \%)$ of those attending this course worked for companies with more than 20 employees with the remaining working for companies from 2 to 5 employees. Although this class was the first class with a truly construction industry audience the company size being larger than 20 employees is not typical of residential construction. Several of those attending were from large companies from the Northern Virginia / Washington DC area that conducted both commercial and residential construction work. The location of this course in Martinsburg area drew contractors from a more metropolitan area. 
Table 10. Cycle I Class 2 Pre Questionnaire Demographic and Injury Data

\begin{tabular}{|c|c|c|}
\hline Question & Response & Percentage \\
\hline \multirow[t]{2}{*}{$\operatorname{Sex}(n=9)$} & Male & $100.00 \%$ \\
\hline & Female & $0.00 \%$ \\
\hline \multirow[t]{5}{*}{ Job Title $(n=9)$} & Supervisor/Foreman & $66.67 \%$ \\
\hline & Employee/Skilled & $0.00 \%$ \\
\hline & Employee/Laborer & $22.22 \%$ \\
\hline & Contractor/Owner & $11.11 \%$ \\
\hline & Others & $0.00 \%$ \\
\hline Type of Construction $(n=7)$ & Residential & $100.00 \%$ \\
\hline \multirow[t]{4}{*}{ Years Worked in Construction $(n=7)$} & Less than 1 year & $0.00 \%$ \\
\hline & 1 to 5 years & $0.00 \%$ \\
\hline & 5 to 10 years & $14.29 \%$ \\
\hline & More than 10 years & $85.71 \%$ \\
\hline \multirow[t]{5}{*}{ Number of Employees at your company $(n=8)$} & 1 employee & $0.00 \%$ \\
\hline & 2 to 5 employees & $37.50 \%$ \\
\hline & 5 to 10 employees & $0.00 \%$ \\
\hline & 10 to 20 employees & $0.00 \%$ \\
\hline & More than 20 & $62.50 \%$ \\
\hline
\end{tabular}

Over half of the students in this class had fallen from a height, although none reported that they had been injured (Table 11$)$. Nearly all (87.5\%) reported that they work at heights with nearly the same number $(77.78 \%)$ reporting that they use fall protection (Table 11$)$. 
Table 11. Cycle I Class 2 Pre Questionnaire Fall Injury and Fall Protection Related Data

\begin{tabular}{lcc}
\hline Question & Response & Percentage \\
\hline Have you fallen from heights $(\mathrm{n}=9)$ & Yes & $55.56 \%$ \\
& No & $44.44 \%$ \\
\hline Have you been injured $(\mathrm{n}=9)$ & Yes & $0.00 \%$ \\
\hline Do you work at heights $(\mathrm{n}=8)$ & No & $100.00 \%$ \\
\hline Do you use fall protection $(\mathrm{n}=9)$ & Yes & $87.5 \%$ \\
& No & $12.5 \%$ \\
\hline & Yes & $77.78 \%$ \\
& No & $22.22 \%$
\end{tabular}

All students attending owned at least 1 DVD player with approximately half owning 2 or more (Table 12). Approximately $66.67 \%$ had accessed advanced features in DVD's. While nearly all of the students have access to a computer ( $88.89 \%$ at home and $50 \%$ at work), only $62.50 \%$ use the computer (Table 13). Those with high speed Internet (DSL and Cable) equaled those with dial up Internet access (37.5\%).

The question asking the students to rate their computer skills resulted in $50 \%$ of the class considering themselves "Intermediate" while $25 \%$ considered themselves a "first time user". The remaining 25\% was evenly spilt between "Beginner" and "Advanced."

Nearly all of the students had received instructor led training and $100 \%$ of them had completed some sort of safety training on other topics. Only 1 student $(11.11 \%)$ had completed any type of web-based training (Table 14). 
Table 12. Cycle I Class 2 Pre Questionnaire - Technology (DVD)

\begin{tabular}{lll}
\hline Question & Response & Percentage \\
\hline Number of DVD Players owned? (n=9) & 0 & $0.00 \%$ \\
& Own 1 & $44.44 \%$ \\
& Own 2 & $33.33 \%$ \\
& Own 3 or more & $22.22 \%$ \\
\hline Own Portable DVD player? (n=9) & Yes & $33.33 \%$ \\
\hline Have used Special Features on DVD? $(\mathrm{n}=9)$ & No & $66.67 \%$ \\
\hline
\end{tabular}

Table 13. Cycle I Class 2 Pre Questionnaire - Technology (Computer Access and Use)

\begin{tabular}{lll}
\hline Have Computer at Home? $(\mathrm{n}=9)$ & Yes & $88.89 \%$ \\
& No & $11.11 \%$ \\
\hline Web Access at Home? $(\mathrm{n}=9)$ & Yes & $77.78 \%$ \\
& No & $22.22 \%$ \\
\hline Connection Speed at Home? $(\mathrm{n}=8)$ & Dial Up & $37.50 \%$ \\
& Cable & $12.50 \%$ \\
& DSL & $25.00 \%$ \\
\hline Computer at Work? $(\mathrm{n}=8)$ & None & $25.00 \%$ \\
\hline Web Access at Work? $(\mathrm{n}=9)$ & Yes & $50.00 \%$ \\
& No & $50.00 \%$ \\
\hline
\end{tabular}




\begin{tabular}{llc}
\hline & No & $66.67 \%$ \\
\hline Do you use the computer? $(\mathrm{n}=8)$ & Yes & $62.50 \%$ \\
& No & $37.50 \%$ \\
\hline Computer Skills Self-Assessment? $(\mathrm{n}=8)$ & First Time User & $25.00 \%$ \\
& Beginner & $12.50 \%$ \\
& Intermediate & $50.00 \%$ \\
& Advanced & $12.50 \%$
\end{tabular}

Table 14. Cycle I Class 2 Pre Questionnaire - Training

\begin{tabular}{lcc}
\hline Ever complete Web-Based training? $(\mathrm{n}=9)$ & Yes & $11.11 \%$ \\
& No & $88.89 \%$ \\
\hline Participated in Instructor Led training? $(\mathrm{n}=9)$ & Yes & $88.89 \%$ \\
& No & $11.11 \%$ \\
\hline Completed Safety Training on Other Topics? $(\mathrm{n}=9)$ & Yes & $100.00 \%$
\end{tabular}

The results of the post-training questionnaire were positive in regards to applicability to the industry and acceptability by the students (Table 15). 100\% of the students reported that the design features of the training that was delivered was either "Excellent" or "Good." The responses to the applicability to real-world construction conditions were 50\% "Always" and 50\% "Often." Additionally $100 \%$ of the students agreed that the safe alternatives offered within the training would be applicable in the field and 100\% reported that they would "Always" or "Often" make use of this training material in the field. The significance of the above responses is 
that they come from a very experienced group. The majority of these attendees have been in the industry for more than 10 years and the reminder for 5 to 10 years. These positive responses landed credibility to the content that supported moving forward with delivery of the content in its current format. The final question asked the students to rate the training compared to other training that they had received. 100\% rated the training "Excellent" or "Good" compared to other safety training that they received.

Table 15. Cycle I Class 2 Post Training Questionnaire - Evaluation of Training

\begin{tabular}{llc}
\hline Question & Response & Percentage \\
\hline Design Features of the training delivered $(\mathrm{n}=8)$ & Excellent & $62.50 \%$ \\
& Good & $37.50 \%$ \\
\hline Did the training address fall hazards that would be & Always & $50.00 \%$ \\
encountered on a residential construction site? (n=8) & Often & $50.00 \%$ \\
& Sometimes & $0.00 \%$ \\
& Rarely, Never & $0.00 \%$ \\
\hline Were the safe alternatives applicable in the field? & Yes & $100.00 \%$ \\
(n=8) & No & $0.00 \%$ \\
\hline To what extent will you make use of this training & Always & $62.50 \%$ \\
material in the field? (n=8) & Often & $37.50 \%$
\end{tabular}

A pre and posttest was administered to measure the student's basic knowledge regarding major areas of residential fall protection. A paired-samples t-test revealed significant differences 
in the residential fall protection skills scores before and after the training, $\mathrm{t}(11)=-6.289, \mathrm{p}<$ .0001 (Table 16). This indicates that the mean fall protection score after the training $(\mathrm{M}=.7917)$ was significantly higher than the mean before the training $(M=.4306)$.

Table 16. Cycle I Class 2 Pre/Post Test Paired T-Test Statistics

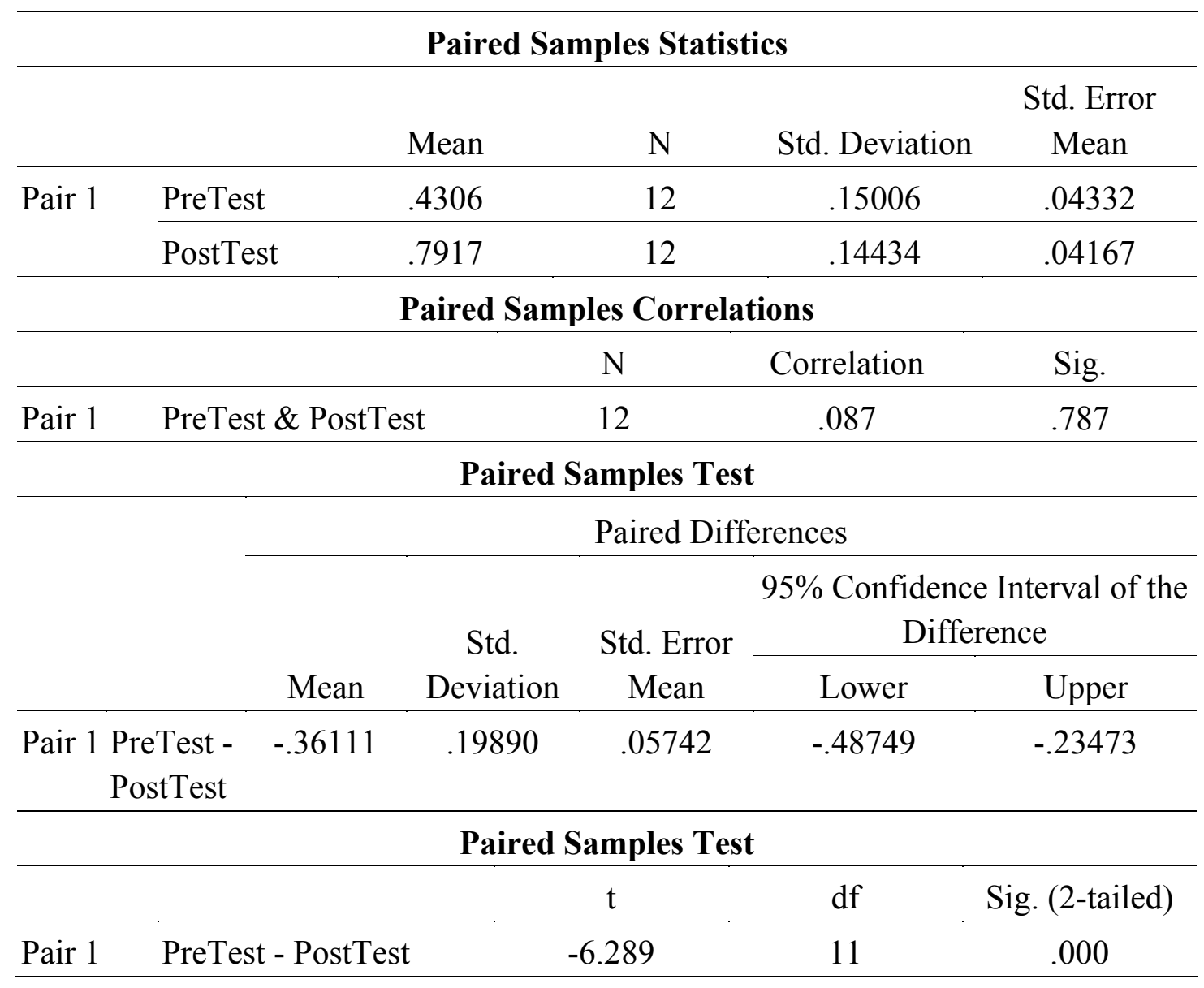

Cycle I Delivery of DVD Training Material and downloadable PowerPoint's

Once WVUSHE completed the training material developed for DVD, a website was created, www.residentialfallsafe.org which provided information on the training grant, presented all of the PowerPoint presentations for viewing and provided an order form for those interested in receiving the 2 Disc DVD set. As of September 30, 2008, 500 DVD disc sets had been 
requested with the majority delivered. Additionally all of those who received instructor led training also received a copy of the DVD for future reference or training.

The original intent of the grant was to format the training material into a web-based course. WVUSHE subcontracted this effort out to WVU Extension Service Office of Technology. Unfortunately, this component of delivery was never completed. As an alternative, WVUSHE posted all completed PowerPoint's on the website for online review as well as provided all PowerPoint's for download directly from the website. This did not allow for WVUSHE to conduct pre and post tests with those who completed a review of the online training material as originally planned.

WVUSHE tracked what online training content was viewed and what PowerPoint material was downloaded through a web based software service provided by Google called “Google Analytics." Table 17 summarizes the data collected through the Google Analytics web visit results by training topic.

Table 17. Website Page Hits Between 10/1/06 - 9/30/08

\begin{tabular}{lc}
\hline Training modules accessed on website & Page Hits \\
\hline Total Visits to Website & 11,946 \\
\hline Total Visits to Residential Fall Protection PowerPoint Training Main Section & 3,013 \\
\hline training/residential_construction/online_training.htm & 708 \\
\hline training/residential_construction/video_training.htm & 537 \\
\hline PowerPoint's/the_problem & 403 \\
\hline PowerPoint's/roofing_work & 259 \\
\hline PowerPoint's/framing & 229 \\
\hline PowerPoint's/site_prep & 191 \\
\hline
\end{tabular}




\begin{tabular}{ll}
\hline PowerPoint's/other_activities & 166 \\
\hline PowerPoint's/flooring & 150 \\
\hline PowerPoint's/siding_and_brick & 138 \\
\hline PowerPoint's/foundation_work & 134 \\
\hline PowerPoint's/the_problem_espanol & 68 \\
\hline PowerPoint's/site_prep_espanol & 57 \\
\hline PowerPoint's/framing_espanol & 56 \\
\hline PowerPoint's/roofing_work_espanol & 55 \\
\hline PowerPoint's/flooring_espanol & 49 \\
\hline PowerPoint's/other_activities_espanol & 41 \\
\hline PowerPoint's/siding_and_brick_espanol & 40 \\
\hline PowerPoint's/foundation_work_espanol & 36 \\
\hline
\end{tabular}

There were a total of 11,946 site visits to the website http://www.residentialfallsafe.org from October 1, 2006 though September 30, 2008. There were over 3,013 visits to the PowerPoint training section addressing residential construction fall protection. This website also houses training material from a second OSHA grant that addresses modular home installation safety. The most visited online training module was the introductory module addressing the problem with falls in residential construction. Other training modules reviewed online included Roofing Work, Framing, Site Preparation, Other Activities, Flooring, Siding and Brickwork, and Foundation Work. The Spanish versions of the training attracted fewer visitors but included the topics The Problem, Site Preparation, Framing, and Roofing Work. 


\section{Cycle I Evaluation of DVD Training Material}

The evaluation strategy utilized to measure the effectiveness of the DVD material developed was to develop and distribute through email, a web based questionnaire using the web based survey software, surveymonkey. The survey was sent via email, to all who requested the DVD through the website, or received it at trade shows, conferences or in training. The questionnaire was developed to gather demographic and injury data and feedback on the content developed as well as the technology used to deliver the training. The results of this data collected are included in Tables 18 through 21. The original research plan in Chapter 3. included collecting a pre test on the website prior to sending the DVD to those who requested it, then collecting a post test after they received and reviewed the DVD. The subcontractor responsible for implementation of this feature, did not complete that portion of work on the website, so WVUSHE made the decision to collect post data only. In hindsight this decision was correct, as the majority of those who requested the DVD did not request it for self-learning, but rather to train others.

The majority of those requesting this DVD set of training materials were safety trainers, safety consultants, safety professionals or safety directors (Table 18). The original intent was to distribute this DVD primarily to residential construction workers, supervisors, and owners for self-guided learning or training of their employees or co-workers. In reality those that sought this technology were safety professionals who's intended use was to train clients or employees. Of those who responded to the email questionnaire, none described themselves as a residential construction worker and only $1.96 \%$ described himself or herself as a supervisor or foreman. WVUSHE hoped to reach those who worked for small companies (less than 10 employees), but the result was that the majority of those requesting and utilizing this DVD were from companies 
with more the 20 employees. It can be assumed though that many of the safety consultants and those with responsibilities to train their "clients" did deliver this material to companies with less than 10 employees.

Table 18. Cycle I DVD Recipient Demographic Data

\begin{tabular}{|c|c|c|}
\hline Question & Response & Percentage \\
\hline \multirow[t]{2}{*}{$\operatorname{Sex}(n=51)$} & Male & $94.12 \%$ \\
\hline & Female & $5.88 \%$ \\
\hline \multirow[t]{6}{*}{ Job Title $(\mathrm{n}=51)$} & Worker (Skilled / Laborer) & $0.00 \%$ \\
\hline & Supervisor / Foreman & $1.96 \%$ \\
\hline & Safety Director & $11.76 \%$ \\
\hline & Safety Trainer & $0.00 \%$ \\
\hline & Saf. Trainer / Consultant / Safety Prof. & $60.78 \%$ \\
\hline & Other & $25.49 \%$ \\
\hline Years worked in residential construction? & Less than 1 year & $10.42 \%$ \\
\hline \multirow[t]{3}{*}{$(n=48)$} & $1-5$ years & $16.67 \%$ \\
\hline & $5-10$ years & $31.25 \%$ \\
\hline & More than 10 years & $41.67 \%$ \\
\hline Current number of employees working in & Individual, not a company & $18.18 \%$ \\
\hline \multirow[t]{4}{*}{ your company? $(n=44)$} & 1 & $6.82 \%$ \\
\hline & 2 to 5 & $4.55 \%$ \\
\hline & 10 to 20 & $11.36 \%$ \\
\hline & More than 20 & $59.09 \%$ \\
\hline
\end{tabular}


When asked how well they liked the design features of the DVD training, $94.87 \%$ responded with "Excellent" or "Good." When asked whether the hazards depicted in the training material where representative of what they would see in the real world of residential construction $92.1 \%$ answered that "All" or "The majority" of the hazards were real world depictions. Similarly when asked if the safe alternatives presented were practical for use on construction sites, $91.67 \%$ responded that "All" or "The majority" would be practical for use in residential construction. Only $14.67 \%$ of those requesting the DVD planned to use it for self-guided training (Table 19). A majority (62.91\%) requested the DVD to train employees or clients. An openended question asked, "To what extent will you make use of the DVD?" The responses included using as part of a larger training program, using it solely as their fall protection training for their residential construction employees or clients, providing it to residential construction company clients and to other safety professionals and peers. Fifteen of the 51 respondents to the survey reported that they combined to train 646 individuals with the use of this DVD. Others responded to this question that they had trained others or planned to train others, but did not report the quantity. This is a very positive result of the use of the DVD and validates that the majority of the respondents intended to use the DVD to conduct training of others, and upon review continued on with the plan to use the material for training. 
Table 19. Cycle I DVD Recipient Training Material Evaluation

\begin{tabular}{lll}
\hline How did you hear about the available DVD & Web Search & $45.10 \%$ \\
training material? (n=51) & OSHA & $21.57 \%$ \\
& WVUSHE Class & $13.73 \%$ \\
& Colleague & $5.88 \%$ \\
& OSHA Office / Education Center & $5.88 \%$ \\
& Other & $7.84 \%$ \\
\hline When requesting the DVD, what was the & To complete self guided training & $14.52 \%$ \\
intended use? (n=62) & To train employees & $25.81 \%$ \\
& To train clients (Contractors) & $37.10 \%$ \\
& Informational purposes only & $12.90 \%$ \\
& Other & $9.68 \%$ \\
\hline Have you reviewed the DVD training material? & Yes & $88.24 \%$ \\
(n=51) & No & $11.76 \%$ \\
\hline How well do you like the design feature of this & Excellent & $38.46 \%$ \\
fall protection training? (n=39) & Good & $56.41 \%$ \\
& Satisfactory & $2.56 \%$ \\
& Unsatisfactory & $2.56 \%$ \\
\hline Do the fall hazards depicted in this training & All & $34.21 \%$ \\
& The majority & $57.89 \%$ \\
& About half & $5.26 \%$ \\
& A few & $2.63 \%$ \\
& None & $0.00 \%$ \\
& & \\
& & \\
& &
\end{tabular}




\begin{tabular}{llc}
\hline Do the safe alternatives depicted in this & All & $30.56 \%$ \\
training accurately depict real work fall & The majority & $61.11 \%$ \\
hazards that you would see on residential & About half & $5.56 \%$ \\
construction site? (n=36) & A few & $2.78 \%$ \\
& None & $0.00 \%$ \\
\hline Did you use these materials as well as the & Yes & $72.22 \%$ \\
DVD based material? (n=36) & No & $27.78 \%$ \\
\hline Have you used the training material to instruct & Yes & $8.11 \%$ \\
Spanish speaking construction workers? & No & $91.89 \%$ \\
(n=37) & & Yes \\
\hline Was the translation accepted and understood & No & $71.43 \%$ \\
by the audience? (n=7) & & $28.57 \%$
\end{tabular}

Table 20. Cycle I DVD Recipient Fall Hazards and Injury Data

\begin{tabular}{lcc}
\hline Have you ever fallen while working on a residential construction & Yes & $19.05 \%$ \\
site? $(\mathrm{n}=42)$ & No & $80.95 \%$ \\
\hline Have you ever been injured from falling while working on a & Yes & $6.98 \%$ \\
residential construction site? (n=43) & No & $93.02 \%$ \\
\hline Do you currently work at heights (roofs, wall and window & Yes & $25.58 \%$ \\
openings, and stairs)? (n=43) & No & $74.42 \%$ \\
\hline Do you or have you used fall protection equipment while & Yes & $48.78 \%$ \\
working on residential jobsites? (n=41) & No & $51.22 \%$
\end{tabular}


Table 21. Cycle I DVD Recipient Technology and DVD Data

\begin{tabular}{llc}
\hline Do you own a DVD player? $(\mathrm{n}=44)$ & Yes & $95.45 \%$ \\
& No & $4.55 \%$ \\
\hline Have you ever participated in web-based safety training? $(\mathrm{n}=43)$ & Yes & $81.40 \%$ \\
& No & $18.60 \%$ \\
\hline Do you have a computer with web access at home? $(\mathrm{n}=44)$ & Yes & $93.18 \%$ \\
& No & $6.82 \%$ \\
\hline Have you previously completed safety training using a DVD? & Yes & $86.36 \%$ \\
(n=44) & No & $13.64 \%$ \\
\hline Have you ever accessed special features on a movie DVD such & Yes & $61.36 \%$ \\
as the Director's Commentary or Deleted Scenes? (n=44) & No & $38.64 \%$ \\
\hline Have you ever participated in traditional instructor led safety & Yes & $97.67 \%$ \\
training? (n=43) & No & $2.33 \%$
\end{tabular}

There were some open-ended responses relating to suggested changes to the DVD and the content. Several respondents commented on the narration or the narrator as not sounding professional or lively enough. One other stated, " Once I got the handle on the menu format the presentations progressed logically. Had a little trouble at first." These suggestions were taken into consideration when revising the DVD.

In regards to the hazards and safe alternatives we asked by major section of training were there fall hazards that needed to be addressed. Nearly all suggestions were hazards that we as the developers of the material believed that we included. These comments were as follows:

Foundation - formwork hazards, proper scaffold construction, and pouring and finishing concrete in a below grade basement. 
Flooring - How to prevent falls when working from floor joists

Framing - Truss work, raising heavy walls

Roofing - Hazards from frost, walking on paper, tile

Other fall hazards - Protection on interior floor openings, ladder safety

The production group took these suggestions under advisement as they developed the second version of the DVD, although every one of these hazards was addressed in the DVD within the modules. This led the group to believe that the architecture and movement through the DVD should be clearer when the DVD is revised

In another open-ended question asking, " Could you describe suggested changes that you would recommend to improve the quality and effectiveness of this training related to the content of the training developed?" The question drew several responses. A suggestion that the file format should be made available on CD-ROM so those without a DVD-ROM drive could access the material. Two more comments regarding the narration and the lack of energy in the narrator's delivery were mentioned. One respondent suggested that WVUSHE attempt to identify all unsafe conditions on the video and photos and not just discuss the fall hazard being addressed. Others commented that the training was "great" and requested that the training be expanded to commercial construction.

\section{Summary of Cycle I Instructor Led Training \& DVD Distribution}

Cycle I included the design and development of the entire original training material in both an interactive video based version on DVD-video and a companion photograph based version developed for delivery on PowerPoint. The material and content was approved by the granting agency and was then delivered in two publically held courses in Morgantown, WV and Martinsburg, WV. The content was delivered utilizing the DVD as the primary delivery medium 
(Table 22). The training for the public resulted in evidence that the training material was accepted from the industry and applicable for use on the jobsite. The pre and posttests validated that knowledge was gained from the training class and the students planned to utilize the knowledge on the jobsite. Even with the positive results the decision was made to utilize PowerPoint presentations as the primary delivery medium in Cycle II based on the instructors notes and impressions from delivering the two courses.

The development of the companion DVD and distribution through the website resulted in requests for 500 sets of DVD sets. Fifty-one of those that received the DVD agreed to complete an online questionnaire. The demographic data collected, showed that nearly all who requested the DVD were not residential construction workers or supervisors but were safety professionals seeking the information to train their employees or clients. It was also documented that nearly 700 additional workers were trained indirectly by those that requested this DVD.

The questionnaire requested detailed feedback for future revisions. Analysis of this feedback data identified some architectural deficiencies in the DVD menu system as well as several unsafe conditions that were not identified in the narration that needed to be added. Data collected from the distribution of the DVD' s through the website continued on with no changes throughout Cycles II through V. New additions and revisions made to the PowerPoint presentation content in Cycle III, IV and V were incorporated into the revised DVD in Cycle V. The DVD was not revised until Cycle V due to the additional effort it takes to reproduce, record and edit the video, audio narration and to complete the DVD authoring. 
Table 22. Summary of Cycle I Design Decisions, Implementation and Revisions

\begin{tabular}{|c|c|c|c|}
\hline & Design Decisions & Implementation & Revisions \\
\hline 1. & $\begin{array}{l}\text { Curriculum developed by } \\
\text { residential construction work } \\
\text { phase using industry specific } \\
\text { photographs and video }\end{array}$ & $\begin{array}{l}\text { Material was approved by } \\
\text { granting agency for } \\
\text { delivery. }\end{array}$ & $\begin{array}{l}\text { No revisions to content } \\
\text { identified. }\end{array}$ \\
\hline 2. & $\begin{array}{l}\text { Curriculum developed as video } \\
\text { based on interactive DVD-video as } \\
\text { well as photograph based on } \\
\text { PowerPoint. }\end{array}$ & $\begin{array}{l}\text { Curriculum delivered to } \\
\text { two classes using DVD as } \\
\text { primary delivery medium. }\end{array}$ & $\begin{array}{l}\text { Decision to deliver } \\
\text { content in Cycle II } \\
\text { utilizing PowerPoint as } \\
\text { the primary delivery } \\
\text { medium. }\end{array}$ \\
\hline 3. & $\begin{array}{l}\text { Content (video and photographs) } \\
\text { and training module categories } \\
\text { were residential construction } \\
\text { specific. }\end{array}$ & $\begin{array}{l}\text { Feedback from the classes } \\
\text { held showed that training } \\
\text { was applicable to the } \\
\text { industry and was accepted } \\
\text { as feasible to implement } \\
\text { in the field. }\end{array}$ & No revisions to content. \\
\hline 4. & $\begin{array}{l}\text { Developed self-guided interactive } \\
\text { DVD and distributed through } \\
\text { website. }\end{array}$ & $\begin{array}{l}500 \text { DVD's were } \\
\text { requested through the } \\
\text { website with } \\
\text { approximately } 700 \\
\text { additional workers being } \\
\text { trained by others. }\end{array}$ & No revisions to DVD. \\
\hline
\end{tabular}




\section{Developmental Cycle II of PowerPoint Training Material}

Based on my perceptions of using the DVD as the primary delivery medium in the Cycle I, a decision was made deliver the training utilizing the companion PowerPoint modules as the primary delivery medium. To ensure that the trainees could still use the DVD as reference after the course, or to train others each class began with a short overview of how to use the DVD and what content it included. Once the introduction to the DVD was completed, I taught the rest of the course using the PowerPoint presentations.

\section{Cycle II Development}

Within this Cycle no training content was revised, so there was no technical redevelopment of either the PowerPoint material or the DVD. The only developmental change was the decision of how to deliver the course using the PowerPoint material as the primary medium and the addition of an introduction and "how-to" module on the use of the interactive DVD.

\section{Cycle II Delivery and Evaluation}

Cycle II delivery makes up the majority of the training delivered over the 2 years of this program. The classes include publically advertised courses as well as courses that were delivered specifically for residential construction companies and other residential construction worker and owner represented organizations.

Class 3, May 19, 2007, Chesapeake, VA. This was a class that was held specifically for a large residential construction builder and that companies subcontractor representatives. I met the safety director for this company when he attended a public OSHA course offered by WVUSHE in Pittsburgh, PA. During my presentation of fall protection I marketed our free course offerings including the residential fall protection grant. After my presentation we agreed upon a date to conduct the training at his companies' facility in Chesapeake, VA. Data collected from this 
training class included various historical documents (i.e., sign-in sheets, instructor notes, class details, training material, quarterly grant report) and pre and post questionnaires.

The class was scheduled for 4 hours and there were 11 attendees. When I arrived the morning of the course I was told by my contact that the intent for this course was to provide training material to his subcontractors that they could use it to training their employees. Due to this being made aware to me I chose to not conduct the pre and posttest but to only collect the pre and post questionnaire data and teach the course with emphasis on how to deliver it to workers.

Data collected from the pre questionnaire are included in Tables 23 through 27 . The class was $100 \%$ male and made up primarily $(88.89 \%$ ) of supervisors, foreman and owners (Table 23 ). There was only one laborer in the class and his first language was Spanish. All in the course were from the residential construction industry with several respondents also selecting both residential and commercial as they did work in both industries. The class had many years of experience in construction with $44.44 \%$ having more than 10 years experience and no attendees with less than 1 year. The responses to the number of employees in the company resulted in the majority of the attendees (60\%) having more than 20 employees. This is mainly a result of the client who invited us to teach the class being a large residential builder in the area who uses established subcontractors that also do work in commercial construction.

The majority of the attendees had not fallen. The same percentage that had fallen $(10 \%)$ reported being injured from a fall. Seventy percent reported working from heights while only $50 \%$ reported using fall protection. Within residential construction this is typical since there are several loopholes in the OSHA regulations regarding residential construction fall protection. 
Table 23. Cycle II Class 3 Pre Questionnaire Demographic and Injury Data

\begin{tabular}{|c|c|c|}
\hline Question & Response & Percentage \\
\hline \multirow[t]{2}{*}{$\operatorname{Sex}(n=10)$} & Male & 100.00 \\
\hline & Female & 0.00 \\
\hline \multirow[t]{5}{*}{ Job Title $(n=9)$} & Supervisor/Foreman & 77.78 \\
\hline & Employee/Skilled & 0.00 \\
\hline & Employee/Laborer & 11.11 \\
\hline & Contractor/Owner & 11.11 \\
\hline & Others & 0.00 \\
\hline \multirow[t]{3}{*}{ Type of Construction $(n=16)$} & Residential & 62.50 \\
\hline & Commercial & 37.50 \\
\hline & Other & 0.00 \\
\hline \multirow[t]{4}{*}{ Years Worked in Construction $(n=9)$} & Less than 1 year & 0.00 \\
\hline & 1 to 5 years & 22.22 \\
\hline & 5 to 10 years & 33.33 \\
\hline & More than 10 years & 44.44 \\
\hline \multirow[t]{5}{*}{ Number of Employees at your company $(n=10)$} & 1 employee & 0.00 \\
\hline & 2 to 5 employees & 10.00 \\
\hline & 5 to 10 employees & 10.00 \\
\hline & 10 to 20 employees & 20.00 \\
\hline & More than 20 & 60.00 \\
\hline
\end{tabular}


Table 24. Cycle II Class 3 Pre Questionnaire Fall Injury and Fall Protection Related Data

\begin{tabular}{l|l|l} 
Question & Response & Percentage \\
\hline Have you fallen from heights $(\mathrm{n}=10)$ & Yes & $10.00 \%$ \\
\hline & No & $90.00 \%$ \\
\hline Have you been injured $(\mathrm{n}=10)$ & Yes & $10.00 \%$ \\
\hline Do you work at heights $(\mathrm{n}=10)$ & No & $90.00 \%$ \\
\hline & Yes & $70.00 \%$ \\
\hline Do you use fall protection $(\mathrm{n}=10)$ & No & $30.00 \%$ \\
\hline & Yes & $50.00 \%$ \\
\hline
\end{tabular}

All attendees had at least 1 DVD player and $77.78 \%$ had accessed special features on the DVD (Table 25). All attendees also had a computer with web access at home and at work with $90 \%$ of these students stating that they use the computer. This is most likely due to the fact that these attendees were supervisors and owners of companies, not workers.

Half of the students stated that they had attended some other type of safety related instructor led training while $37.5 \%$ had completed web-based training (Table 26). This percentage is higher than other classes held again most likely do to the job classification of the students.

Table 25. Cycle II Class 3 Pre Questionnaire - Technology (DVD)

\begin{tabular}{llc}
\hline Question & Response & Percentage \\
\hline Number of DVD Players owned? (n=10) & Own 1 & $20.00 \%$ \\
& Own 2 & $40.00 \%$ \\
\hline
\end{tabular}




\begin{tabular}{llc}
\hline & Own 3 or more & $40.00 \%$ \\
\hline Have used Special Features on DVD? (n=9) & Yes & $77.78 \%$ \\
& No & $22.22 \%$ \\
\hline
\end{tabular}

Table 26. Cycle II Class 3 Pre Questionnaire - Technology (Computer Access and Use)

\begin{tabular}{lll}
\hline Have Computer at Home? $(\mathrm{n}=10)$ & Yes & $100.00 \%$ \\
\hline Web Access at Home? $(\mathrm{n}=9)$ & Yes & $100.00 \%$ \\
\hline Connection Speed at Home? $(\mathrm{n}=10)$ & Dial Up & $0.00 \%$ \\
& Cable & $70.00 \%$ \\
& DSL & $20.00 \%$ \\
& None & $10.00 \%$ \\
\hline Computer at Work? $(\mathrm{n}=10)$ & Yes & $100.00 \%$ \\
\hline Web Access at Work? (n=9) & Yes & $100.00 \%$ \\
\hline Do you use the computer? (n=10) & Yes & $90.00 \%$ \\
& No & $10.00 \%$ \\
\hline Computer Skills Self-Assessment? & First Time User & $0.00 \%$ \\
& Beginner & $40.00 \%$ \\
& Intermediate & $30.00 \%$ \\
& Advanced & $30.00 \%$ \\
\hline
\end{tabular}

Table 27. Cycle II Class 3 Pre Questionnaire - Training

\begin{tabular}{lcc}
\hline Ever complete Web-Based training? $(\mathrm{n}=8)$ & Yes & 37.50 \\
& No & 62.50 \\
\hline Participated in Instructor Led training? $(\mathrm{n}=10)$ & Yes & 50.00 \\
\hline
\end{tabular}




\begin{tabular}{llc}
\hline & No & 50.00 \\
\hline Completed Safety Training on Other Topics? (n=10) & Yes & 90.00 \\
& No & 10.00 \\
\hline
\end{tabular}

A post-training questionnaire was completed after the course had ended (Table 28). The results were not as positive as classes previous, but still offered results that showed the training was being received positively from the industry. Additionally, anecdotal information collected during the course of the training indicated a resistance to attending the training and that this training was "required" attendance by the primary residential contractor that invited WVUSHE to conduct the training. This may have resulted in less than excellent feedback.

Forty percent of the attendees believed that the design features of the training was "Excellent" while 50\% reported it as "Good" and 10\% "Satisfactory." The majority (66.67\%) responded that "Often" the hazards demonstrated in the training would be hazards that are encountered on the jobsite with $22.22 \%$ reporting "Sometimes" and $11.11 \%$ reporting "Rarely." This was the first instance of the hazards being reported back as rarely representing hazards that are encountered on the jobsite. In contrast to the hazards being "real-world", $100 \%$ of the class believed that the safe alternatives shown were applicable on the construction site and $66.67 \%$ reported that they would "Often" make use of this material.

Table 28. Cycle II Class 3 Post Training Questionnaire

\begin{tabular}{llc}
\hline Question & Response & Percentage \\
\hline Design Features of the training delivered $(\mathrm{n}=10)$ & Excellent & $40.00 \%$ \\
& Good & $50.00 \%$ \\
& Satisfactory & $10.00 \%$ \\
\hline
\end{tabular}




\begin{tabular}{lll}
\hline Did the training address fall hazards that would be & Always & $0.00 \%$ \\
encountered on a residential construction site? $(\mathrm{n}=9)$ & Often & $66.67 \%$ \\
& Sometimes & $22.22 \%$ \\
& Rarely & $11.11 \%$ \\
\hline Were the safe alternatives applicable in the field? (n=10) & Yes & $0.00 \%$ \\
\hline To what extent will you make use of this training & Always & $100.00 \%$ \\
material in the field ? (n=9) & Often & $0.00 \%$ \\
& Sometimes & $66.67 \%$ \\
& Rarely, Never & $22.22 \%$ \\
\hline This training compared to others (n=10) & Excellent & $11.11 \%$ \\
\hline & Good & $40.00 \%$ \\
& Satisfactory & $30.00 \%$ \\
\end{tabular}

Class 4, September 18, 2007, Charleston, $W V$. WVUSHE publically advertised a class for delivery in Charleston, WV. The class was held at the Kanawha Valley Home Builders Association headquarters, which helped in marketing the course. Data collected from this training class included various historical documents (i.e., sign-in sheets, instructor notes, class details, training material, marketing, quarterly grant report), pre tests, posttests, post-post tests, post WVUSHE instructor evaluations, post-post attendee interviews, post-post construction site field observations and fall hazard audits. 
The class size was only 9 attendees but truly represented the residential construction industry with the class being made up of two Kanawha Valley area residential construction company employees, supervisors, and owners. The class was 3 hours in duration.

Due to time constraints of the 3-hour course I made a decision to only collect the pre and post test, not the pre and post questionnaires. Instead, I collected a post training instructor evaluation based on a standard WVUSHE training evaluation form (Table 29). The results are positive in regard to all areas of the instructor's effectiveness as well as the effectiveness of the subject matter.

Table 29. Cycle II Class 4 Post Training Instructor Evaluation

\begin{tabular}{ll}
\hline Question & $\begin{array}{l}\text { Class Average Evaluation Score } \\
(\text { Poor }=1, \text { Excellent }=5)\end{array}$ \\
\hline Instructors ability to communicate $(\mathrm{n}=9)$ & 5.00 \\
\hline Instructors degree of preparedness $(\mathrm{n}=9)$ & 4.89 \\
\hline Instructors organization of materials $(\mathrm{n}=9)$ & 5.00 \\
\hline Instructors coverage of subject matter $(\mathrm{n}=9)$ & 5.00 \\
\hline Instructors responsiveness to class $(\mathrm{n}=9)$ & 4.89 \\
\hline Instructors overall effectiveness $(\mathrm{n}=9)$ & 5.00 \\
\hline Overall Average Evaluation Score $(\mathrm{n}=9)$ & 4.96
\end{tabular}

A pre and posttest was administered to measure the student's basic knowledge regarding major areas of residential fall protection. A paired-samples t-test revealed significant differences in the residential fall protection skills scores before and after the training, $\mathrm{t}(8)=-5.716, \mathrm{p}<$ .0001 (Table 30). This indicates that the mean fall protection score after the training $(\mathrm{M}=.8148)$ was significantly higher than the mean before the training $(\mathrm{M}=.4259)$. 
Additionally 4 of the original 9 attendees completed a post-post test. A paired samples ttest revealed no significant differences in the residential fall protection skills scores from the post test completed immediately after the original training and the post-post test completed approximately 7 months after the training was completed, $\mathrm{t}(3)=.818, \mathrm{p}=0.473$ (Table 31 ). This indicates that the mean fall protection score conducted immediately after training $(M=0.875)$ was not significantly higher than the mean fall protection score conducted seven months after the training $(\mathrm{M}=.80)$. This result indicates that the information that the students understood on the day of the day of the training, was retained when tested on the same content 7 months after the training.

Table 30. Cycle II Class 4 Pretest to Posttest Paired T Test

\section{Paired Samples Statistics}

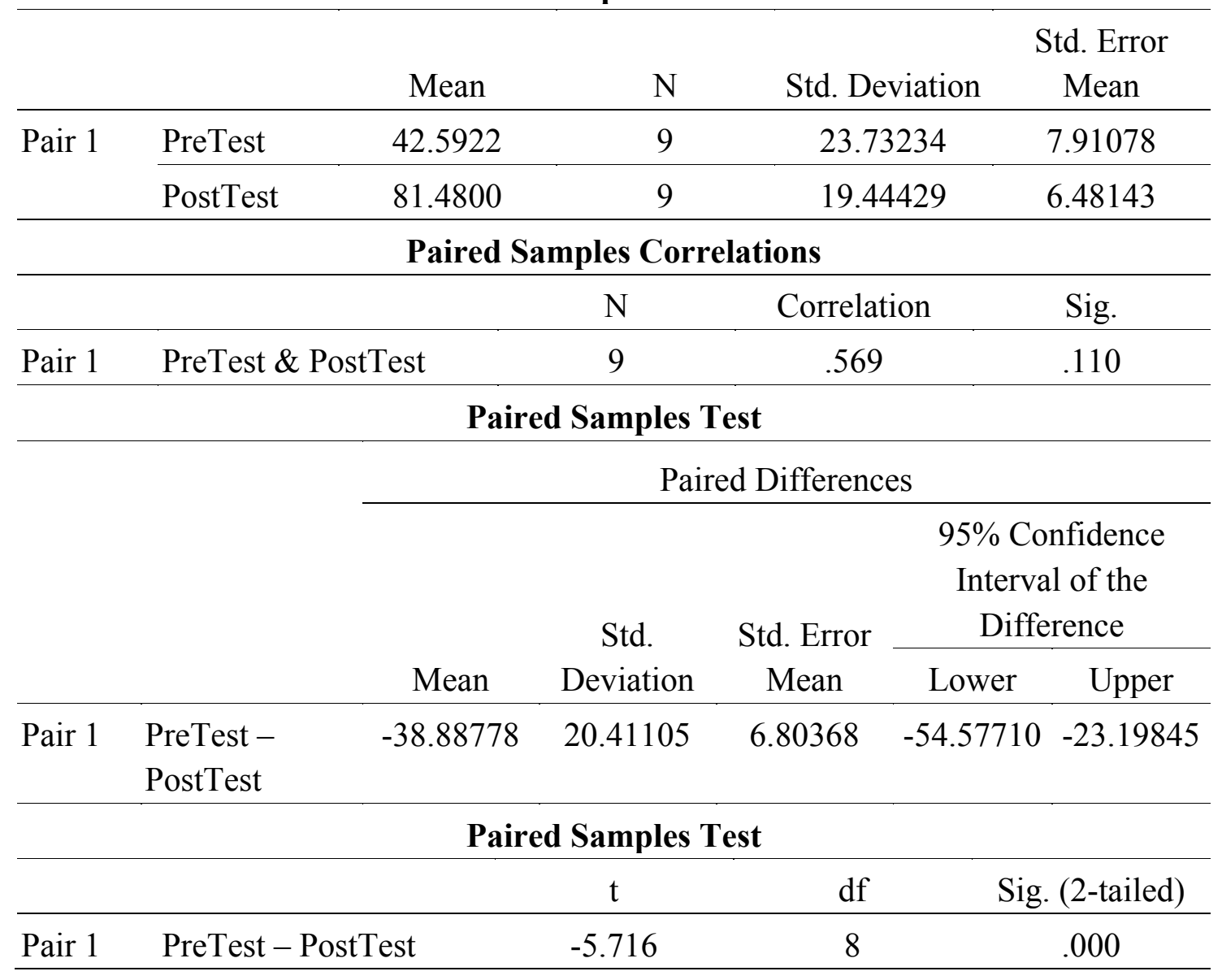


Table 31. Cycle II Class 4 Posttest to Post Posttest Paired T-Test

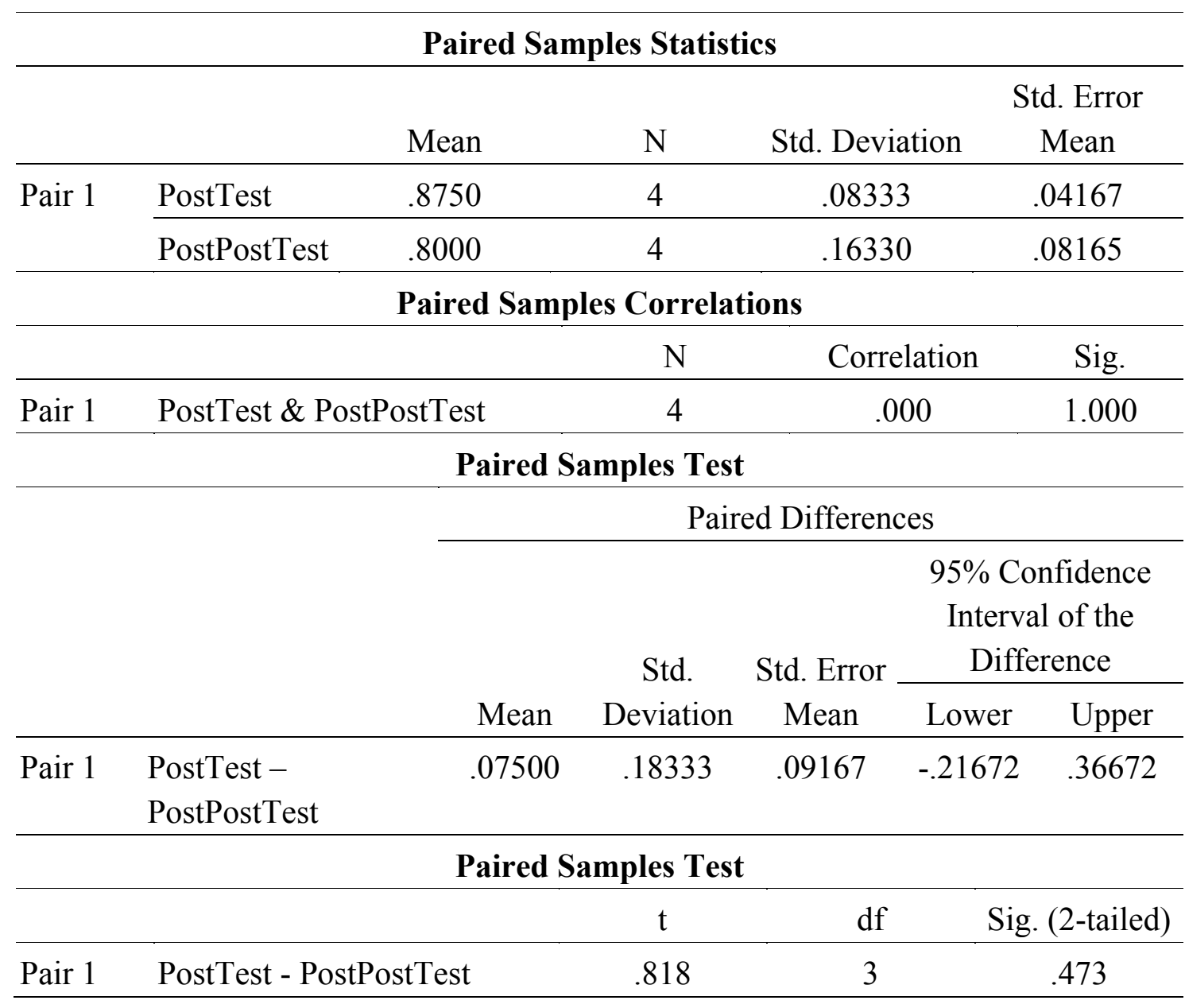

WVUSHE contacted attendees several months after the training to request access to their current jobsites to conduct field observations, a fall hazard audit and to conduct interviews of those who attended the training.

There were three post training interviews conducted based on the interview protocol developed. One interview was conducted with an owner of a small residential construction company that was in the process of constructing a single level ranch home in Hurricane, WV. The second set of interviews were conducted with two foreman level workers constructing a new home in Charleston, WV. 
All three agreed during the interviews that falls are a serious problem in residential construction. One of the three interviewed had been injured from a fall on a residential construction site. Two of the three had seen someone else fall on a residential construction site. When asked what they believed would have to take place in order for falls to be reduced on residential construction sites one responded, “ We need a training class every year for all employees to refresh their memory." Another stated, "You can never stop thinking about it. There is nothing better than accessing safety each day before starting." The third person interviewed simply said "knowledge with enforcement."

The questions then addressed the training that they completed with WVUSHE. All three answered, "Yes" to the question, "Do you think our training applies to "the real world" of construction?" When asked if there would be anything they would change or add, one suggestion was to add hands-on training and another was to pull from manufacturers recommendations for installation of materials such as trusses. Finally, one interviewee mentioned that there was the issue discussed in the training of how to protect yourself from falling while installing trusses. His suggestion was to find a safe, practical set of instructions on that task and add to the training.

When asked if they believe that training works in reducing falls one interviewee responded "it definitely does work" and his example was that every time he walks on a foundation wall he thinks of something that I said in training seven months earlier, that "you can walk on a foundation wall, but you must protect impalement hazards below." Another person responded that he believes training works as long as there are also on site inspections. He went on to say that his company employs a safety consultant to conduct site inspections. The third interviewee stated that the workers from his company that did not attend the training asked the 
other workers what they missed. He believed that if nothing else attending training sets an example for those that don't attend.

The interviews were conducted on active residential construction sites which provided me the opportunity to conduct field observations and to conduct a previously validated fall hazard inspection that utilizes a PDA to collect all fall hazard and control data. There were two jobsites inspected, the first in Hurricane, WV and the second in Charleston, WV.

The first field observation and fall hazard audit took place at a construction site of a new one-story ranch house. The weather prevented any exterior work to be conducted on the house limiting the work to two workers on the interior completing plumbing work. Based on my previous experience conducting fall hazard audits of several hundred sites I immediately noticed that the jobsite walkways were kept relatively clean for a construction site, which if not kept clean have the potential to cause slip and trip falls on the same level. Otherwise the fall hazards were limited to two stepladders that were set up for use but were not being used at the time of the inspection. Both ladders were set up correctly and were not damaged or defective and had proper access with no trip hazards at the base.

The audit conducted along side the field observation validated and quantified the observations. The audit tool scores how well contractors control fall hazards first based on how many questions answered correctly based on the fall hazard control being inspected. Second, the audit tool gives a higher scoring algorithm for fall hazards controlled with engineering controls over the use of Personal Protective Equipment or Administrative controls like warning lines or safety monitors. The report generates a percentage score. WVUSHE has validated this audit tool and has set $70 \%$ as a passing score (Becker, et al., 2001). This contractor site received a site 
score of $91.67 \%$. This compares to an average contractor post intervention score of $83 \%$ from the previous intervention research project called "Fall-Safe."

The second field observation was conducted on a residential construction site of a new multi-story residential home in Charleston, WV. This site was much larger than the previous and there were approximately six residential construction workers on site. In observing the site from the exterior of the home the first potential fall hazard was two large sections of fixed scaffold along the back of the home. The scaffold had been installed by a scaffold company and had no apparent deficiencies, which is rare on construction sites. As I moved to the inside of the house the potential fall hazards were from window and door openings to the exterior of the house as well as potential fall hazards on the interior of the house. There were also several stairways that required handrails and stairrails. There was a scaffold set up in the interior of the house with no deficiencies. There were some minor deficiencies identified onsite including either toprails or midrails missing from guardrails. Overall though, the jobsite was in order and housekeeping was impeccable especially for residential construction.

The audit conducted along side the field observation validated and quantified my observations. This contractor site received a site score of $80.12 \%$. This compares to an average contractor post intervention score of $83 \%$ from the previous intervention research project FallSafe.

Both of these audit scores were on equal with commercial, industrial and heavy/highway contractor's scores after they had participated in a long-term organizational intervention that included development of a safety program, training of workers and supervisors, and quarterly audits with continued assistance for improvement (Becker, Takacs \& Fullen, 2008). 
Class 5, September 24, 2007, Morgantown, WV. WVUSHE again publicly advertised a class that was held at WVUSHE in Morgantown, WV. The class had 19 attending and was delivered over 3 hours. The data collected from this training includes historical documents (i.e., press release, sign-in sheets, training material, instructor notes, quarterly grant report), pre and post questionnaires, pre and posttests, and a post-post questionnaire.

Demographic data collected from this class is included in Tables 32 through 34 . The class was made up of all males, which were all supervisor/foreman, employees, or contractors/owners. Eighty percent of those attending were from the residential construction industry with the remaining from commercial construction (Table 32). The majority of the class had been in the business for more than 10 years.

In asking the students about fall injury experience $27.78 \%$ of those being trained had fallen although only 5.56\% reported that they were injured from a fall (Table 33). When asked about working at height $83.33 \%$ reported that they do work at heights and $88.89 \%$ stated they use fall protection.

Table 32. Cycle II Class 5 Pre Questionnaire Demographic and Injury Data

\begin{tabular}{llc}
\hline Question & Response & Percentage \\
\hline Sex $(\mathrm{n}=17)$ & Male & $100.00 \%$ \\
\hline Job Title $(\mathrm{n}=17)$ & Supervisor/Foreman & $41.18 \%$ \\
& Employee/Skilled & $0.00 \%$ \\
& Employee/Laborer & $47.06 \%$ \\
& Contractor/Owner & $11.76 \%$ \\
\hline Type of Construction $(\mathrm{n}=20)$ & Others & $0.00 \%$ \\
\hline
\end{tabular}




\begin{tabular}{lll} 
& Commercial & $20.00 \%$ \\
\hline Years Worked in Construction $(\mathrm{n}=18)$ & Less than 1 year & $5.56 \%$ \\
& 1 to 5 years & $27.78 \%$ \\
& 5 to 10 years & $5.56 \%$ \\
\hline Number of Employees at your company $(\mathrm{n}=18)$ & More than 10 years & $61.11 \%$ \\
& 1 employee & $0.00 \%$ \\
& 2 to 5 employees & $0.00 \%$ \\
& 5 to 10 employees & $27.78 \%$ \\
& 10 to 20 employees & $33.33 \%$
\end{tabular}

Table 33. Cycle II Class 5 Pre Questionnaire Fall Injury and Fall Protection Related Data

\begin{tabular}{lcc}
\hline Question & Response & Percentage \\
\hline Have you fallen from heights $(\mathrm{n}=18)$ & Yes & $27.78 \%$ \\
& No & $72.22 \%$ \\
\hline Have you been injured $(\mathrm{n}=18)$ & Yes & $5.56 \%$ \\
\hline Do you work at heights $(\mathrm{n}=18)$ & No & $94.44 \%$ \\
\hline Do you use fall protection $(\mathrm{n}=18)$ & Yes & $83.33 \%$ \\
& No & $16.67 \%$ \\
\hline & Yes & $88.89 \%$ \\
& No & $11.11 \%$
\end{tabular}

All who attended owned at least 1 DVD player and $66.67 \%$ have accessed special features on a DVD (Table 34). Of those attending $78.95 \%$ have a computer at home and only 
$21.05 \%$ have a computer at work. This correlates to the percentage of workers attending this training. Only $10.53 \%$ of the students had ever completed web-based training, while $52.63 \%$ have completed instructor led training.

Table 34. Cycle II Class 5 Pre Questionnaire - Technology \& Training

Question

Response

Percentage

\begin{tabular}{|c|c|c|}
\hline Number of DVD Players owned? $(n=19)$ & 0 & $0.00 \%$ \\
\hline & Own 1 & $26.32 \%$ \\
\hline & Own 2 & $47.37 \%$ \\
\hline & Own 3 or more & $26.32 \%$ \\
\hline Own Portable DVD player? $(n=19)$ & Yes & $42.11 \%$ \\
\hline & No & $57.89 \%$ \\
\hline Have used Special Features on DVD? $(n=18)$ & Yes & $66.67 \%$ \\
\hline & No & $33.33 \%$ \\
\hline Have Computer at Home? $(n=19)$ & Yes & $78.95 \%$ \\
\hline & No & $21.05 \%$ \\
\hline Web Access at Home? $(n=19)$ & Yes & $68.42 \%$ \\
\hline & No & $31.58 \%$ \\
\hline Connection Speed at Home? $(n=18)$ & Dial Up & $27.78 \%$ \\
\hline & Cable & $22.22 \%$ \\
\hline & DSL & $27.78 \%$ \\
\hline & None & $22.22 \%$ \\
\hline Computer at Work? $(\mathrm{n}=19)$ & Yes & $21.05 \%$ \\
\hline & No & $78.95 \%$ \\
\hline
\end{tabular}




\begin{tabular}{|c|c|c|}
\hline \multirow[t]{2}{*}{ Web Access at Work? $(n=19)$} & Yes & $21.05 \%$ \\
\hline & No & $78.95 \%$ \\
\hline \multirow[t]{2}{*}{ Do you use the computer? $(n=19)$} & Yes & $52.63 \%$ \\
\hline & No & $47.37 \%$ \\
\hline \multirow[t]{4}{*}{ Computer Skills Self-Assessment? $(\mathrm{n}=19)$} & First Time User & $10.53 \%$ \\
\hline & Beginner & $47.37 \%$ \\
\hline & Intermediate & $42.11 \%$ \\
\hline & Advanced & $0.00 \%$ \\
\hline \multirow[t]{2}{*}{ Ever complete Web-Based training? $(n=19)$} & Yes & $10.53 \%$ \\
\hline & No & $89.47 \%$ \\
\hline \multirow[t]{2}{*}{ Participated in Instructor Led training? $(\mathrm{n}=19)$} & Yes & $52.63 \%$ \\
\hline & No & $47.37 \%$ \\
\hline \multirow[t]{2}{*}{ Completed Safety Training on Other Topics? $(n=19)$} & Yes & $73.68 \%$ \\
\hline & No & $26.32 \%$ \\
\hline
\end{tabular}

Once the training ended, the students completed a post questionnaire (Table 35). The question measuring whether the design features of the training were acceptable resulted in $88.24 \%$ reporting that the design features were "Excellent" or "Good." The majority of students (70.59\%) reported that "Always" or "Often" the fall hazards shown in the training were hazards that would be encountered on construction sites. Similarly, $81.25 \%$ of the students said "Yes", the safe alternatives offered were applicable in the field. Most importantly of all of this data, $82.36 \%$ of those attending said they will "Always" or "Often" make use of this training material. 
Table 35. Cycle II Class 5 Post Training Questionnaire

\begin{tabular}{|c|c|c|}
\hline Question & Response & Percentage \\
\hline \multirow[t]{3}{*}{ Design Features of the training delivered $(n=17)$} & Excellent & $17.65 \%$ \\
\hline & Good & $70.59 \%$ \\
\hline & Satisfactory & $11.76 \%$ \\
\hline Did the training address fall hazards that would be & Always & $29.41 \%$ \\
\hline \multirow[t]{3}{*}{ encountered on a residential construction site $(n=17)$} & Often & $41.18 \%$ \\
\hline & Sometimes & $17.65 \%$ \\
\hline & Rarely, Never & $11.76 \%$ \\
\hline Were the safe alternatives applicable in the field & Yes & $81.25 \%$ \\
\hline$(n=16)$ & No & $18.75 \%$ \\
\hline To what extent will you make use of this training & Always & $41.18 \%$ \\
\hline \multirow[t]{3}{*}{ material in the field $(n=17)$} & Often & $41.18 \%$ \\
\hline & Sometimes & $17.65 \%$ \\
\hline & Rarely, Never & $0.00 \%$ \\
\hline \multirow[t]{3}{*}{ This training compared to others $(n=17)$} & Excellent & $35.29 \%$ \\
\hline & Good & $58.82 \%$ \\
\hline & Satisfactory & $5.88 \%$ \\
\hline
\end{tabular}

A pre and posttest was administered to measure the student's basic knowledge regarding major areas of residential fall protection. A paired-samples t-test revealed significant differences in the residential fall protection skills scores before and after the training, $\mathrm{t}(15)=-5.856, \mathrm{p}<$ 
.0001 (Table 36). This indicates that the mean fall protection score after the training $(\mathrm{M}=.8437)$ was significantly higher than the mean before the workshop $(\mathrm{M}=.5104)$.

Table 36. Cycle II Class 5 Pretest to Posttest Paired T Test

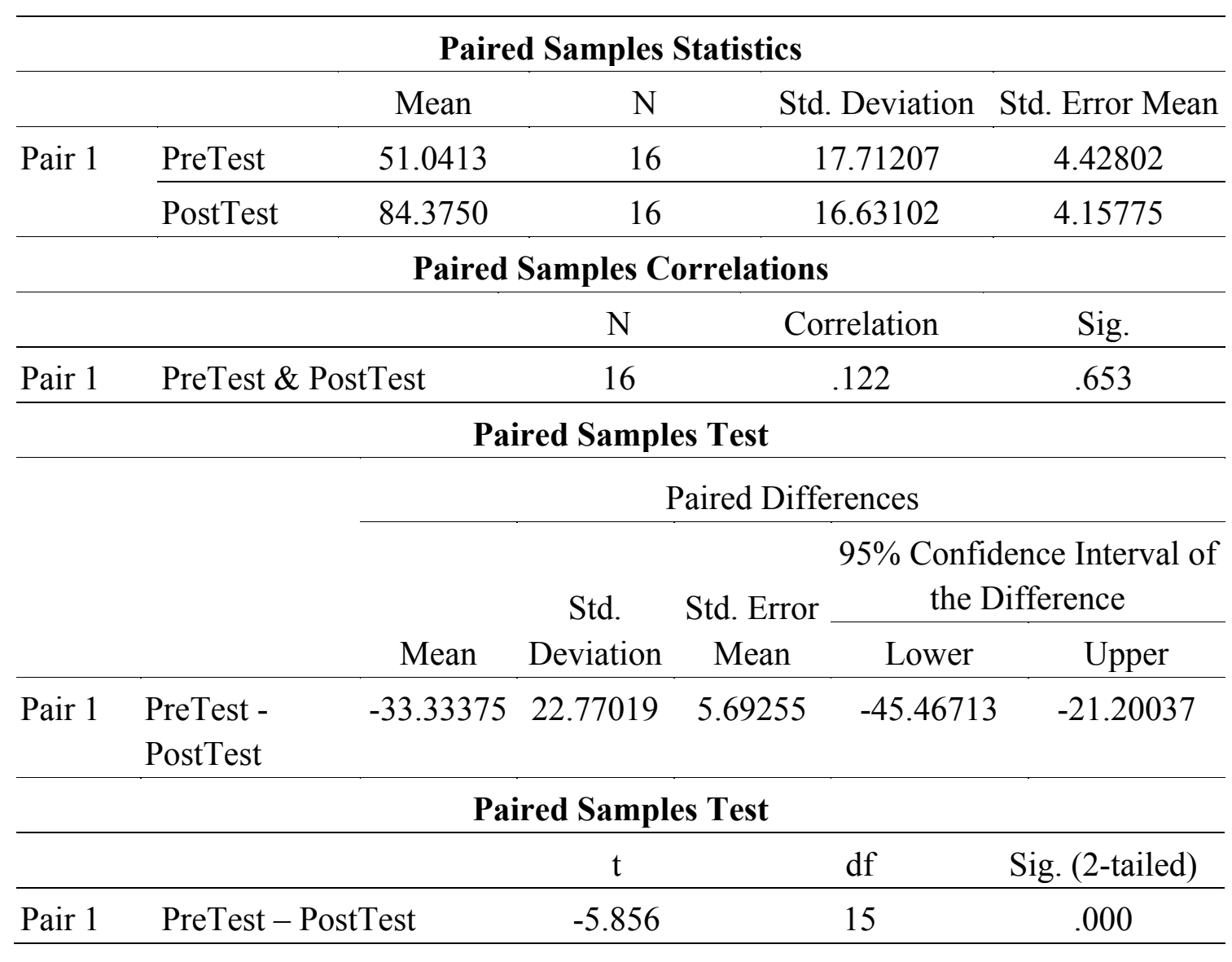

One person responded to a web-based (surveymonkey.com) post-post test. This person did not identify himself or her, but did complete the post-post test with a score of $80 \%$. This score is similar to the posttest average score of $84.37 \%$. This post-post test was completed in July 2008, which was nearly ten months after the first posttest was completed.

Class 6, September 28, 2007, Washington DC. This class was held specifically for a single company whose work is focused on roof and siding installation. The class was conducted at the companies location in Washington DC. The class was 3 hours in length and 21 employees attended. Data collected from this training includes historical documents (i.e., training material, 
sign-in sheets, instructors notes), pre and posttests, post instructor evaluations, post-post field observation and a fall hazard audit.

The post training instructor evaluation (Table 37) demonstrates that the effectiveness of the instructor in delivering the content and the quality and acceptability of the training material was highly effective with this group. The choice to not have the class complete the pre and post questionnaire was based on site conditions. When I arrived to deliver the training, the room was not set up, and once I began training the LCD projector malfunctioned which delayed the course start for 10 to 15 minutes. Knowing that these students had to also go to work that day, I chose not to take additional time away from them or their employer. Table 37. Cycle II Class 6 Post Training Instructor Evaluation

\begin{tabular}{ll}
\hline Question & Class Average Evaluation Score \\
& $($ Poor $=1$, Excellent $=5)$ \\
\hline Instructors ability to communicate $(\mathrm{n}=17)$ & 4.94 \\
\hline Instructors degree of preparedness $(\mathrm{n}=17)$ & 5.00 \\
\hline Instructors organization of materials $(\mathrm{n}=17)$ & 4.94 \\
\hline Instructors coverage of subject matter $(\mathrm{n}=17)$ & 5.00 \\
\hline Instructors responsiveness to class $(\mathrm{n}=17)$ & 5.00 \\
\hline Instructors overall effectiveness $(\mathrm{n}=17)$ & 4.88 \\
\hline Overall Average Evaluation Score $(\mathrm{n}=17)$ & 4.96 \\
\hline
\end{tabular}

A pre and posttest was administered to measure the student's basic knowledge regarding major areas of residential fall protection. This test differed form the test prior in that the audience only installed roofing and siding. Since the work was so specific some training modules were not delivered. This also impacted some of the questions posed in the pre and posttest. The 
questions that did not apply were removed. A paired-samples t-test revealed significant differences in the residential fall protection skills scores before and after the training, $t(11)=$ 8.123, $\mathrm{p}<.0001$ (Table 38). This indicates that the mean fall protection score after the training $(\mathrm{M}=.100)$ was significantly higher than the mean before the workshop $(\mathrm{M}=.6667)$. Table 38. Cycle II Class 6 Pretest to Posttest Paired T Test

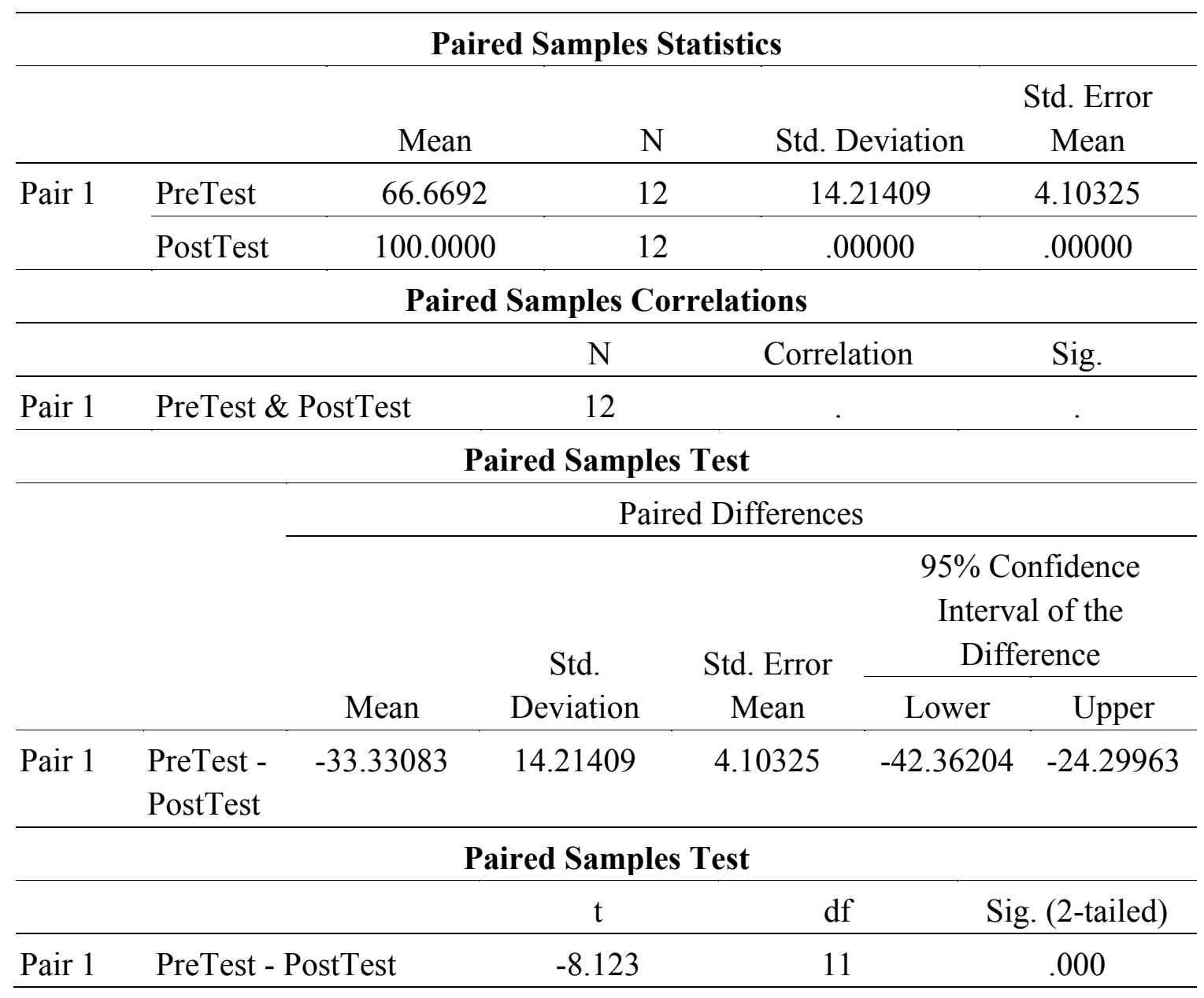

A post-post training field observation and fall hazard audit was conducted of a jobsite being completed by this contractor. The jobsite was in the Washington DC and was a re-roofing project being completed on a townhouse. When I arrived on site I communicated with the foreman, which was not one of the attendees in the class months earlier. As I walked the construction site I realized that none of the workers had attended the training previously. This is 
a common problem in residential construction. Many informal discussions with those in the construction industry often include comments regarding the lost investment of training individuals that will not stay employed with that same company for long enough for the company to recover the cost investment of training.

I continued with the field observation knowing that the owner and some management from the company did attend the training and quite possibly the training had filtered down to new workers as I had also provided them with the DVD training material. As I continued my observations I realized that all of the workforce were Hispanic and only the foreman was bilingual and able to communicate with me. The training that was developed by WVUSHE was also developed in Spanish, so the training could still have been delivered to these individuals.

The major potential fall hazards that were apparent while I was on site was work being conducted from a pump jack scaffold system and work being conducted from several extension ladders. The work crews were removing the old cedar shake roof shingles and beginning to install new shingles. The pump jack ladder scaffold had some major deficiencies in how it was installed and some of the ladders were not installed or being used properly. These deficiencies became apparent when the audit quantified the uncontrolled fall hazards. This contractor site received a site score of $67.22 \%$. This is the lowest site summary score of all post training audits conducted as part of this research and also does not meet WVUSHE's minimum score requirement of $70 \%$. This compares to an average contractor post intervention score of $83 \%$ from the intervention research project Fall-Safe (Becker, et al., 2008).

The pre and posttest results as well as the questionnaire data shows that the training was well received and that knowledge was gained. This contradicts with the site audit that shows 
some serious deficiencies with fall hazards on the jobsite. This problem could be due to the fact that none of the employees on site were in the training delivered by WVUSHE.

Class 7: October 9, 2007, Harrisburg, PA. This class was conducted based on a request from a company. The company is in the business of new construction, building maintenance and managing rental properties. There were 23 that attended the class and the duration of the course was 3 hours. Data collected from this training class include historical documents (i.e., sign-in sheets, instructor notes, training materials, quarterly grant report), pre and posttests and pre and post questionnaires. Demographic data was collected in a pre training questionnaire (Tables 39 through 41).

The class was 100\% male and made up of employees (62.5\%) and supervisors/foreman $(37.5 \%)$ (Table 39). The majority in the class labeled themselves as being from the commercial construction industry (42.42\%) and residential construction (39.39\%). Many selected multiple answers on this question due to the nature of the rental property business. This is mainly due to the nature of this companies business of managing both commercial and residential properties. The class attendees had many years of experience in construction with the majority (33.33\%) having more than 10 years experience. All responses to the question of number of employees in the company resulted in the same answer of more than 20 employees since all attending the class worked for the same company.

Table 39. Cycle II Class 7 Pre Questionnaire Demographic and Injury Data

\begin{tabular}{llc}
\hline Question & Response & Percentage \\
\hline Sex $(\mathrm{n}=15)$ & Male & $100.00 \%$ \\
\hline Job Title $(\mathrm{n}=8)$ & Supervisor/Foreman & $37.50 \%$ \\
& Employee/Skilled & $0.00 \%$
\end{tabular}




\begin{tabular}{llc} 
& Employee/Laborer & $62.50 \%$ \\
& Contractor/Owner & $0.00 \%$ \\
\hline Type of Construction $(\mathrm{n}=33)$ & Residential & $39.39 \%$ \\
& Commercial & $42.42 \%$ \\
& Heavy Construction & $6.06 \%$ \\
& Industrial & $6.06 \%$ \\
\hline Years Worked in Construction $(18)$ & Other & $6.06 \%$ \\
\hline Number of Employees at your company $(\mathrm{n}=13)$ & Less than 1 year & $5.56 \%$ \\
& 1 to 5 years & $16.67 \%$ \\
& More than 20 & $16.67 \%$ \\
\hline & 5 to 10 years & $100.00 \%$
\end{tabular}

Of those responding to the questions related to falls and injuries, $26.67 \%$ reported that they had fallen and $20 \%$ that they had been injured from a fall (Table 40 ). Interestingly $85.71 \%$ reported that they work from heights while only $35.71 \%$ said they use fall protection. Much of this could be due to the fact that many in the class work as building maintenance personnel on rental properties. Even though much of maintenance work is construction, these workers often don't receive construction safety training and they often work on their own having responsibility for maintenance of one or several buildings. This often results in completing work at heights without the use of fall protection. 
Table 40. Cycle II Class 7 Pre Questionnaire Fall Injury and Fall Protection Related Data

\begin{tabular}{lcc}
\hline Question & Response & Percentage \\
\hline Have you fallen from heights $(\mathrm{n}=15)$ & Yes & 26.67 \\
& No & 73.33 \\
\hline Have you been injured $(\mathrm{n}=15)$ & Yes & 20.00 \\
\hline Do you work at heights $(\mathrm{n}=14)$ & No & 80.00 \\
\hline Do you use fall protection $(\mathrm{n}=14)$ & Yes & 85.71 \\
& No & 14.29 \\
\hline & Yes & 35.71 \\
& No & 64.29
\end{tabular}

Nearly all (92.86\%) who responded owned at least 1 DVD player and $71.43 \%$ reported using the special features on a DVD (Table 41). Computer ownership with web access at home was $92.86 \%$ while having a computer at work was only $30.77 \%$ and web access at work was $23.08 \%$. Only $7.69 \%$ had completed web based training while $80 \%$ had completed some sort of instructor led training.

Table 41. Cycle II Class 7 Pre Questionnaire - Technology \& Training

Question $\quad$ Response Percentage

$\begin{array}{lll}\text { Number of DVD Players owned? }(n=14) & 0 & 7.14 \%\end{array}$

Own 1

Own 2

Own 3 or more $\quad 21.43 \%$

\begin{tabular}{lll}
\hline Have used Special Features on DVD? $(n=14)$ & Yes & $71.43 \%$
\end{tabular}




\begin{tabular}{|c|c|c|}
\hline & No & $28.57 \%$ \\
\hline \multirow[t]{2}{*}{ Have Computer at Home? $(n=14)$} & Yes & $92.86 \%$ \\
\hline & No & $7.14 \%$ \\
\hline \multirow[t]{2}{*}{ Web Access at Home? $(n=14)$} & Yes & $92.86 \%$ \\
\hline & No & $7.14 \%$ \\
\hline \multirow[t]{4}{*}{ Connection Speed at Home? $(n=14)$} & Dial Up & $14.29 \%$ \\
\hline & Cable & $42.86 \%$ \\
\hline & DSL & $35.71 \%$ \\
\hline & None & $7.14 \%$ \\
\hline \multirow[t]{2}{*}{ Computer at Work? $(n=13)$} & Yes & $30.77 \%$ \\
\hline & No & $69.23 \%$ \\
\hline \multirow[t]{2}{*}{ Web Access at Work? $(n=13)$} & Yes & $23.08 \%$ \\
\hline & No & $76.92 \%$ \\
\hline \multirow[t]{2}{*}{ Do you use the computer? $(n=14)$} & Yes & $71.43 \%$ \\
\hline & No & $28.57 \%$ \\
\hline \multirow[t]{4}{*}{ Computer Skills Self-Assessment? $(\mathrm{n}=14)$} & First Time User & $0.00 \%$ \\
\hline & Beginner & $50.00 \%$ \\
\hline & Intermediate & $50.00 \%$ \\
\hline & Advanced & $0.00 \%$ \\
\hline \multirow[t]{2}{*}{ Ever complete Web-Based training? $(n=13)$} & Yes & $7.69 \%$ \\
\hline & No & $92.31 \%$ \\
\hline \multirow[t]{2}{*}{ Participated in Instructor Led training? $(n=15)$} & Yes & $80.00 \%$ \\
\hline & No & $20.00 \%$ \\
\hline
\end{tabular}


Completed Safety Training on Other Topics? $(n=15) \quad$ Yes

$93.33 \%$

No

$6.67 \%$

Table 42. Cycle II Class 7 Post Training Questionnaire

\begin{tabular}{lll}
\hline Question & Response & Percentage \\
\hline Design Features of the training delivered $(\mathrm{n}=23)$ & Excellent & $39.13 \%$ \\
& Good & $56.52 \%$ \\
& Satisfactory & $4.35 \%$ \\
\hline Did the training address fall hazards that would be & Always & $45.45 \%$ \\
encountered on a residential construction site $(\mathrm{n}=22)$ & Often & $31.82 \%$ \\
& Sometimes & $13.64 \%$ \\
\hline Were the safe alternatives applicable in the field & Yes & $95.65 \%$ \\
(n=23) & No & $4.35 \%$ \\
\hline To what extent will you make use of this training & Always & $40.91 \%$ \\
material in the field (n=22) & Often & $40.91 \%$ \\
& Sometimes & $13.64 \%$ \\
& Rarely, Never & $4.55 \%$ \\
\hline This training compared to others (n=22) & Excellent & $45.45 \%$ \\
& Good & $50.00 \%$ \\
& Satisfactory & $4.55 \%$ \\
\hline
\end{tabular}

A pre and posttest was administered to measure the student's basic knowledge regarding major areas of residential fall protection. A paired-samples t-test revealed significant differences in the residential fall protection skills scores before and after the training, $\mathrm{t}(18)=-6.997, \mathrm{p}<$ 
.0001 (Table 43). This indicates that the mean fall protection score after the training $(\mathrm{M}=.8771)$ was significantly higher than the mean before the workshop $(\mathrm{M}=.5175)$.

Table 43. Cycle II Class 7 Pretest to Posttest Paired T Test

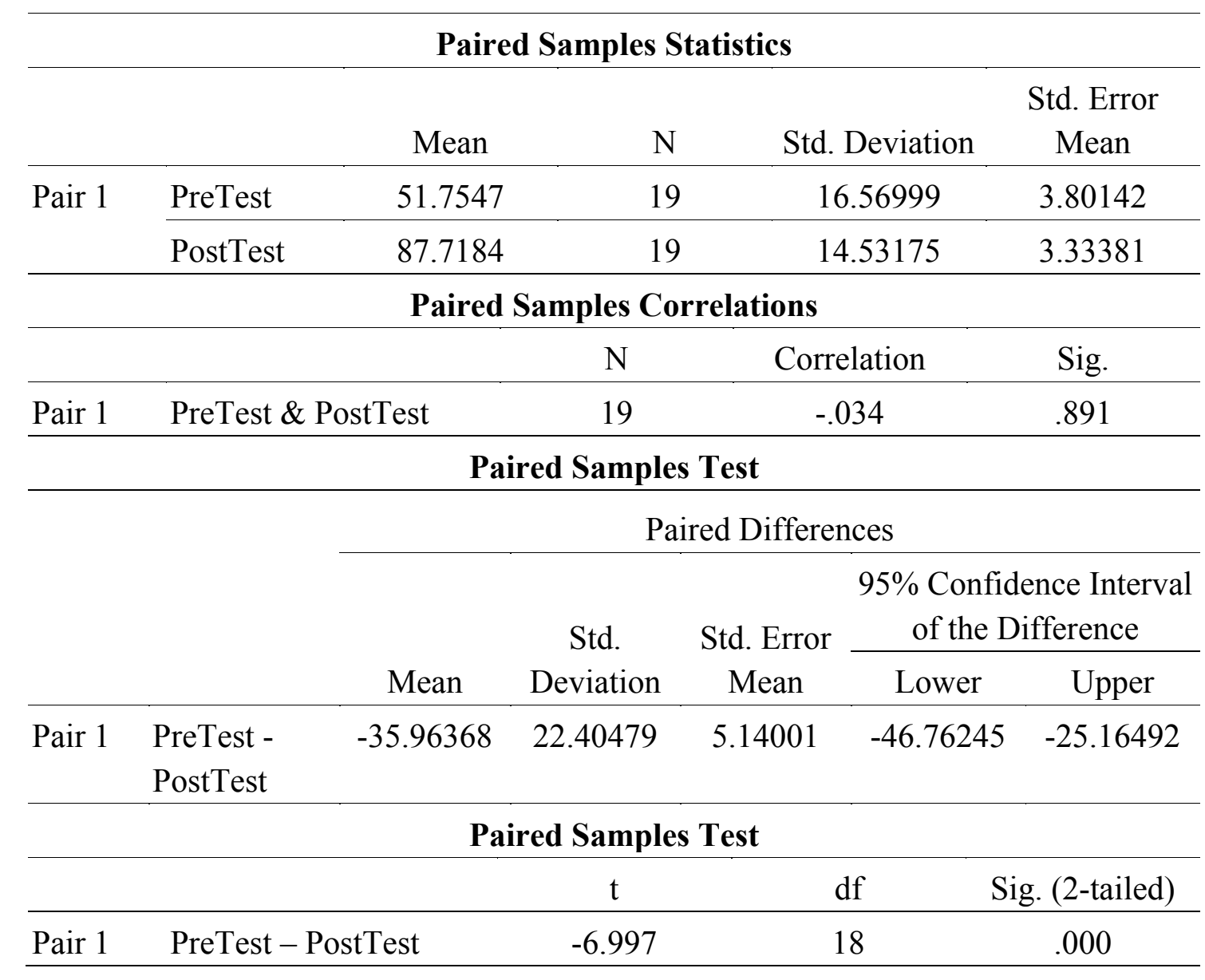

Summary of Cycle II

Cycle II began with the decision to make no revisions to the training curriculum from

Cycle I. The primary change was to conduct classes utilizing PowerPoint as the primary delivery medium instead of the DVD video. There were 5 courses held in Chesapeake, VA, Charleston, WV, Morgantown, WV, Washington DC and Harrisburg, PA (Table 44). The training was scheduled and delivered in public classes and for specific companies. The data collected resulted in evidence that the training material was accepted by the workers as applicable for use on the 
jobsite. The pre, post and post-post tests as well as the post training interviews, site inspections and field observations validated that knowledge was gained from the training class and retained and used on the jobsite.

Table 44. Summary of Cycle II Design Decisions, Implementation and Revisions

\begin{tabular}{llll}
\hline \multicolumn{2}{l}{ Design Decisions } & Implementation & Revisions \\
\hline $\begin{array}{lll}\text { utilized with no changes } \\
\text { in content. }\end{array}$ & classes using PowerPoint as & No revisions to content \\
& primary delivery medium. & \\
\hline 2. & Feedback from the classes, & No revisions to content \\
& interviews, field observations and & identified. \\
& audits verified that training was & \\
& applicable to the industry and was & \\
& accepted as feasible to implement & \\
& in the field. &
\end{tabular}

Developmental Cycle III of PowerPoint Training Material

\section{Cycle III Development}

This cycle of development is unique compared to the other cycles in that that no plans for changes were planned originally, but changes to the curriculum did occur based on a request from a private company for WVUSHE to conduct the OSHA approved training for their employees but to also include two new segments that were not included in the original curriculum and also to address a set of OSHA interim safety guidelines that are less stringent than the actual fall protection standards. WVUSHE intentionally did not include these interim 
safety guidelines in the original training material in Cycle I and II because these guidelines are less stringent and WVUSHE felt strongly that there were feasible ways to comply with the more stringent standards, which would result in a safer worksite.

Although during the course of WVUSHE delivering training throughout Developmental Cycle I and II we did encounter questions from the trainees on practical ways to protect themselves from falling from foundation walls, while installing flooring and roof trusses and while roofing. The developed training material did not always provide a clear safe alternative to protect the workers from a fall that could be taught to the students. These interim guidelines, although not preferred, did offer a safety procedure for how to complete those activities. For the purpose of this client request we developed additional power point slides that would train the workers on all of the interim safety guidelines addressed in the OSHA Directive on this topic. Additionally we developed a new set of PowerPoint slides on the basics of fall protection and on gutter and downspout installation.

\section{Cycle III Delivery and Evaluation}

Cycle III delivery includes four training sessions delivered to one company as well as a training class provided to a local non-profit group training youth ages 16 to 24 in learning a construction trade while obtaining their GED or high school diploma. The four classes delivered for the one company did not include any pre or post in class data but did include a pre and post on site audit and field observation. The additional class for the youth group did include pre and post tests and questionnaires.

Class 8, 9, $10 \& 11$ December 19, 2007 and January 25, 2008, Uniontown, PA. A lumber company with an installation division requested that WVUSHE deliver the residential construction fall protection training to their workforce with some requests for modifications to 
the training material. The training was conducted at the company's facility in Uniontown, PA. One hundred and twenty-one workers were trained during the 4 sessions. Data that was collected during this training includes historical documents (i.e., training material, sign-in sheets, quarterly grant reports, instructor(s) notes), pre training site fall hazard inspection and field observation and a post training site fall hazard inspection and field observation.

As described above, WVUSHE made a decision when developing this training material that less protective interim guidelines would not be included in the training material because the developers of the material believed that there were safer ways to protect the worker that were still practical. For the most part, training evaluation data up to this point had proven this theory out. WVUSHE agreed to make these modifications to the training to meet the request of the client. The classes took place over two days in December 2007 and January 2008 with two, three hour training sessions each day. Due to the large group of workers in each class and the tight schedule the employer requested that we did not collect pre and post tests or questionnaires. WVUSHE did however have the opportunity to conduct audits and field observations prior to and following the training.

The site audit prior to the training was conducted on a work crew installing gutters and downspouts on a new house being constructed. The hazards identified during the field observation included improper ladder selection and unsafe use of the ladder. Additionally a worker accessed a steep slope roof to install a gutter with no form of fall protection.

The posttest audit was also of a newly constructed house that was in the process of a gutter and downspout installation. A nearly identical job for the work crew. The field observations from this worksite were very different. The ladder use was proper, including tying the ladder off to the roof to ensure that it would not slip off the roof edge and the installation and 
proper use of multiple roof top anchors. There was one issue of the rope grab device being used improperly that was corrected by the on site supervisor. Additional ladder use was witnessed with no serious or dangerous deficiencies.

The fall hazard site audit that was conducted during the field observations of the two sites validated the differences. The pre training fall hazard site audit resulted in a site summary score of $42.59 \%$. This is well below acceptable and was due in large part to auditing a worker exposed to a fall from a steep sloped roof with no fall protection. The post training fall hazard site audit resulted in a site summary score of $83.80 \%$, which is above the $70 \%$ passing score and identical with the final average score of the Fall-Safe contractors described earlier.

The training material that was originally developed specifically for this client made both trainers conducting this training aware that some elements of the less stringent interim guidelines needed to be added to the full curriculum for all that WVUSHE would train. Additionally, gutter installation, which is not specifically addressed in the interim guidelines, would be added as a training module as one of the building phases. And finally, the module developed entitled "The Basics of Fall Protection" was seen as a vital component to introduce the concept of fall protection to workers that may have never had any training on the subject.

Class 12, Morgantown, WV, February 7, 2008. Based on the revisions and new training material developed for the previous four classes, WVUSHE conducted the new version of the training for a non-profit group whose mission it is to assist low-income young people ages 16 to 24 to obtain their GEDs or high school diplomas, and to learn job skills and serve their communities by building affordable housing. WVUSHE held a class for this group in Morgantown, WV at the offices of WVUSHE. There were 9 students that attended the 4 hour course. Data collected from the training include historical documents (i.e., training materials, 
sign-in sheets, quarterly grant report, instructor notes), pre and post tests and pre and post questionnaires.

Demographic data from this class is located in Table 45. The average age of the students excluding the program coordinator (supervisor) was 23.13 years. The class was $66.67 \%$ male and $33.33 \%$ female. The majority labeled themselves as laborers $(66.67 \%)$ and skilled employees $(22.22 \%)$ with the remaining being supervision (11.11\%). Nearly all (71.43\%) selected residential construction as their primary industry while some selected more then one category including heavy construction and industrial construction. Fifty percent of the students had been in the construction industry for less than 1 year and $25 \%$ from 1 to 5 years. The remaining $25 \%$ had been in the industry from 5 or more years. The majority $(71.43 \%)$ of the students worked for this non-profit organization, which had 5 to 10 employees. The average age of this group as well as the years of experience is important to note. This is the youngest and least experienced group to complete this training.

Table 45. Cycle III Class 12 Pre Questionnaire Demographic and Injury Data

\begin{tabular}{llc}
\hline Question & Response & Percentage \\
\hline Sex $(\mathrm{n}=9)$ & Male & 66.67 \\
& Female & 33.33 \\
\hline Job Title $(\mathrm{n}=9)$ & Supervisor/Foreman & 11.11 \\
& Employee/Skilled & 22.22 \\
& Employee/Laborer & 66.67 \\
& Contractor/Owner & 0.00 \\
\hline Type of Construction $(\mathrm{n}=7)$ & Others & 0.00 \\
\hline
\end{tabular}




\begin{tabular}{llc} 
& Commercial & 0.00 \\
& Heavy Construction & 14.29 \\
& Industrial & 14.29 \\
\hline Years Worked in Construction $(\mathrm{n}=8)$ & Less than 1 year & 50.00 \\
& 1 to 5 years & 25.00 \\
& 5 to 10 years & 12.50 \\
\hline Number of Employees at your company $(\mathrm{n}=7)$ & More than 10 years & 12.50 \\
\hline & 2 to 5 employees & 0.00 \\
& 5 to 10 employees & 71.43 \\
& 10 to 20 employees & 28.57 \\
& More than 20 & 0.00
\end{tabular}

Only $14.29 \%$ of this group had fallen and $12.50 \%$ had been injured (Table 46). Half of the group reported working at heights and half reported using fall protection. At the time of this training this group was constructing a townhouse and discussed several fall protection scenarios with me during the training session. This group had also recently received an OSHA 10 hour training, which requires at least one hour of training on fall protection.

Table 46. Cycle III Class 12 Pre Questionnaire Fall Injury and Fall Protection Related Data

\begin{tabular}{lcc}
\hline Question & Response & Percentage \\
\hline Have you fallen from heights $(\mathrm{n}=7)$ & Yes & 14.29 \\
& No & 85.71 \\
\hline Have you been injured $(\mathrm{n}=8)$ & & 12.50
\end{tabular}




\begin{tabular}{lcc} 
& No & 87.50 \\
\hline Do you work at heights $(\mathrm{n}=8)$ & Yes & 50.00 \\
& No & 50.00 \\
\hline Do you use fall protection $(\mathrm{n}=8)$ & Yes & 50.00
\end{tabular}

All students at this course had at least 1 DVD player and $77.78 \%$ had accessed special features menus on a DVD (Table 47). The students reported that 55.56\% had a computer at home with web access and $88.89 \%$ reported a computer at work with web access. This is in contradiction to traditional construction workers who most often have a computer at home to access and not at work. These students have additional computer access at work due to the nature and goal of the program that they are enrolled. When asked if they use these computers, $66.67 \%$ reported that they do. Half of the students had completed other instructor led training courses while only $11.11 \%$ had completed web-based training.

Table 47. Cycle III Class 12 Pre Questionnaire - Technology \& Training Question $\quad$ Response Percentage

\begin{tabular}{llc}
\hline Number of DVD Players owned? $(\mathrm{n}=9)$ & 0 & 0.00 \\
& Own 1 & 33.33 \\
& Own 2 & 22.44 \\
\hline Own Portable DVD player? (n=9) & Own 3 or more & 33.33 \\
& Yes & 66.67 \\
\hline Have used Special Features on DVD? $(\mathrm{n}=9)$ & No & 77.78
\end{tabular}




\begin{tabular}{|c|c|c|}
\hline & No & 22.22 \\
\hline \multirow[t]{2}{*}{ Have Computer at Home? $(\mathrm{n}=9)$} & Yes & 55.56 \\
\hline & No & 44.44 \\
\hline \multirow[t]{2}{*}{ Web Access at Home? $(n=9)$} & Yes & 55.56 \\
\hline & No & 44.44 \\
\hline \multirow[t]{4}{*}{ Connection Speed at Home? $(\mathrm{n}=9)$} & Dial Up & 22.22 \\
\hline & Cable & 11.11 \\
\hline & DSL & 22.22 \\
\hline & None & 44.44 \\
\hline \multirow[t]{2}{*}{ Computer at Work? $(\mathrm{n}=9)$} & Yes & 88.89 \\
\hline & No & 11.11 \\
\hline \multirow[t]{2}{*}{ Web Access at Work? $(\mathrm{n}=9)$} & Yes & 88.89 \\
\hline & No & 11.11 \\
\hline \multirow[t]{2}{*}{ Do you use the computer? $(\mathrm{n}=9)$} & Yes & 66.67 \\
\hline & No & 33.33 \\
\hline \multirow[t]{4}{*}{ Computer Skills Self Assessment? $(\mathrm{n}=8)$} & First Time User & 0.00 \\
\hline & Beginner & 0.00 \\
\hline & Intermediate & 87.50 \\
\hline & Advanced & 12.50 \\
\hline \multirow[t]{2}{*}{ Ever complete Web-Based training? $(n=9)$} & Yes & 11.11 \\
\hline & No & 88.89 \\
\hline \multirow[t]{2}{*}{ Participated in Instructor Led training? $(\mathrm{n}=8)$} & Yes & 50.00 \\
\hline & No & 50.00 \\
\hline
\end{tabular}


Completed Safety Training on Other Topics? $(n=9) \quad$ Yes

No
55.56

44.44

In evaluating the training material, $88.89 \%$ reported that the design features of the training material were "Excellent" (Table 48). The same percentage responded that the fall hazards in the training were "Always" or "Often" similar to the real hazards they would encounter on the construction site. Once again, $88.89 \%$ reported that the safe alternatives offered in the training were applicable in field. When asked to what extent they will make use of this training $100 \%$ responded that they will "Always" or "Often" make use of this training. Table 48. Cycle III Class 12 Post Training Questionnaire

\begin{tabular}{|c|c|c|}
\hline Question & Response & Percentage \\
\hline \multirow[t]{3}{*}{ Design Features of the training delivered $(n=9)$} & Excellent & 88.89 \\
\hline & Good & 11.11 \\
\hline & Satisfactory & 0.00 \\
\hline Did the training address fall hazards that would be & Always & 55.56 \\
\hline \multirow[t]{3}{*}{ encountered on a residential construction site $(n=9)$} & Often & 33.33 \\
\hline & Sometimes & 11.11 \\
\hline & Rarely / Never & 0.00 \\
\hline Were the safe alternatives applicable in the field & Yes & 88.89 \\
\hline$(\mathrm{n}=9)$ & No & 11.11 \\
\hline To what extent will you make use of this training & Always & 77.78 \\
\hline \multirow[t]{2}{*}{ material in the field $(n=9)$} & Often & 22.22 \\
\hline & Sometimes & 0.00 \\
\hline
\end{tabular}




\begin{tabular}{llc}
\hline & Rarely / Never & 0.00 \\
\hline This training compared to others $(\mathrm{n}=9)$ & Excellent & 88.89 \\
& Good & 11.11 \\
& Satisfactory & 0.00 \\
& N/A. & 0.00
\end{tabular}

The students approval and acceptance of the material did not impact or correlate with the results of their pre and posttests. A pre and posttest was administered to measure the student's basic knowledge regarding major areas of residential fall protection. The average score after the training $(\mathrm{M}=.5500)$ was less than the average score prior to the training $(\mathrm{M}=.6250)$. The difference between the two means is not statistically significant $t(7)=.814, p<.05$ (Table 49). It could be surmised that the training material that was developed for residential construction workers was not effective with young or inexperienced workers or the pre and post test did not adequately or effectively measure their knowledge gained.

Table 49. Cycle III Class 12 Pretest to Posttest Paired T-Test

\begin{tabular}{lllllc}
\hline \multicolumn{5}{c}{ Paired Samples Statistics } \\
\hline & Mean & N & Std. Deviation & $\begin{array}{c}\text { Std. Error } \\
\text { Mean }\end{array}$ \\
\hline Pair 1 & PreTest & 62.5000 & 8 & 16.69046 & 5.90097 \\
\cline { 2 - 6 } & PostTest & 55.0000 & 8 & 20.70197 & 7.31925 \\
\hline & \multicolumn{7}{c}{ Paired Samples Correlations } & \\
\hline Pair 1 & PreTest \& PostTest & 8 & Correlation & Sig. \\
\hline
\end{tabular}

Paired Samples Test

Paired Differences 


\begin{tabular}{|c|c|c|c|c|c|c|}
\hline & & \multirow[b]{2}{*}{ Mean } & \multirow{2}{*}{$\begin{array}{c}\text { Std. } \\
\text { Deviation }\end{array}$} & \multirow{2}{*}{$\begin{array}{c}\text { Std. Error } \\
\text { Mean }\end{array}$} & \multicolumn{2}{|c|}{$\begin{array}{c}95 \% \text { Confidence } \\
\text { Interval of the } \\
\text { Difference }\end{array}$} \\
\hline & & & & & Lower & Upper \\
\hline Pair 1 & $\begin{array}{l}\text { PreTest - } \\
\text { PostTest }\end{array}$ & 7.50000 & 26.04940 & 9.20985 & -14.27785 & 29.27785 \\
\hline
\end{tabular}

Paired Samples Test

\begin{tabular}{llccc}
\hline & $\mathrm{t}$ & $\mathrm{df}$ & Sig. (2-tailed) \\
\hline Pair 1 & PreTest - PostTest & .814 & 7 & .442 \\
\hline
\end{tabular}

Summary of Cycle III

Cycle III began with a request from a company for new material to be developed. With those changes WVUSHE realized that some elements of the new material needed to be included in the standard curriculum available to all participants. The training for that specific company was effective based on the pre and post site observations and inspections. Cycle III concluded with the revised training being delivered for the first time to youth in construction. The training resulted in positive feedback from the evaluations but was not effective based on the pre and posttest analysis. 
Table 50. Summary of Cycle III Design Decisions, Implementation and Revisions

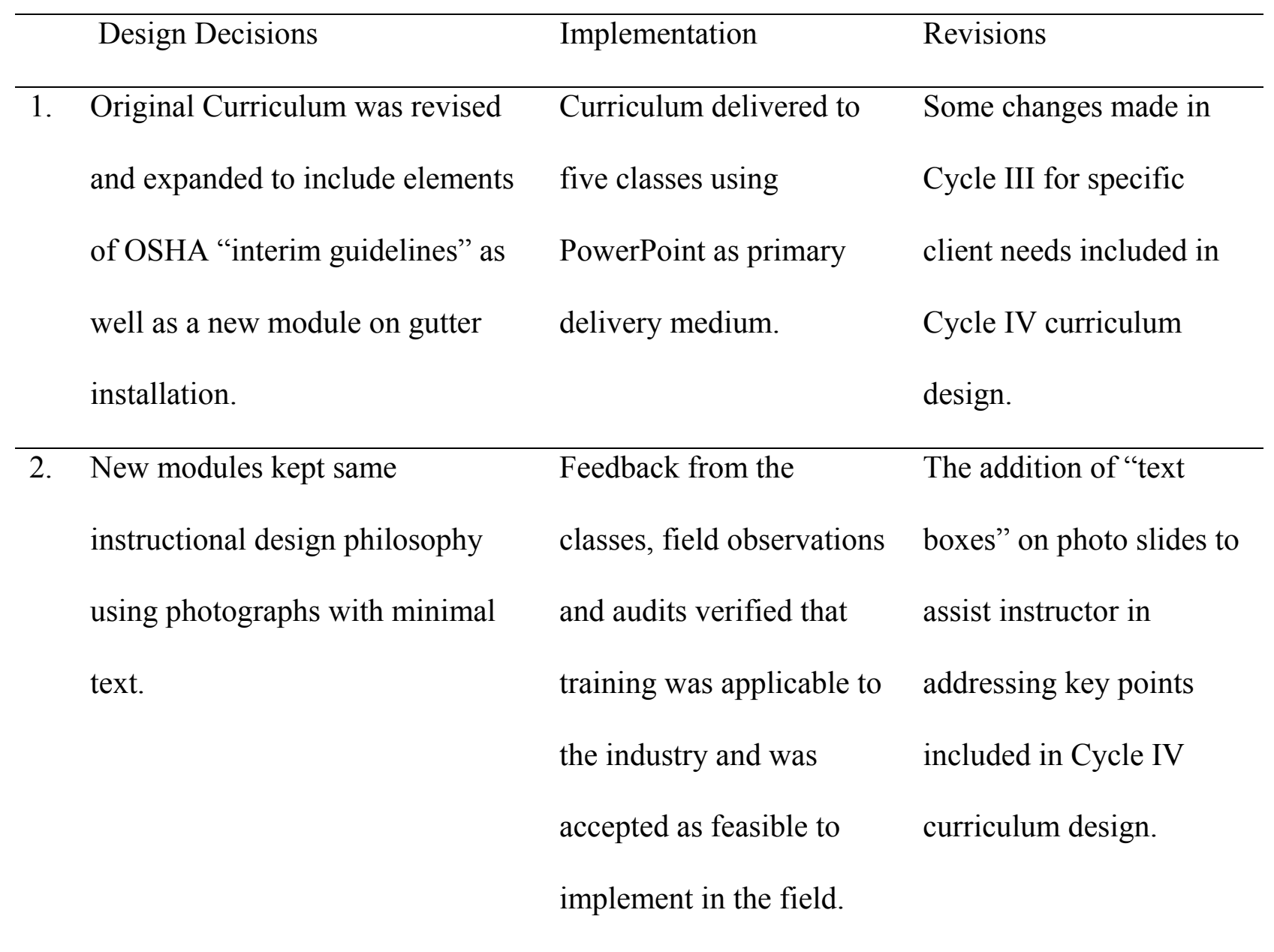

Developmental Cycle IV of PowerPoint Training Material

Cycle IV built on the changes made in Cycle III by improving the in-class usability of the PowerPoint's by adding text boxes to remind the instructor of key points to address in each slide. Cycle IV also kept included some elements of the new content developed in Cycle III.

\section{Cycle IV Development}

The changes made for Cycle IV were based primarily on my perceptions from delivering the classes using the PowerPoint as the primary delivery medium throughout Cycle II and III. The original decision when proposing this training material development in the grant proposal 
was to minimize text and focus on photographs and video. When using PowerPoint's this relied on all photographs with no text on the screen and detailed speaker notes. When conducting 4 hours of training it is difficult to recall all of the key points that need to be addressed in each photograph. Based on this realization, and with the assistance of a graduate student, I identified key points from the speaker notes from each slide and included that in a text box would appear into the slide with a mouse click. The hope was that this would allow the instructor to recall all of the pertinent information from each slide without overwhelming the audience with text slides. The photograph was still the primary teaching element on the screen with the text being there to assist the instructor. In addition to assisting the primary WVUSHE instructor, it was added so other potential trainers that received the material could more easily use this curriculum without the need to have all of the speaker notes printed out.

In addition to adding the on screen text, a new module was developed entitled "The Basics of Fall Protection." Content slides were added within the "Foundation", "Flooring", and "Roofing" training modules. These additional content slides included the allowance of three interim fall protection rules that allow workers to work at heights without traditional fall protection as long as a set of less stringent rules are flowed. Traditionally, WUSHE had determined not to use these less stringent rules, but realized after conducting the previous courses and conducting site audits and worker interviews that there are some situations during residential construction when the fall protection regulation as written is not applicable. With this knowledge WVUSHE chose not to add all of the elements of the less stringent interim guideline, but only a select few that created a unique hazard that other more traditional alternatives would not suffice. 


\section{Cycle IV Delivery and Evaluation}

Two classes were held within Cycle IV. Each class was taught by an instructor that had not previously delivered the training. To this point in the study, this author had conducted all classes. Prior to these instructors presenting this material I met with them, provided them with copies of the training material with detailed speaker notes and made suggestions on how to deliver the course based on my experiences.

The training was under somewhat different circumstances. The training was delivered within a larger OSHA curriculum, known as an OSHA 502. This is a refresher course for individuals who already have certification from OSHA to be an OSHA outreach trainer. This provides the student the ability to deliver two OSHA based construction courses for workers and supervisors known as the OSHA 10 hour and the OSHA 30 Hour. Additionally, these students were also vocational teachers, many of which supervised high school students in the construction of traditional stick built homes and modular homes. With that background it seemed appropriate to provide this group with the residential construction fall protection training and companion DVD for their knowledge and for their future use.

Class 13, August 4, 2008, Roanoke, VA. As described above this training was conducted within a 3 day OSHA 502 course with 29 attendees. The training was 4 hours in duration. Data collected from this training includes historical documents (i.e., training material, quarterly grant reports, OSHA class sign in sheets), pre and post tests, pre and post questionnaires, and post training instructor interviews.

The pre questionnaire data included in Table 51 shows that $96.43 \%$ of the students were male and that the majority (79.31\%) of them identified themselves as skilled employees. It is known that $100 \%$ of these students are also Vocational Education Teachers. The majority 
$(48.72 \%)$ selected residential construction as the construction industry in which they work. The majority $(75.86 \%)$ have worked in the industry for more than 10 years. Half report that they work for an employer with more than 20 employees, which is due to the fact that $100 \%$ of the students in this class work for Boards of Education.

Table 51. Cycle IV Class 13 Pre Questionnaire Demographic and Injury Data

\begin{tabular}{|c|c|c|}
\hline Question & Response & Percentage \\
\hline \multirow{2}{*}{$\operatorname{Sex}(n=28)$} & Male & 96.43 \\
\hline & Female & 3.57 \\
\hline \multirow[t]{5}{*}{ Job Title $(n=29)$} & Supervisor/Foreman & 3.45 \\
\hline & Employee/Skilled & 79.31 \\
\hline & Employee/Laborer & 13.79 \\
\hline & Contractor/Owner & 3.45 \\
\hline & Others & 0.00 \\
\hline \multirow[t]{5}{*}{ Type of Construction $(n=39)$} & Residential & 48.72 \\
\hline & Commercial & 25.64 \\
\hline & Heavy Construction & 0.00 \\
\hline & Industrial & 5.13 \\
\hline & Other & 20.51 \\
\hline \multirow[t]{4}{*}{ Years Worked in Construction $(n=29)$} & Less than 1 year & 3.45 \\
\hline & 1 to 5 years & 3.45 \\
\hline & 5 to 10 years & 17.24 \\
\hline & More than 10 years & 75.86 \\
\hline Number of Employees at your comp & 1 employee & 6.67 \\
\hline
\end{tabular}


$\begin{array}{ll}2 \text { to } 5 \text { employees } & 0.00 \\ 5 \text { to } 10 \text { employees } & 6.67 \\ 10 \text { to } 20 \text { employees } & 33.33\end{array}$

More than 20

Forty percent of the students reported that they had fallen from a height and $20 \%$ reported being injured from a fall (Table 52). Nearly all (83.33\%) reported that they work at heights and $73.33 \%$ reported that they do use fall protection when working at heights.

Table 52. Cycle IV Class 13 Pre Questionnaire Fall Injury and Fall Protection Related Data

\begin{tabular}{lcc}
\hline Question & Response & Percentage \\
\hline Have you fallen from heights $(\mathrm{n}=30)$ & Yes & 40.00 \\
& No & 60.00 \\
\hline Have you been injured $(\mathrm{n}=30)$ & Yes & 20.00 \\
\hline Do you work at heights $(\mathrm{n}=30)$ & No & 80.00 \\
\hline Do you use fall protection $(\mathrm{n}=30)$ & Yes & 83.33 \\
& No & 16.67 \\
\hline & Yes & 73.33 \\
\hline
\end{tabular}

In regards to technology, $100 \%$ own at least one DVD player and $64.29 \%$ had accessed the special features of a DVD. Nearly all (93.33\%) have a computer at home while $78.57 \%$ report having web access on that home computer (Table 53). Nearly all (96.67\%) have a computer at work with web access and report that they use the computer. Half reported completing web-based training while $90 \%$ had completed instructor led training. 
Table 53. Cycle IV Class 13 Pre Questionnaire - Technology \& Training

Question $\quad$ Response Percentage

\begin{tabular}{|c|c|c|}
\hline \multirow[t]{4}{*}{ Number of DVD Players owned? $(n=30)$} & 0 & 0.00 \\
\hline & Own 1 & 36.67 \\
\hline & Own 2 & 46.67 \\
\hline & Own 3 or more & 16.67 \\
\hline \multirow[t]{2}{*}{ Own Portable DVD player? $(n=30)$} & Yes & 56.67 \\
\hline & No & 43.33 \\
\hline \multirow[t]{2}{*}{ Have used Special Features on DVD? $(n=28)$} & Yes & 64.29 \\
\hline & No & 35.71 \\
\hline \multirow[t]{2}{*}{ Have Computer at Home? $(\mathrm{n}=30)$} & Yes & 93.33 \\
\hline & No & 6.67 \\
\hline \multirow[t]{2}{*}{ Web Access at Home? $(n=28)$} & Yes & 78.57 \\
\hline & No & 21.43 \\
\hline \multirow[t]{4}{*}{ Connection Speed at Home? $(\mathrm{n}=28)$} & Dial Up & 14.29 \\
\hline & Cable & 39.29 \\
\hline & DSL & 28.57 \\
\hline & None & 17.86 \\
\hline \multirow[t]{2}{*}{ Computer at Work? $(n=30)$} & Yes & 96.67 \\
\hline & No & 3.33 \\
\hline \multirow[t]{2}{*}{ Web Access at Work? $(n=30)$} & Yes & 96.67 \\
\hline & No & 3.33 \\
\hline Do you use the computer? $(n=30)$ & Yes & 96.67 \\
\hline
\end{tabular}




\begin{tabular}{lll}
\hline Computer Skills Self-Assessment? $(\mathrm{n}=30)$ & First Time User & 0.00 \\
& Beginner & 10.00 \\
& Intermediate & 76.67 \\
& Advanced & 13.33 \\
\hline Ever complete Web-Based training? $(\mathrm{n}=30)$ & Yes & 50.00 \\
& No & 50.00 \\
\hline Participated in Instructor Led training? (n=30) & Yes & 90.00 \\
& No & 10.00 \\
\hline Completed Safety Training on Other? Topics $(\mathrm{n}=30)$ & Yes & 93.33 \\
& No & 6.67
\end{tabular}

The post-training questionnaire reported positive results with $93.33 \%$ of the students responding that the design features of the training were "Excellent" or "Good" (Table 54). In asking about how well the training addressed fall hazards, $93.33 \%$ reported that the training "Always" or "Often" represented the hazards as they would be encountered on a construction site. Similarly $100 \%$ of the students said that the safe alternatives offered in the training were applicable in the real world of construction.

These vocational education teachers reported that $95.83 \%$ of them would "Always" or "Often" make use the training material. This coincides with the post training interview that I conducted with the instructor of this course who reported that the teachers were "very excited" about the training material and the availability of the DVD for their use in the classroom. 
Table 54. Cycle IV Class 13 Post Training Questionnaire

\begin{tabular}{|c|c|c|}
\hline Question & Response & Percentage \\
\hline \multirow[t]{3}{*}{ Design Features of the training delivered $(n=30)$} & Excellent & 46.67 \\
\hline & Good & 46.67 \\
\hline & Satisfactory & 6.67 \\
\hline Did the training address fall hazards that would be & Always & 43.33 \\
\hline \multirow[t]{3}{*}{ encountered on a residential construction site $(n=30)$} & Often & 50.00 \\
\hline & Sometimes & 6.67 \\
\hline & Rarely / Never & 0.00 \\
\hline Were the safe alternatives applicable in the field & Yes & 100.00 \\
\hline$(n=30)$ & No & 0.00 \\
\hline To what extent will you make use of this training & Always & 46.67 \\
\hline \multirow[t]{4}{*}{ material in the field $(n=30)$} & Often & 40.00 \\
\hline & Sometimes & 10.00 \\
\hline & Rarely & 3.33 \\
\hline & Never & 0.00 \\
\hline \multirow[t]{4}{*}{ This training compared to others $(n=30)$} & Excellent & 46.67 \\
\hline & Good & 50.00 \\
\hline & Satisfactory & 3.33 \\
\hline & $\mathrm{N} / \mathrm{A}$ & 0.00 \\
\hline
\end{tabular}

A pre and posttest was administered to measure the student's basic knowledge regarding major areas of residential fall protection. The average score after the training $(\mathrm{M}=.6092)$ was 
just slightly higher than the average score prior to the training $(\mathrm{M}=.5459)$. The difference between the two means was not statistically significant $\mathrm{t}(28)=-1.134, \mathrm{p}<.05$ (Table 55 ). It can be surmised that this being the first class that utilized an instructor that was not also the curriculum developer could have impacted the results of the posttest scores and that the curriculum was not designed with a proper trainer's guide. It also is possible that this training, developed specifically for the residential construction industry is not as effective with nonindustry participants.

Table 55. Cycle IV Class 13 Pretest to Posttest Paired T Test

\section{Paired Samples Statistics}

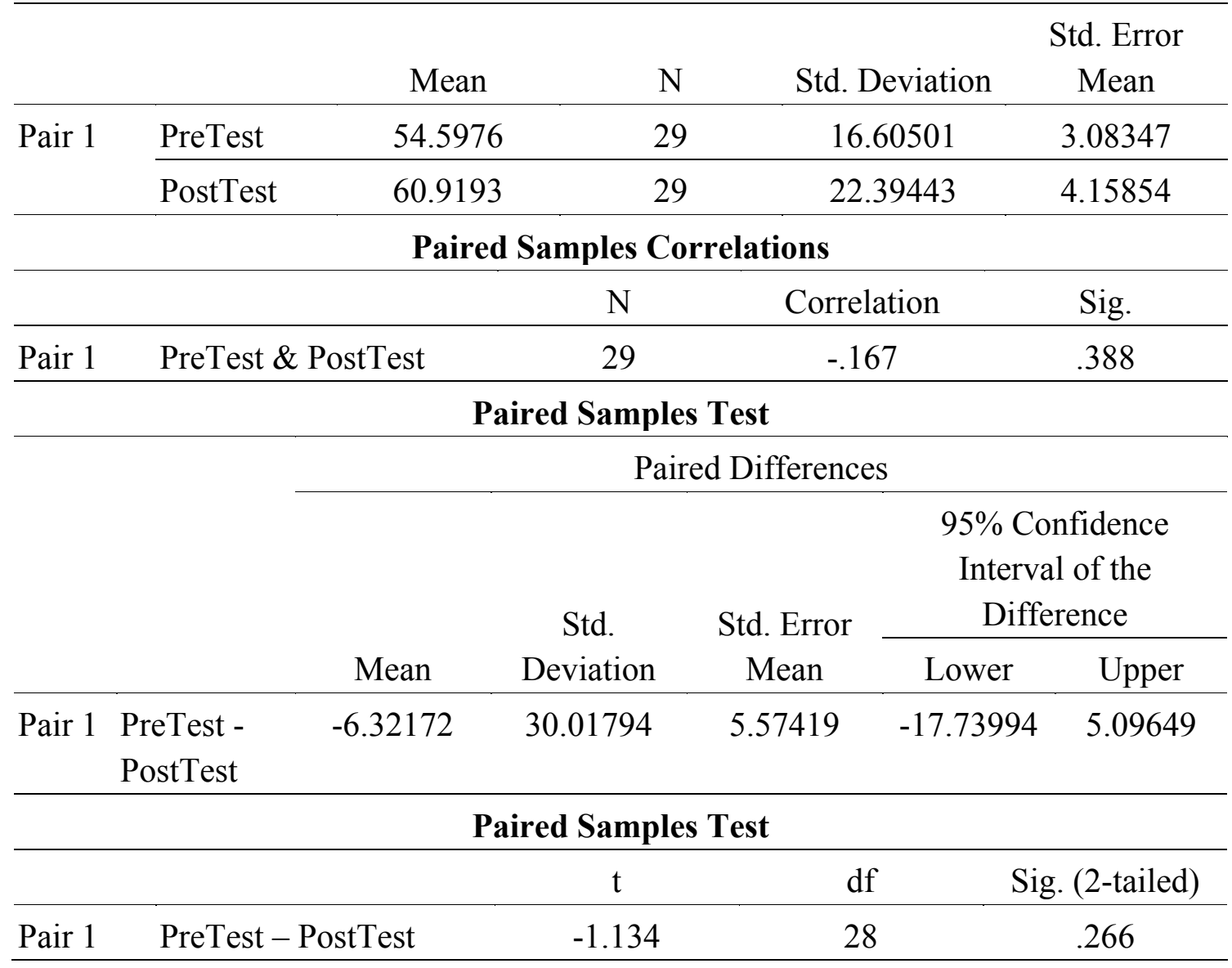


Class 14, August 7, 2008, Roanoke, VA. Just as in Class 13, this training class was conducted within a 3 day OSHA 502 course with 26 attendees. This training was 4 hours in duration. Data collected from this training includes historical documents (i.e., training material, quarterly grant reports, OSHA class sign in sheets), pre and post tests, pre and post questionnaires, and a post training instructor interview.

The pre questionnaire data included in Table 56 shows that $100 \%$ of the students were male and that the majority $(66.67 \%)$ of them identified themselves as skilled employees. It is known that $100 \%$ of these students are also Vocational Education Teachers. The majority $(68.18 \%)$ selected residential construction as the construction industry in which they work. Nearly all (95.24\%) have worked in the industry for more than 10 years. Half report that they work for an employer with more than 20 employees, which is due to the fact that $100 \%$ of the students work for Boards of Education.

Table 56. Cycle IV Class 14 Pre Questionnaire Demographic and Injury Data

\begin{tabular}{llc}
\hline Question & Response & Percentage \\
\hline Sex $(\mathrm{n}=20)$ & Male & $100.00 \%$ \\
& Female & $0.00 \%$ \\
\hline Job Title $(\mathrm{n}=18)$ & Supervisor/Foreman & 11.11 \\
& Employee/Skilled & 66.67 \\
& Employee/Laborer & 0.00 \\
& Contractor/Owner & 5.56 \\
\hline Type of Construction $(\mathrm{n}=22)$ & Others & 16.67 \\
& Residential & 68.18 \\
& Commercial & 4.55
\end{tabular}




\begin{tabular}{lll} 
& Heavy Construction & 0.00 \\
& Industrial & 4.55 \\
& Other & 0.00 \\
\hline Years Worked in Construction $(\mathrm{n}=22)$ & Less than 1 year & 0.00 \\
& 1 to 5 years & 0.00 \\
& 5 to 10 years & 4.76 \\
\hline Number of Employees at your company $(\mathrm{n}=16)$ & More than 10 years & 95.24 \\
\hline & 2 to 5 employees & 0.00 \\
& 5 to 10 employees & 0.00 \\
& 10 to 20 employees & 37.50 \\
& More than 20 & 50.00
\end{tabular}

A staggering $80.95 \%$ The percentage students reported that they had fallen from a height and nearly half (47.62\%) reported being injured from a fall (Table 57). These are the highest numbers of falls and injuries from falls in all of the data collected as part of this research. Nearly all $(95.24 \%)$ reported that they work at heights and $85.71 \%$ reported that the do use fall protection when working at heights.

Table 57. Cycle IV Class 14 Pre Questionnaire Fall Injury and Fall Protection Related Data

\begin{tabular}{lcc}
\hline Question & Response & Percentage \\
\hline Have you fallen from heights $(\mathrm{n}=21)$ & Yes & 80.95 \\
& No & 19.05 \\
\hline Have you been injured $(\mathrm{n}=21)$ & & 47.62
\end{tabular}




\begin{tabular}{lcc} 
& No & 52.38 \\
\hline Do you work at heights $(\mathrm{n}=21)$ & Yes & 95.24 \\
& No & 4.76 \\
\hline Do you use fall protection $(\mathrm{n}=21)$ & Yes & 85.71
\end{tabular}

In regards to technology questions, $95.24 \%$ own at least one DVD player and $75 \%$ had accessed the special features of a DVD (Table 58). All who responded have a computer at home while $80.95 \%$ report having web access on that home computer. Nearly all $(95.24 \%)$ have a computer at work and all students have web access at work. Similarly, 95.24\% report that they use a computer.

A very high percentage $(85.71 \%)$ had completed web-based training, which is much higher than responses reported in all previous classes. All the students had completed some other form of instructor led training.

Table 58. Cycle IV Class 14 Pre Questionnaire - Technology \& Training

\begin{tabular}{llc}
\hline Question & Response & Percentage \\
\hline Number of DVD Players owned? (n=21) & 0 & 4.76 \\
& Own 1 & 52.38 \\
& Own 2 & 23.81 \\
\hline Own Portable DVD player? (n=21) & Own 3 or more & 47.62 \\
& Yes & 52.38 \\
\hline Have used Special Features on DVD? $(\mathrm{n}=20)$ & No & 75.00
\end{tabular}




\begin{tabular}{|c|c|c|}
\hline & No & 25.00 \\
\hline \multirow[t]{2}{*}{ Have Computer at Home? $(\mathrm{n}=21)$} & Yes & 100.00 \\
\hline & No & 0.00 \\
\hline \multirow[t]{2}{*}{ Web Access at Home? $(n=21)$} & Yes & 80.95 \\
\hline & No & 19.05 \\
\hline \multirow[t]{4}{*}{ Connection Speed at Home? $(\mathrm{n}=18)$} & Dial Up & 44.44 \\
\hline & Cable & 16.67 \\
\hline & DSL & 33.33 \\
\hline & None & 5.56 \\
\hline \multirow[t]{2}{*}{ Computer at Work? $(\mathrm{n}=21)$} & Yes & 95.24 \\
\hline & No & 4.76 \\
\hline \multirow[t]{2}{*}{ Web Access at Work? $(n=21)$} & Yes & 100.00 \\
\hline & No & 0.00 \\
\hline \multirow[t]{2}{*}{ Do you use the computer? $(\mathrm{n}=21)$} & Yes & 95.24 \\
\hline & No & 4.76 \\
\hline \multirow[t]{4}{*}{ Computer Skills Self Assessment? $(\mathrm{n}=20)$} & First Time User & 0.00 \\
\hline & Beginner & 5.00 \\
\hline & Intermediate & 80.00 \\
\hline & Advanced & 15.00 \\
\hline \multirow[t]{2}{*}{ Ever complete Web-Based training? $(n=21)$} & Yes & 85.71 \\
\hline & No & $14.29 \%$ \\
\hline \multirow[t]{2}{*}{ Participated in Instructor Led training? $(n=21)$} & Yes & 100.00 \\
\hline & No & 0.00 \\
\hline
\end{tabular}


Completed Safety Training on Other? Topics $(n=21) \quad$ Yes

No
95.24

4.76

The post training questionnaire reported positive results with $100 \%$ of the students responding that the design features of the training was "Excellent" or "Good" (Table 59). In asking about how well the training addressed fall hazards, 100\% reported that the training "Always" or "Often" represented the hazards as they would be encountered on a construction site. Similarly $100 \%$ of the students said that the safe alternatives offered in the training were applicable in the real world of construction. As vocational instructors teaching tomorrows construction workers, $95.83 \%$ reported that they would "Always" or "Often" make use of the training material.

Table 59. Cycle IV Class 14 Post Training Questionnaire

\begin{tabular}{|c|c|c|}
\hline Question & Response & Percentage \\
\hline \multirow[t]{3}{*}{ Design Features of the training delivered $(n=24)$} & Excellent & 50.00 \\
\hline & Good & 50.00 \\
\hline & Satisfactory & 0.00 \\
\hline Did the training address fall hazards that would be & Always & 50.00 \\
\hline \multirow[t]{3}{*}{ encountered on a residential construction site $(n=24)$} & Often & 50.00 \\
\hline & Sometimes & 0.00 \\
\hline & Rarely/Never & 0.00 \\
\hline Were the safe alternatives applicable in the field & Yes & 100.00 \\
\hline$(n=24)$ & No & 0.00 \\
\hline
\end{tabular}




\begin{tabular}{llc}
\hline To what extent will you make use of this training & Always & 37.50 \\
material in the field $(\mathrm{n}=24)$ & Often & 58.33 \\
& Sometimes & 4.17 \\
& Rarely/Never & 0.00 \\
\hline This training compared to others $(\mathrm{n}=24)$ & Excellent & 79.17 \\
& Good & 20.83 \\
& Satisfactory & 0.00 \\
& N/A. & 0.00
\end{tabular}

A post training interview was conducted with the instructor of this course focusing on the quality and applicability of the training material for the instructor's perspective. The instructor made several suggestions regarding the training material. First, he stated that he liked the training approach of teaching fall hazards by phases of construction but noted that this does create some redundancy from training module to training module. He also mentioned that functionally, the text boxes added after Cycle III slowed down delivery of the content due to how they each were animated to appear separately with a mouse click. He did believe that the fall hazards depicted accurately hazards that would be found on an actual construction site, but stated that it was not always apparent what hazards were to be discussed in each photograph and that this often led the classroom discussion to other areas away from the main point of the slide. He also stated that the safe alternatives provided were also applicable on the construction site.

This instructor responded to the question, "Do you think training can help in the reduction of falls on construction sites?" by responding, "Yes, if there is buy in from the 
employer and employees.” He went on to say that he believes that “...training reduces injuries proportionally, training repeated increases performance.”

A pre and posttest was administered to measure the student's basic knowledge regarding major areas of residential fall protection. The average score after the training $(\mathrm{M}=.6458)$ was just slightly higher than the average score prior to the training $(\mathrm{M}=.6250)$. The difference between the two means is not statistically significant, $\mathrm{t}(23)=-.360, \mathrm{p}<.05$ (Table 60 ). This being the same audience type as the previous class, which is made up of all vocational education teachers, it could be surmised once again that this training is not as effective for those not in the residential construction industry. Additionally, this was the first time this instructor taught this content using this curriculum.

Table 60. Cycle IV Class 14 Pretest to Posttest Paired T Test

\section{Paired Samples Statistics}

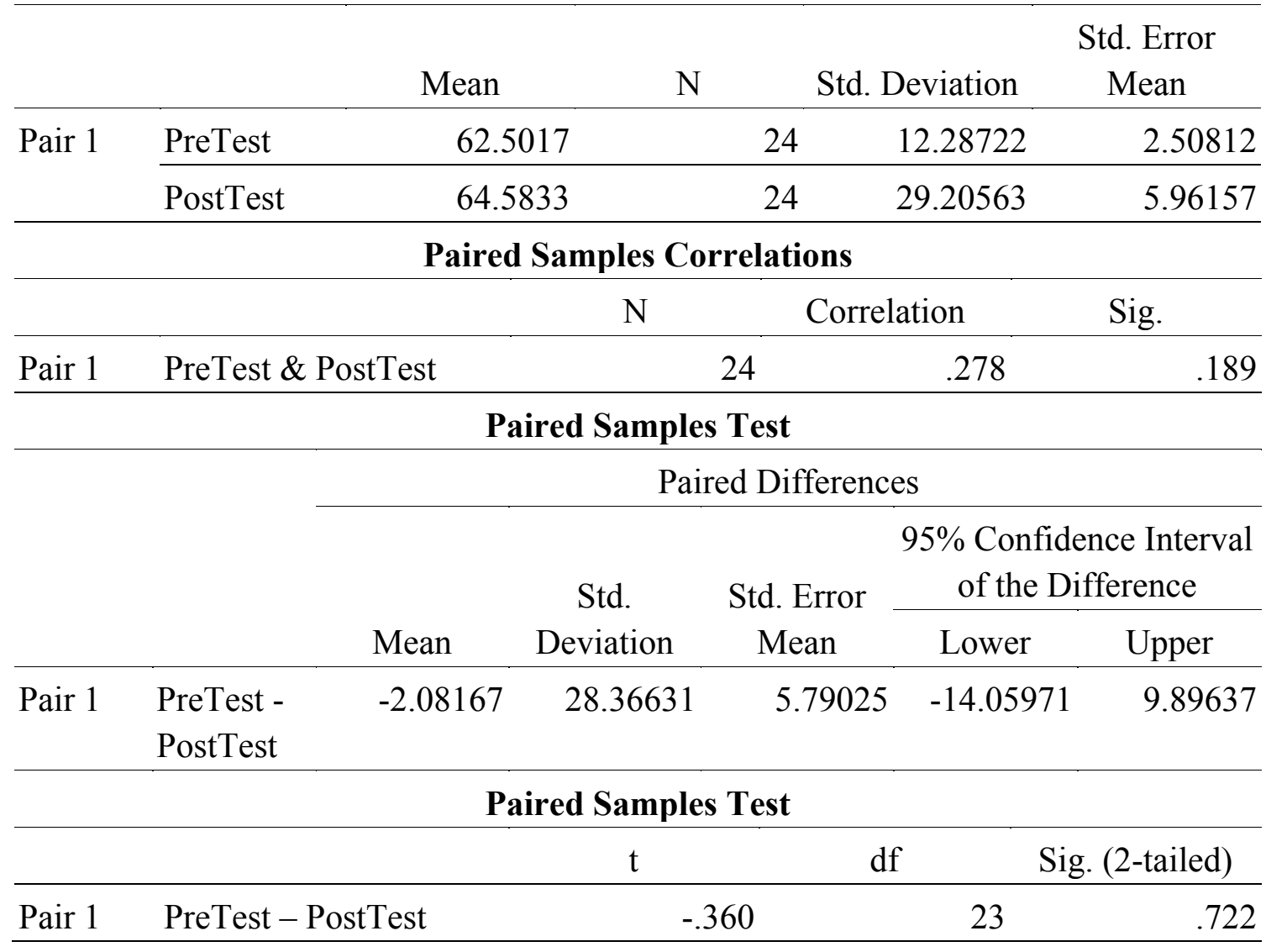


Summary of Cycle IV

Cycle IV included revisions of the training material based on the decision to keep some of the new content added during curriculum changes made in Cycle III (Table 61). Some instructional design changes were also made to the photo based slides with the addition of text boxes to assist the instructor in remembering the key points to discuss within each slide. Implementation included delivery of two courses with two different trainers; neither of which had taught the course previously. The training resulted in evidence that the training material was accepted from the industry and applicable for use on the jobsite. The pre and posttests did not show evidence that knowledge was gained during the course. In addition to this being the first time in this study that other instructor were utilized, the conditions of the class being incorporated into a larger 3 day course certification course with vocational education teachers also made these two cases unique compared to previous classes delivered within this study. Table 61. Summary of Cycle IV Design Decisions, Implementation and Revisions

\begin{tabular}{llll}
\hline Design Decisions & Implementation & Revisions \\
\hline 1. & Curriculum was revised from & Curriculum delivered to two & Text boxes added in \\
Cycle III to include animated & classes using PowerPoint as & Cycle III to be made \\
text boxes to assist instructor & primary delivery medium. & fixed on the slide (non- \\
with addressing key points. & & animated). \\
\hline 2. & The addition of a new module & Feedback from the classes & Photos to be added to the \\
"Basics of Fall Protection" was & and instructors verified & "Problem with Falls" \\
revised from Cycle III and & training was applicable to the & introductory module. \\
included in Cycle IV. & industry and was accepted as & \\
& feasible to implement in the & \\
& &
\end{tabular}


field.

\begin{tabular}{lll}
\hline 3. New content slides added to 3 & Pre and Posttests did not & "Basics of Fall \\
existing modules (foundation, & result in significant & Protection" PowerPoint \\
flooring, and roofing) that & knowledge gain. & presentation to be made \\
included previously excluded & & into a video. \\
interim fall protection & \\
guidelines.
\end{tabular}

Developmental Cycle V of PowerPoint Training Material and Interactive DVD

Based on the combined feedback from the DVD questionnaire responses, the changes made to the PowerPoint's throughout the process, the field observations and fall hazard audits, historical document analysis, classroom evaluations, pre and post tests and worker and instructor interviews, major revisions were made to the DVD. All changes made to the DVD in this cycle had to be reflected in identical changes made to the PowerPoint training material, which was included on the DVD-ROM portion of the DVD-Video. The changes made to the DVD were delayed because of the amount of effort that is required to collect video, record new narration, edit video and author the new version of the DVD.

\section{Cycle V Developmental Changes to the DVD and PowerPoint}

Based on comments and feedback from the web requested DVD recipients the introductory video segment, entitled "The Problem” was dramatically revised. The original video was white text over a black background with dramatic narration and music with the goal of driving home to the audience the serious problem of falls in residential construction. The result however was that the students in the classroom and the DVD recipients felt as if they were being 
read to which was not the intent. The changes made to this segment were to keep the narration and the music but to add photographs and video clips to show the problem versus just the text on a black background. We had many hours of video from worksites that demonstrated unsafe acts being performed by residential construction workers that we could use in this opening segment. This new version was included in the DVD.

Additionally, two new video segments were added that came out of the revision completed in Developmental Cycle III specifically for the client that requested a basic overview and introduction to fall protection as well as a new segment on gutter installation. Based originally on the slides developed for that client, a companion video entitled "Basics of Fall Protection" was developed and is included on the DVD on the Main Menu following "The Problem.” The new segment "Gutter Installation" was developed and added to the DVD menu that shows the sections of a residential home and allows the user to select what training module to review.

Other changes to the DVD included editing and re-recording many segments of narration that were either revised for clarity or were added based on changes made to the PowerPoint's from Developmental Cycle III and IV. Once re-recorded, the PowerPoint's with the included narration had to be revised and the video segments that correlated with those PowerPoint slides had to be added or re-edited to match the narrative changes. There were also several new segments that required new video to be shot and photographs to be collected. These revisions were mainly in the area of roof fall protection and gutter installation. There was also a more detailed set of instructions developed as an insert with the DVD to provide clearer direction on the variety of ways to make use of the DVD and PowerPoint content. 
The DVD training is on 2 discs. It was determined when authoring the DVD's to create 2 different types of interactivity. On Disc 1 each hazard category is provided as a separate video segment and once complete the DVD goes to a menu that provided several safe alternatives. This was in the format of the first version of the DVD originally produced. The concern with this format, identified by this author was that depending on the length of the hazard video segments this could require the trainee to maneuver through menu selections frequently, disturbing the flow of the content. Disc 2 was authored to minimize this issue. The hazard videos were edited into one combined hazard video segment and all safe alternatives were edited into one video segment. On some modules that had very short hazard and safe alternative segments both were combined into one video segment. This author noted difficulties in storing and identifying the large digital video and audio files to recompile the DVD authored files. Also, WVUSHE committed in 2005 to a DVD authoring software that in 2009 had become unstable due to lack of updates and support from the software company. These problems were overcome and the DVD was completed, although this added several days of additional work onto the project.

In addition to making changes to the PowerPoint to match the DVD video content changes were made to the PowerPoint presentations based on feedback from the instructors to reduce redundancy and to reduce the amount of animated "fly-in" text boxes. This work included removing the same photographs from different training modules and selecting alternative photographs so as not be redundant when delivering all training modules to the same class. Additionally, a determination was made to introduce the instructor led classes by presenting video versions of the two introductory modules; "The Problem" and "The Basics of Fall Protection." These modules set the stage for the remainder of the class by giving the students an 
understanding of the dangers of working at heights and a basic knowledge of available fall protection measures and equipment.

Cycle V Delivery and Evaluation of DVD and PowerPoint's

DVD version 2.0 delivery and evaluation. Once the revisions to the DVD were completed, this author contacted several individuals with varying expertise to review the material. This included safety professionals that work in residential construction, safety trainers that previously delivered this training material, residential construction workers that attended the instructor led training and safety professionals with expertise in safety curriculum development. The training material was not placed for order on the www.residentialfallsafe.org for the public due to the fact that OSHA had not yet approved the revised material and due to time constraints of this research. The results of this data collected are included in Tables 18 through 21 .

The majority of those that reviewed the DVD were safety trainers, safety consultants, safety professionals or safety directors (Table 62). Of those that reviewed the DVD $40 \%$ worked for companies with 10 to 20 employees and $40 \%$ for companies with more than 20 employees. Table 62. Cycle V DVD Recipient Demographic Data

\begin{tabular}{llc}
\hline Question & Response & Percentage \\
\hline Sex $(\mathrm{n}=11)$ & Male & $100.00 \%$ \\
\hline Job Title (n=11) & Worker (Skilled / Laborer) & $0.0 \%$ \\
& Supervisor / Foreman & $9.1 \%$ \\
& Safety Director & $9.1 \%$ \\
& Saf. Trainer / Consultant / Safety Prof. & $72.7 \%$ \\
& & $0.0 \%$ \\
Years worked in residential construction? & Less than 1 year & $22.2 \%$
\end{tabular}


5-10 years

More than 10 years
Current number of employees working in your company? $(\mathrm{n}=10)$
Individual, not a company

1

2 to 5

10 to 20

More than 20
$55.6 \%$

$22.2 \%$

$10.0 \%$

$0.0 \%$

$10.0 \%$

$40.0 \%$

$40.0 \%$

When asked how well they liked the design features of the DVD training, $100 \%$ responded with "Excellent" or "Good." When asked if there were changes that they would recommend there were two open ended responses. One respondent stated that the video quality on a laptop made the text difficult to read. The other respondent detailed some suggested changes that included more clear instructions or a "road map" of what to expect in the course including how long each section. Additionally this reviewed suggested an included document that would describe this roadmap of instructions for the training. A final suggestion was to embed quizzes into the DVD before and after each module.

When asked if the hazards depicted in the training material were representative of what would be seen in the real world of residential construction $100 \%$ answered that "All" or "The majority" of the hazards were real world depictions. Similarly when asked if the safe alternatives presented were practical for use on construction sites, $100 \%$ responded that "All" or "The majority" would be practical for use in residential construction. One respondent identified that there were equipment hazards in the "Site Preparation", "Foundation Work" and "Other Fall Hazards" that needed to be addressed in the training. All other respondents reported that there were no additional hazards or safe alternatives that needed to be added to the training. When 
asked if they could suggest changes to improve the quality and effectiveness of the content one respondent suggested increasing the speed of the narration. This respondent played the DVD back at 1.5 to 2.0 times normal speed and was able to keep up with the training material.

All respondents planned to use the DVD to either train employees or to train client employees. (Table 63). An open-ended question asked, "To what extent will you make use of the DVD?" The responses included using the training in weekly toolbox talks, utilizing the training in OSHA training program, and using the training material when working with the residential construction industry.

Table 63. Cycle V DVD Recipient Training Material Evaluation

\begin{tabular}{|c|c|c|}
\hline How did you hear about the available DVD & Web Search & $0.0 \%$ \\
\hline \multirow[t]{5}{*}{ training material? $(\mathrm{n}=11)$} & OSHA & $0.0 \%$ \\
\hline & WVUSHE Class & $18.2 \%$ \\
\hline & Colleague & $63.6 \%$ \\
\hline & OSHA Office / Education Center & $0.0 \%$ \\
\hline & Other & $18.2 \%$ \\
\hline When requesting the DVD, what was the & To complete self guided training & $0.0 \%$ \\
\hline \multirow[t]{3}{*}{ intended use? $(n=11)$} & To train employees & $45.5 \%$ \\
\hline & To train clients (Contractors) & $63.6 \%$ \\
\hline & Informational purposes only & $0.0 \%$ \\
\hline Reviewed the DVD training material? $(n=11)$ & Yes & $100.0 \%$ \\
\hline How well do you like the design feature of this & Excellent & $87.5 \%$ \\
\hline fall protection training? $(n=8)$ & Good & $12.5 \%$ \\
\hline
\end{tabular}




\begin{tabular}{|c|c|c|}
\hline & Satisfactory & $0.0 \%$ \\
\hline & Unsatisfactory & $0.0 \%$ \\
\hline Do the fall hazards depicted in this training & All & $62.5 \%$ \\
\hline accurately depict real work fall hazards that & The majority & $37.5 \%$ \\
\hline you would see on residential construction site? & About half & $0.0 \%$ \\
\hline \multirow[t]{2}{*}{$(n=8)$} & A few & $0.0 \%$ \\
\hline & None & $0.0 \%$ \\
\hline Do the safe alternatives depicted in this & All & $75.0 \%$ \\
\hline training accurately depict real work fall & The majority & $25.0 \%$ \\
\hline hazards that you would see on residential & About half & $0.0 \%$ \\
\hline \multirow[t]{2}{*}{ construction site? $(\mathrm{n}=8)$} & A few & $0.0 \%$ \\
\hline & None & $0.0 \%$ \\
\hline Did you review the PowerPoint materials? & Yes & $85.7 \%$ \\
\hline$(\mathrm{n}=7)$ & No & $14.3 \%$ \\
\hline Did you previously review the first version of & Yes & $71.4 \%$ \\
\hline this DVD? $(\mathrm{n}=7)$ & No & $28.6 \%$ \\
\hline \multirow{5}{*}{$\begin{array}{l}\text { How do you rate the revised DVD in } \\
\text { comparison to the first version? }(n=5)\end{array}$} & Much improved (addressed and & $100.0 \%$ \\
\hline & corrected all deficiencies). & \\
\hline & Improved (addressed the & $0.0 \%$ \\
\hline & majority of deficiencies). & \\
\hline & The previous version was better. & $0.0 \%$ \\
\hline Disc 1 or Disc 2 instructional design & Disc 1 & $0.0 \%$ \\
\hline preference? $(\mathrm{n}=6)$ & Disc 2 & $16.7 \%$ \\
\hline
\end{tabular}


The respondents to the questionnaire reported that $57.1 \%$ of them had fallen on a construction site and $28.6 \%$ of them had been injured from a fall (Table 64$)$. Early half (42.9\%) reported currently working at heights with over $71 \%$ reporting that they use fall protection when working at heights.

Table 64. Cycle V DVD Recipient Fall Hazards and Injury Data

\begin{tabular}{|c|c|c|}
\hline Have you ever fallen while working on a residential construction & Yes & $57.1 \%$ \\
\hline site? $(\mathrm{n}=7)$ & No & $42.9 \%$ \\
\hline Have you ever been injured from falling while working on a & Yes & $28.6 \%$ \\
\hline residential construction site? $(\mathrm{n}=7)$ & No & $71.4 \%$ \\
\hline Do you currently work at heights (roofs, wall and window & Yes & $42.9 \%$ \\
\hline openings, and stairs)? $(\mathrm{n}=7)$ & No & $57.1 \%$ \\
\hline Do you or have you used fall protection equipment while working & Yes & $71.4 \%$ \\
\hline on residential jobsites? $(\mathrm{n}=7)$ & No & $28.6 \%$ \\
\hline \multicolumn{3}{|c|}{ Questions related to technology use and ownership showed that $100 \%$ of the respondents } \\
\hline \multicolumn{3}{|c|}{ have a DVD player and a computer with web access at home (Table 65). All of the respondents } \\
\hline \multicolumn{3}{|c|}{ had completed web based safety training and had participated in an instructor led safety training } \\
\hline \multicolumn{3}{|c|}{ class. These high percentages are most likely due to the fact that this group of respondents were } \\
\hline selected to review the material and have some level of expertise $i$ & ety, & or residential \\
\hline
\end{tabular}


Table 65. Cycle V DVD Recipient Technology and DVD Data

\begin{tabular}{lll}
\hline Do you own a DVD player? $(\mathrm{n}=7)$ & Yes & $100.0 \%$
\end{tabular}

\begin{tabular}{lll}
\hline Have you ever participated in web-based safety training? $(\mathrm{n}=7)$ & Yes & $100.0 \%$
\end{tabular}

$\begin{array}{lll}\text { Do you have a computer with web access at home? }(\mathrm{n}=7) & \text { Yes } & 100.0 \%\end{array}$

\begin{tabular}{llll}
\hline Have you previously completed safety training using a DVD? $(\mathrm{n}=7)$ & Yes & $100.0 \%$
\end{tabular}

\begin{tabular}{lcc}
\hline Have you ever accessed special features on a movie DVD such as & Yes & $85.7 \%$ \\
the Director's Commentary or Deleted Scenes? $(\mathrm{n}=7)$ & No & $14.3 \%$ \\
\hline Have you ever participated in traditional instructor led safety & Yes & $100.00 \%$ \\
training? $(\mathrm{n}=7)$ & &
\end{tabular}

Two new questions were asked that were not asked in the Cycle I DVD questionnaire.

First, if the respondents had reviewed both version 1 and version 2 of the DVD, did the newer version make the needed improvements. All (100\%) of the responses were that the material was much improved and the revisions corrected and addressed all of the deficiencies. The second question was in regards to Disc 1 and Disc 2 having different instructional design architecture. Disc 1 followed the architecture of DVD version 1, in that each hazard was presented as a standalone video segment, with each hazard offering to the student several safe alternatives. Disc 2 reduced the amount of navigation required and combined all hazards from each training module into a single video segment as well as combining all safe alternatives for that hazard into a follow-up single video segment. This was done to reduce time between segments for the student. The respondents when asked which architecture they preferred responded with $83.3 \%$ having no preference and $16.7 \%$ preferring Disc 2. 
Suggestions made from the respondents and data collected will be considered by the program team at WVUSHE as future development occurs. One reported concern that was identified in Cycle V evaluation of the DVD as well as in Cycle I was criticism of the narration pace. WVUSHE took this under advisement in the Cycle I evaluation but did not have the time or resources to re-record all of the English narration. As the developmental cycles continue into the future the narration will be re-recorded.

Class 15, March 2, 2009, Morgantown, WV. WVUSHE scheduled a training course to be delivered on March 2, 2009 located at the WVUSHE training center in Morgantown, WV. The class was held specifically for a non-profit organization and was not open to the public. This organization is a group that recruits low-income young people ages 16 to 24 work toward their GEDs or high school diplomas and to learn job skills and serve their communities by building affordable housing. This group works locally with Habitat for Humanity to construct homes while learning the residential construction trade. WVUSHE previously conducted a training for this non-profit group. The class included 16 attendees, two of which were supervisors. The class was held for 3 hours.

WVUSHE completed the revision to the PowerPoint training materials as well as the DVD. This class began with the first two modules, "The Problem" and "The Basics of Fall Protection", being presented to the class as stand alone video presentations. Once these two introductory videos were completed the remaining modules were taught using the PowerPoint presentations. These presentations included all of the phases of construction including the new module, "Gutter Installation" and the revised content included in the modules "Foundation Work", "Flooring Work", and "Roofing Work." 
Evaluation data collected during the course included administering a pre and post test to measure knowledge gained as well as a pre and post questionnaire to collect demographic and technology data as well as to evaluate the effectiveness and acceptability of the training to the residential construction industry. The pre questionnaire data included in Table 66. shows that $68.75 \%$ of the students were male and that $55.56 \%$ of them identified themselves as skilled construction laborers with $22.22 \%$ selecting skilled employee (i.e., electrician, plumber). The majority $(88.24 \%)$ selected residential construction as the construction industry in which they work. More than half (56.25\%) have worked in the industry for less than 1 year and $31.25 \%$ between 1 and 5 years. The non-profit organization currently employs that students, which is why the $56.25 \%$ of the students reported that they worked for an employer with between 10 and 20 employees.

Table 66. Cycle V Class 15 Pre Questionnaire Demographic and Injury Data

\begin{tabular}{llc}
\hline Question & Response & Percentage \\
\hline Sex $(\mathrm{n}=16)$ & Male & $68.75 \%$ \\
& Female & $31.25 \%$ \\
\hline Job Title $(\mathrm{n}=18)$ & Supervisor/Foreman & $16.67 \%$ \\
& Employee/Skilled & $22.22 \%$ \\
& Employee/Laborer & $55.56 \%$ \\
\hline Type of Construction $(\mathrm{n}=18)$ & Contractor/Owner & $5.56 \%$ \\
\hline Years Worked in Construction $(\mathrm{n}=16)$ & Residential & $88.24 \%$ \\
& Commercial & $11.76 \%$ \\
& Less than 1 year & $56.25 \%$ \\
& 1 to 5 years & $31.25 \%$
\end{tabular}




\begin{tabular}{llc} 
& 5 to 10 years & $0.00 \%$ \\
& More than 10 years & $12.50 \%$ \\
\hline Number of Employees at your company $(\mathrm{n}=16)$ & 1 employee & $6.25 \%$ \\
& 2 to 5 employees & $6.25 \%$ \\
& 5 to 10 employees & $18.75 \%$ \\
& 10 to 20 employees & $56.25 \%$ \\
& More than 20 & $12.50 \%$
\end{tabular}

The percentage students reported that they had fallen from a height was $18.75 \%$ with $13.33 \%$ reported being injured from a fall (Table 67). Seventy-five percent reported working at heights with $43.75 \%$ using fall protection when at heights.

Table 67. Cycle V Class 15 Pre Questionnaire Fall Injury and Fall Protection Related Data

\begin{tabular}{lcc}
\hline Question & Response & Percentage \\
\hline Have you fallen from heights $(\mathrm{n}=16)$ & Yes & $18.75 \%$ \\
& No & $81.25 \%$ \\
\hline Have you been injured $(\mathrm{n}=16)$ & Yes & $13.33 \%$ \\
\hline Do you work at heights $(\mathrm{n}=16)$ & No & $86.67 \%$ \\
\hline Do you use fall protection $(\mathrm{n}=16)$ & Yes & $75.00 \%$ \\
& No & $25.00 \%$ \\
\hline & Yes & $43.75 \%$ \\
& No & $56.25 \%$
\end{tabular}


In regards to technology questions, $100.00 \%$ own at least one DVD player and $87.50 \%$ had accessed the special features of a DVD (Table 68). Nearly all have a computer at home (93.75\%) with $86.67 \%$ having a computer at work. Seventy-five percent have web access on their home computer and $86.67 \%$ have Internet access at work. Of the 16 students surveyed, $87.50 \%$ report that they use the computer either at home or work. Only $25 \%$ had completed web based training.

Table 68. Cycle V Class 15 Pre Questionnaire - Technology \& Training

Question $\quad$ Response Percentage

\begin{tabular}{|c|c|c|}
\hline Number of DVD Players owned? $(n=16)$ & 0 & $0.00 \%$ \\
\hline & Own 1 & $12.50 \%$ \\
\hline & Own 2 & $50.00 \%$ \\
\hline & Own 3 or more & $37.50 \%$ \\
\hline Have used Special Features on DVD? $(n=16)$ & Yes & $87.50 \%$ \\
\hline & No & $12.50 \%$ \\
\hline Have Computer at Home? $(n=16)$ & Yes & $87.50 \%$ \\
\hline & No & $12.50 \%$ \\
\hline Web Access at Home? $(n=16)$ & Yes & $75.00 \%$ \\
\hline & No & $25.00 \%$ \\
\hline Connection Speed at Home? $(\mathrm{n}=16)$ & Dial Up & $6.25 \%$ \\
\hline & Cable & $50.00 \%$ \\
\hline & DSL & $18.75 \%$ \\
\hline & None & $25.00 \%$ \\
\hline Computer at Work? $(\mathrm{n}=16)$ & Yes & $86.67 \%$ \\
\hline
\end{tabular}




\begin{tabular}{lll} 
& No & $13.33 \%$ \\
\hline Web Access at Work? $(\mathrm{n}=16)$ & Yes & $86.67 \%$ \\
& No & $13.33 \%$ \\
\hline Do you use the computer? $(\mathrm{n}=16)$ & Yes & $86.67 \%$ \\
& No & $13.33 \%$ \\
\hline Computer Skills Self Assessment? (n=16) & First Time User & $0.00 \%$ \\
& Beginner & $12.50 \%$ \\
& Intermediate & $68.75 \%$ \\
\hline Ever complete Web-Based training? (n=16) & Advanced & $18.75 \%$ \\
\hline Participated in Instructor Led training? (n=16) & Yes & $12.50 \%$ \\
& No & $87.50 \%$ \\
\hline Completed Safety Training on Other? Topics $(\mathrm{n}=16)$ & Yes & $25.00 \%$ \\
& No & $75.00 \%$ \\
\hline
\end{tabular}

The post training questionnaire reported positive results with $87.50 \%$ of the students responding that the design features of the training was "Excellent" or "Good" (Table 69). In asking about how well the training addressed fall hazards, $62.50 \%$ reported that the training "Always" or "Often" represented the hazards as they would be encountered on a construction site. Similarly $100 \%$ of the students said that the safe alternatives offered in the training were applicable in the real world of construction. These students reported that $93.75 \%$ would "Always" or "Often" make use of the training material on the jobsite. When asked to compare 
this training to other safety training that they had received, $81.25 \%$ rated it as "Excellent" or "Good" in comparison.

Table 69. Cycle V Class 15 Post Training Questionnaire

\begin{tabular}{|c|c|c|}
\hline Question & Response & Percentage \\
\hline \multirow[t]{3}{*}{ Design Features of the training delivered $(n=16)$} & Excellent & $62.50 \%$ \\
\hline & Good & $25.00 \%$ \\
\hline & Satisfactory & $12.50 \%$ \\
\hline Did the training address fall hazards that would be & Always & $31.25 \%$ \\
\hline \multirow[t]{4}{*}{ encountered on a residential construction site $(n=16)$} & Often & $31.25 \%$ \\
\hline & Sometimes & $31.25 \%$ \\
\hline & Rarely & $0.00 \%$ \\
\hline & Never & $6.25 \%$ \\
\hline Were the safe alternatives applicable in the field & Yes & $100.00 \%$ \\
\hline$(n=16)$ & No & 0.00 \\
\hline To what extent will you make use of this training & Always & $37.50 \%$ \\
\hline \multirow[t]{2}{*}{ material in the field $(n=16)$} & Often & $56.25 \%$ \\
\hline & Sometimes & $6.25 \%$ \\
\hline \multirow[t]{4}{*}{ This training compared to others $(\mathrm{n}=16)$} & Excellent & $62.50 \%$ \\
\hline & Good & $18.75 \%$ \\
\hline & Satisfactory & $6.25 \%$ \\
\hline & $\mathrm{N} / \mathrm{A}$ & $12.50 \%$ \\
\hline
\end{tabular}


A paired-samples t-test revealed significant differences in the residential fall protection skills scores before and after the training, $\mathrm{t}(15)=-2.660, \mathrm{p}<.05$ (Table 70 ). This indicates that the mean fall protection score after the training $(\mathrm{M}=.7375)$ was significantly higher than the mean before the training $(\mathrm{M}=.4875)$.

Table 70. Cycle V Class 15 Pretest to Posttest Paired T Test

\begin{tabular}{|c|c|c|c|c|c|c|}
\hline \multicolumn{7}{|c|}{ Paired Samples Statistics } \\
\hline \multicolumn{3}{|r|}{ Mean } & \multirow{2}{*}{$\begin{array}{l}\mathrm{N} \\
16\end{array}$} & Std. Deviation & \multicolumn{2}{|c|}{ Std. Error Mean } \\
\hline \multirow[t]{2}{*}{ Pair 1} & PreTest & .4875 & & .17842 & \multicolumn{2}{|c|}{.04460} \\
\hline & PostTest & .7375 & 16 & .27049 & \multicolumn{2}{|c|}{.06762} \\
\hline \multicolumn{7}{|c|}{ Paired Samples Correlations } \\
\hline & & $\mathrm{N}$ & \multicolumn{2}{|c|}{ Correlation } & \multicolumn{2}{|c|}{ Sig. } \\
\hline Pair 1 & $\begin{array}{l}\text { PreTest \& } \\
\text { PostTest }\end{array}$ & 16 & \multicolumn{2}{|c|}{-.376} & \multicolumn{2}{|c|}{.151} \\
\hline \multicolumn{7}{|c|}{ Paired Samples Test } \\
\hline & & \multicolumn{5}{|c|}{ Paired Differences } \\
\hline & & & Std. & Std. Error & \multicolumn{2}{|c|}{$\begin{array}{c}95 \% \text { Confidence } \\
\text { Interval of the } \\
\text { Difference }\end{array}$} \\
\hline & & Mean & Deviation & Mean & Lower & Upper \\
\hline Pair 1 & PreTest - PostTest & -.25000 & .37594 & .09399 & -.45033 & -.04967 \\
\hline \multicolumn{7}{|c|}{ Paired Samples Test } \\
\hline & & \multicolumn{2}{|c|}{$\mathrm{t}$} & $\mathrm{df}$ & \multicolumn{2}{|c|}{ Sig. (2-tailed) } \\
\hline Pair 1 & PreTest - PostTest & \multicolumn{2}{|l|}{-2.660} & 15 & \multicolumn{2}{|c|}{.018} \\
\hline
\end{tabular}

Summary of Cycle $V$

Cycle V included the first revision of the DVD to include all changes that had occurred to the PowerPoint presentations over the previous 4 cycles as well as a complete revision of the PowerPoint presentations (Table 71). This required a great deal of effort to reproduce the video and audio content and to author the DVD. There were technological obstacles that were 
overcome to reproduce the DVD, and these obstacles did delay the release of version 2.0. The revisions included adding content to three training modules, revising the introductory "The Problem" video and the creation of a new video segment entitled "The Basics of Fall Protection." In addition to a total revision of the DVD, all PowerPoint material was revised to match the changes to the DVD. Also, the majority of the "animated" text boxes were made fixed based on instructor feedback. It was also determined to embed "The Problem" and "The Basics of Fall Protection" into an introductory set of slides that overviews the whole course instead of offering PowerPoint versions of the two video segments.

The feedback from the reviewers of the DVD were positive with $100 \%$ of the respondents acknowledging that version 2.0 of the DVD was much improved compared to version 1.0. As in the first version, the respondents accepted the hazard and safe alternative content as applicable useable to the industry. All respondents also accepted the design features of the DVD as either "Excellent" or "Good".

Table 71. Summary of Cycle V Design Decisions, Implementation and Revisions

\begin{tabular}{llll}
\hline \multicolumn{2}{l}{ Design Decisions } & Implementation & Revisions \\
\hline 1. & Text boxes added made fixed & Curriculum delivered to one & Minor content corrections \\
& on the slides (non-animated). & class using PowerPoint as & identified that were \\
& primary delivery medium. & included in PowerPoint's \\
& & Feedback from the classes & Based on feedback on \\
\hline 2. "Problem with Falls" reedited & and instructor verified & DVD the video segments \\
& PowerPoint version removed & training was applicable to the & will be combined to \\
and video embedded in & industry and was accepted as & reduce the breaks in \\
\hline
\end{tabular}




\begin{tabular}{llll}
\hline $\begin{array}{l}\text { introductory PowerPoint } \\
\text { presentation. }\end{array}$ & feasible to implement in the & content. \\
\hline 3. & "Basics of Fall Protection" & Pre and Posttests resulted in & Spanish translation needs \\
video segment developed. & significant knowledge gain. & recorded and included for \\
Video embedded in & & new content areas. \\
introductory PowerPoint & & \\
presentation. & & DVD distributed to select & Material needs to be \\
\hline DVD completely revised to & D. & made available online \\
include all changes of Cycles II & audience of reviewers for & once approved by OSHA. \\
through IV. & analysis prior to mass & \\
& distribution. &
\end{tabular}

\section{Summary of All Developmental Cycles}

Fifteen instructor led training sessions were delivered between February 2007 and March 2009 (Table 72). This section will review the data collection at each of the training sessions and the redevelopment that took place throughout the process based on student feedback, evaluations, pre and post tests, qualitative data collected by the instructor, training interviews and student interviews. 
Table 72. Training Classes by Developmental Cycle

\begin{tabular}{|c|c|c|c|c|}
\hline Date & & Location & Hours & Total Trained \\
\hline & & Cycle I & & \\
\hline 1 & $2 / 19 / 07$ & Morgantown, WV & 3 & 22 \\
\hline \multirow[t]{2}{*}{2} & $2 / 27 / 07$ & Martinsburg, WV & 3 & 13 \\
\hline & & Cycle II & & \\
\hline 3 & $5 / 19 / 07$ & Chesapeake, VA & 4 & 11 \\
\hline 4 & $9 / 18 / 07$ & Charleston, WV & 3 & 9 \\
\hline 5 & $9 / 24 / 07$ & Morgantown WV & 3 & 19 \\
\hline 6 & $9 / 28 / 07$ & Washington DC & 3 & 21 \\
\hline \multirow[t]{2}{*}{7} & $10 / 9 / 07$ & Harrisburg, PA & 3 & 23 \\
\hline & & Cycle III & & \\
\hline 8 & $12 / 19 / 07$ & Uniontown, PA & 3 & 31 \\
\hline 9 & $12 / 19 / 07$ & Uniontown, PA & 3 & 28 \\
\hline 10 & $1 / 25 / 08$ & Uniontown, PA & 3 & 36 \\
\hline 11 & $1 / 25 / 08$ & Uniontown, PA & 3 & 40 \\
\hline \multirow[t]{2}{*}{12} & $2 / 7 / 08$ & Morgantown, WV & 4 & 9 \\
\hline & & Cycle IV & & \\
\hline 13 & $8 / 4 / 08$ & Roanoke, VA & 4 & 29 \\
\hline \multirow[t]{2}{*}{14} & $8 / 7 / 08$ & Roanoke, VA & 4 & 26 \\
\hline & & Cycle V & & \\
\hline \multirow[t]{2}{*}{15} & $3 / 2 / 09$ & Morgantown, WV & 3 & 16 \\
\hline & & Totals & 49 & 333 \\
\hline
\end{tabular}


As a review, Cycle I utilized the grant developed and approved material with delivery through the use of the interactive DVD. The acceptability and applicability of the training by the students was very positive in addressing training design, applicability, and usability on the jobsite. Additionally, the pre and post test results showed significant increase in knowledge. The primary source for change to the delivery method came from the instructor, who felt that utilizing the DVD with narration hampered the delivery of content.

Cycle II transferred the primary delivery medium to the PowerPoint material and this was utilized for the majority of the training completed. Similar to Cycle I the feedback from evaluations of the training was overwhelmingly positive in regards to applicability to the real world and the student's intentions on using this material when back on the construction site. With small exception the pre and posttests again proved that there was knowledge gained during Cycle II. Additionally, a small group of students completed a post-post test, which showed that the knowledge was retained from the training. Furthermore, post site field observations and fall hazard audits resulted in 2 of the 3 jobsites reporting fall hazards on par with contractors that had implemented very comprehensive fall hazard management programs. There was one exception, which was a site audit of a roofing contractor that scored an unacceptable fall hazard score post training, although it was noted that none of the trainees were working on site.

Cycle III was a transitional cycle where WVUSHE worked to develop new modules specifically for a client, which resulted in adding some of those additions to the curriculum. The data collected within this module included a pre and post field observation and fall hazard audit of the same company including employees that participated in the training. The result was a significant increase in fall hazard control on the construction site post training. The third class during this cycle received the customized training developed for the client. This class was made 
up of youth 16 to 24 years old with the majority having less than one year of construction experience. The group feedback on the training was very positive including applicability and plans for future use on the construction but the pre an post test results did not show a significant increase or knowledge gain.

Cycle IV made changes to the look and feel of the PowerPoint material by adding text boxes with key words to point the instructor to the discussion point on the photograph. Two groups received this training. Both groups were vocational education teachers and the training was integrated into a larger OSHA training course provided by WVUSHE. As typical of the feedback from the previous training, the feedback on applicability and usefulness of the training was very positive, but the pre and posttests did not show significant knowledge gain during the training. Three conditions could have caused this. First, both classes utilized an instructor that had not delivered the material previously. Second, the class had never been delivered within a larger OSHA course. Third, evidence within this study suggests that the training is not as effective for groups that are not in this industry.

Cycle V, based on data collected from all previous cycles included the first revision of the DVD since its original development in cycle I. This included the addition of two new training modules and numerous editorial corrections identified throughout the four previous cycles. The PowerPoint material was revised to match the revisions made to the DVD. A final revision of the text boxes was made to the PowerPoint slides as well as a reduction in redundancy of similar slides across modules was completed. This revised material was delivered on March 2, 2009 in Morgantown, WV. This group was a non-profit organization teaching youth ages 16 to 24 a construction trade. 
The evaluation data collected from the courses showed that the training material was residential construction specific and was accepted by those in the industry as being applicable on the jobsite. The students reported that they would make use of this material after completion of the training. The pre to posttest results showed significant knowledge gain in the area of fall protection.

The revised DVD was distributed to 11 individuals for review. These individuals included residential construction supervisors, company owners, safety trainers, and safety professionals in the residential construction industry. The revised DVD was also accepted as applicable to the industry and the safe alternatives were reported back as practical for implementation on the worksite.

There were five developmental cycles that emerged as this training was delivered (Table 73). The majority of the developmental changes that were made throughout the five cycles were to the PowerPoint material as this was the primary delivery medium beginning in Cycle II. There were only 2 developmental cycles for the DVD format due to the overwhelming amount of work that shooting the video, recording narration, editing both video and audio and producing the DVD entails and also because the core content did not change significantly within the PowerPoint. The DVD cycles were in Cycle I and Cycle V. The major changes to content did take place for both the PowerPoint and the DVD in Cycle V, which was a result of the cumulative evaluation of all previous developmental cycles and data collected. 
Table 73. Summary of All Cycles I through V Design Decisions, Implementation and Revisions

\begin{tabular}{|c|c|c|c|}
\hline Cycle & Design Decisions & Implementation & Revisions \\
\hline 1. & $\begin{array}{l}\text { Curriculum developed to meet OSHA grant } \\
\text { requirements in PowerPoint and DVD } \\
\text { format. }\end{array}$ & $\begin{array}{l}\text { Curriculum delivered to two classes } \\
\text { using the DVD as primary delivery } \\
\text { medium. } \\
\text { Training applicable to and accepted by } \\
\text { the industry. } \\
\text { Significant knowledge gain in classes. } \\
500 \text { DVD's distributed through website. } \\
\text { DVD applicable and accepted by } \\
\text { industry. } \\
\text { DVD results in nearly } 700 \text { additional } \\
\text { trained. }\end{array}$ & No content revisions made. \\
\hline 2. & $\begin{array}{l}\text { Curriculum delivered with PowerPoint as } \\
\text { delivery medium }\end{array}$ & $\begin{array}{l}5 \text { classes taught. } \\
\text { Training applicable to and accepted by } \\
\text { the industry. } \\
\text { Significant knowledge gain / retention. } \\
\text { Training having impact on jobsite. }\end{array}$ & No content revisions made. \\
\hline 3. & $\begin{array}{l}\text { Content revised and added to meet client } \\
\text { request }\end{array}$ & 5 classes taught. & $\begin{array}{l}\text { Elements of client requested new } \\
\text { content added into regular } \\
\text { curriculum. }\end{array}$ \\
\hline
\end{tabular}


Training applicable to and accepted by

the industry.

Training had impact on jobsite safety.

Knowledge gain not significant in 1

class.

4. Addition of content from Cycle III added to training modules.

Animated text boxes added to aid instructor in covering key points.
2 classes taught by 2 new instructors. Audience: VocEd teachers.

Training applicable to and accepted by the industry.

Knowledge gain not significant

immediately following training.

\section{Revisions identified in Cycle IV included in 1 class taught.}

revisions.

Complete revision of DVD.

Complete revision of PowerPoint to match DVD.

Creation of 2 new video segments.
Training applicable to and accepted by the industry.

Knowledge gain significant.

DVD distributed to select audience of reviewers for analysis prior to mass distribution.

DVD applicable and accepted by industry.
Animated text boxes made fixed in slide.

Repetition across training modules corrected.

Minor content corrections

identified in PowerPoint's. DVD video segments combined to reduce breaks in content. Spanish translation needs included for new content areas. Material needs to be made available online once approved by OSHA. 


\section{Chapter 5 \\ Conclusions \\ Research Questions}

A case study was used to conduct a Type I developmental research project that included both qualitative and quantitative data collection and analysis from multiple designimplementation-evaluation cycles. This research design sought to answer three research questions.

Research Question 1. Does the training program addressing residential fall hazards and safety bring about individual or group behaviors that may reduce the likelihood of falls from heights on residential construction sites?

More specifically, will the training material developed and its organization of information (hazards and controls demonstrated by phase of construction) increase learner knowledge and have a real impact on how work is completed on the jobsite and how falls are controlled?

The primary test executed in this research to determine knowledge gained in the instructor led training setting was collecting pre and posttests prior to and immediately following the training. This was not completed at every training session due to a variety of site conditions and circumstances that arose. The primary use of this data was to collect all tests to respond to Research Question 1. The intermediate analyses were conduced to evaluate the classes for the purposes of revisions within developmental cycles. A pre and posttest was administered to 166 of the 333 trained students throughout the complete study to measure the student's basic knowledge regarding major areas of residential fall protection (Table 74). A paired-samples ttest revealed significant differences in the residential fall protection test scores before and after the training, $\mathrm{t}(165)=-9.085, \mathrm{p}<.05$. This indicated that the mean fall protection score after the training $(\mathrm{M}=.7528)$ was significantly higher than the mean before the training $(\mathrm{M}=.5484)$. 
Table 74. All Cycles Pretest to Posttest Paired T-Test

\begin{tabular}{|c|c|c|c|c|c|c|}
\hline \multicolumn{7}{|c|}{ Paired Samples Statistics } \\
\hline \multicolumn{3}{|r|}{ Mean } & \multirow{2}{*}{$\frac{\mathrm{N}}{166}$} & Std. Deviation & \multicolumn{2}{|c|}{ Std. Error Mear } \\
\hline \multirow[t]{2}{*}{ Pair 1} & PreTest & .5484 & & .17092 & & .01327 \\
\hline & PostTest & .7528 & 166 & .23528 & & .01826 \\
\hline \multicolumn{7}{|c|}{ Paired Samples Correlations } \\
\hline & & \multicolumn{2}{|c|}{$\mathrm{N}$} & Correlation & \multicolumn{2}{|c|}{ Sig. } \\
\hline Pair 1 & PreTest \& PostTest & \multicolumn{2}{|l|}{166} & .007 & \multicolumn{2}{|c|}{.931} \\
\hline \multicolumn{7}{|c|}{ Paired Samples Test } \\
\hline & & \multicolumn{5}{|c|}{ Paired Differences } \\
\hline & & \multirow[b]{2}{*}{ Mean } & \multirow{2}{*}{$\begin{array}{c}\text { Std. } \\
\text { Deviation }\end{array}$} & \multirow{2}{*}{$\begin{array}{c}\text { Std. Error } \\
\text { Mean }\end{array}$} & \multicolumn{2}{|c|}{$\begin{array}{c}95 \% \text { Confidence } \\
\text { Interval of the } \\
\text { Difference }\end{array}$} \\
\hline & & & & & Lower & Upper \\
\hline Pair 1 & PreTest - PostTest & -.20440 & .28987 & .02250 & -.24882 & -.15998 \\
\hline \multicolumn{7}{|c|}{ Paired Samples Test } \\
\hline & & \multicolumn{2}{|c|}{$\mathrm{t}$} & $\mathrm{df}$ & \multicolumn{2}{|c|}{ Sig. (2-tailed) } \\
\hline Pair 1 & PreTest - PostTest & \multicolumn{2}{|l|}{-9.085} & 165 & \multicolumn{2}{|c|}{.000} \\
\hline
\end{tabular}

Additionally, when asked in the post training questionnaire, "How this training compared to others they had taken?" $45.16 \%$ rated the training as "Excellent" and $45.16 \%$ as "Good" in comparison to other training. WVUSHE made a concerted effort to develop this content to be uniquely industry specific, which resulted in positive feedback on the applicability and potential future usability of the training throughout all development cycles.

In determining if this training reduced the likelihood of falls on residential construction sites, post training fall hazard audits were conducted on four construction sites. Three of those four construction sites had workers and supervisors on site that had attended the training. All three of the resulting fall hazard audits resulted in a fall hazard summary score that was comparable to contractors from another research study conducted by WVUSHE, who had 
participated in an 18 month intensive fall hazard management program and were considered acceptable in the control of fall hazards (Becker, et al., 2008). This score represents the percentage of fall hazards that are being controlled on the construction site. Additionally, two fall hazard audits were conducted of one contractor that resulted in a pre training audit score of $42.59 \%$ to a post training fall hazard audit score of $83.80 \%$. The on-site hazard data collected lends evidence that the training did reduce the incidence of fall hazards, thus had the potential to result in fewer falls from heights.

Post training questionnaires further validated that this training had the potential to reduce fall hazards. The majority of the students agreed that the fall hazards presented in the training represented hazards that they would experience on the jobsite (36\% Always and 45\% Often). Similarly, the students agreed that the safe alternatives to those hazards were applicable and useable on the construction site (95.04\% responded "Yes"). Most importantly, 83\% reported that they would "Always" or "Often" make use of the training on the construction site after the training, with $15 \%$ reporting that they will "Sometimes" make use of the training material.

Three student interviews were conducted approximately seven months after training. These interviews verified that the training was being utilized on the construction site and that the workers recalled content that was taught in the classroom. One worker said, "every time I am on a foundation wall I remember that you said it is OK to walk the wall but you have to protect impalement hazards." The fact that the interview took place seven months after the training and the individual paraphrased something that was said in the training validated some level of retention of knowledge. This same worker also asked for additional copies of the DVD, for his fellow workers. These workers re-verified in the interviews that they had made use of the training on the worksite in the 7 months in between the training and the interview. 
Four workers completed post posttests approximately seven months after they completed training. The post posttest scores were not significantly different than the posttest completed immediately after the training. This would indicate that the workers retained the information from the classroom seven months earlier.

This combination of data shows that the training was applicable to the residential construction worker and that the students took this knowledge with them to the construction site, which would lead them to work safer when at heights which should reduce their likelihood of falling from a height.

Research Question 2. Does the technology-based availability and delivery of this training material increase trainee interest?

More specifically, does the utilization of new technologies (interactive DVD, material made available through the Internet) for safety training in residential construction to deliver the training material increase the trainee's interest in the program and in turn have the potential to reach and impact more of the impacted population?

The original intent of the training program was to reach residential construction workers, supervisors and employers not only through the classroom and the instructor led classes but also through the website and thus through self-guided learning. This would have taken place either by reviewing or downloading the content online or by ordering the DVD for self-guided learning.

The result was that no construction workers requested the DVD. Nearly all who requested the DVD were safety trainers, safety consultants, safety directors or some other safety and health professional. In comparing the access to the Internet and technology and familiarity with items such as the DVD player, the personal computer and web access the residential construction 
employees, supervisors, and owners that attended the instructor led classes had very similar access and knowledge as the safety professionals and "others" that requested the DVD set from the website (Table 75). Availability and understanding of the technology was not the hindrance that stopped these individuals from seeking the material out.

Table 75. Technology Comparison of Instructor Led Students and DVD Recipients.

\begin{tabular}{lll}
\hline Technology Questionnaire & Instructor Led Class Students & DVD recipients $(72.54 \%$ \\
Responses & $(86 \%$ residential construction & safety and health \\
& workers, supervisors, owners $)$ & professionals, $1.96 \%$ \\
& construction \\
& foreman/supervisor $)$
\end{tabular}

\begin{tabular}{lll}
\hline Own at least 1 DVD Player & $98.59 \%$ & $95.45 \%$
\end{tabular}

\begin{tabular}{lll}
\hline Have accessed special features $74.45 \%$ & $61.36 \%$
\end{tabular}

on DVD

$\begin{array}{ll}\text { Computer with Web access at } \quad 82.73 \% & 93.18 \%\end{array}$

Home

\begin{tabular}{lcl}
\hline High Speed Internet Access & $65.19 \%$ & - \\
\hline Computer at Work & $74.29 \%$ & - \\
\hline Internet at Work & $72.66 \%$ & - \\
\hline Use the Computer & $85.11 \%$ & $81.40 \%$ \\
\hline Completed Web Based & $38.85 \%$ & \\
Training & & \\
\hline
\end{tabular}


The safety and health professionals do have more access to a computer and the Internet at work and typically work from a desk, where construction workers have computers at the worksite but do not often have time or access to the computer. Thus, construction workers typically access the Internet at home on their personal time, which may decrease their interest in seeking out work related information on the Internet. Consequently, the Internet availability of this product did not directly increase their interest in this product from the residential construction community. Anecdotally though, through conversations with the attendees in the classroom, the DVD increased and held their interest during the training sessions. This perception was validated in the response to the post-training questionnaire asking the attendees if they liked the design layout of the training. This was in regards to the layout of the training by construction phases and the use of demonstrating unsafe conditions then safe alternatives those unsafe conditions. The response to this question for all of the training sessions was that $44.80 \%$ of the students responded that the design of the training was "Excellent" and $48.80 \%$ reported that it was "Good." This verifies the instructor's perception that the use of technology in the classroom increased the learner's interest in the content. Additionally there were several written comments on the post evaluations that stated that this was the best training on this topic that they had ever received and that they appreciated that the training was designed specifically for residential construction and was not just a regurgitation of OSHA standards.

Determining if the availability of the training material on the Internet increased the number of individuals reached was a different question. Those who requested the DVD primarily had the intention of training others with the training material. In fact, $62.91 \%$ of those who requested the DVD and responded to the questionnaire reported that their intention was to train clients, contractors, or employees while only $14.52 \%$ reported that they requested the 
DVD for self-guided learning. Of the 15 DVD recipients that reported that they trained others with the training material and that tracked how many they trained, reported a total of 646 individuals trained with the DVD material. Several others reported that they did not know how many they had trained or that they planned to use the DVD to conduct training in the future.

The availability of the training increased student interest and increased the number reached with the training material. The goal to directly reach the residential construction workers, supervisors and owners through the Internet was not successful but indirectly, the Internet did broaden the reach.

Research Question 3. Does including residential construction worker, supervisor and expert feedback into the developmental cycle of training development impact the relevance and acceptability of the residential fall protection training material?

More specifically, does the developmental research model of multiple iterations of development, implementation and evaluation, result in a training program with more relevance and residential construction community (worker, supervisor, owners, experts) acceptability? In particular, will the feedback after each cycle of the training impact the quality of the final training product of the following cycle of training?

From the perspective of the curriculum developer and primary deliverer of the training, the developmental cycles improved the training material and the delivery of the training material and made the material more relevant and acceptable to the audience. The training was originally developed by individuals with experience in this industry and also included an industry focus group to help guide the initial developmental decisions. For these reasons, the improvements, through developmental cycles may not have always been verified by the student data collected.

The instructor feedback and informal data collected from the students by the instructor 
provided a great deal of data for developmental change. It was identified that the post evaluative data questionnaire collected from each developmental cycle had a somewhat limited value in making developmental changes, because the ratings were high throughout all cycles, with very few suggestions for change made. The suggestions and critiques that were received were evaluated and implemented when applicable and possible. The in class students rated the training, design, and applicability to the field as highly acceptable and appropriate. This could have been because the original content was developed with the deliberate intention of reaching this specific group.

On the contrary though, the feedback from the DVD through the web requests, although still rated very positive, included more detailed suggestions and critiques of the material. This was more beneficial for making revisions to content and improved the DVD and in-class material. This difference may have been due to the fact that these individuals were more likely to be critical because the evaluation of the training material was done remotely, not in person. In addition, the feedback from the instructors on changes to content from Developmental Cycle IV addressing instructional design and delivery issues helped identify the need for clearer instructions for those who would use the material to train others.

Additionally, a one-way analysis of variance was conducted to evaluate the relationship between the developmental cycles and the change in test scores. The independent variable, the developmental cycle factor, included five levels: Cycle I, Cycle II, Cycle III, Cycle IV, and Cycle V. The dependent variable was the change in tests scores from pretest to posttest. The ANOVA was significant $\mathrm{F}(4,161)=6.61, \mathrm{p}=<.001$ (Table 76). There was a relationship between the developmental cycles and the change in test scores as assessed by $\eta^{2}$, with the developmental cycles factor accounting for $24.1 \%$ of the variance of the dependent variable. 
Follow-up tests were conducted to evaluate the pairwise differences among the means. The test of homogeneity of variance was significant, $p=<.001$ so we chose to assume unequal variances and conducted post hoc comparisons using the Tukey test. The means of developmental cycles III and IV were significantly different than the means of developmental cycles I, II, and V.

Table 76. Differences Among Test Scores by Developmental Cycle.

Dependent Variable: Difference in tests scores from pre test to posttest

\begin{tabular}{lccr}
\hline Developmental Cycle & Mean & Std. Deviation & N \\
\hline 1 & .2626 & .19996 & 33 \\
\hline 2 & .3512 & .20271 & 56 \\
\hline 3 & -.0750 & .26049 & 8 \\
\hline 4 & .0440 & .29080 & 53 \\
\hline 5 & & & 16 \\
\hline Total & .2500 & .37594 & 166
\end{tabular}

This quantitative analysis correlated with the qualitative and quantitative data collected throughout all cycles. Developmental cycle III was, as described a transitional cycle that introduced new information into the training curriculum as requested by a specific client. Developmental cycle IV incorporated elements of the curriculum added in Cycle III for delivery to the public and also included the first use of instructors to teach the course that had never delivered previously delivered the curriculum. More globally, this analysis verified that the knowledge gained by the students was correlated to the developmental cycles. 
Finally, the developmental cycle was used to evaluate the effectiveness of the training and make ongoing changes. The instructor was always aware that the training material could always be improved. As all of the data collected was triangulated, the developmental process provided the needed information for redevelopment. Often in worker training, these efforts are not taken due to time constraints and lack of understanding of these processes or lack of interest in making changes to "stock" curriculum. Elements of this developmental cycle will continue to be used within WVUSHE training programs.

\section{Implications for Training Material Development}

\section{Use of Work Specific Content by Phase of Work}

Literature evaluating the effectiveness of training developed specifically for residential construction was limited. Several state agencies developed and delivered fall protection safety training for residential construction workers but resulting data was not reported ("Washington State," 2005). One study developed training for small construction companies addressing fall and back injuries. A result was that the employees found the training realistic but not particularly applicable to their work (Wojcik, et al., 2003). A conclusion was that including worker and supervisor feedback into the design of the training material would make the training more applicable (Wojcik, et al., 2003). The results of this study validated that when effort is made to develop training that is specific to the audience the training will be more accepted by the students and will result in knowledge retention.

Worker safety regulations are not exciting subject matter for instructors or students. The training developed in this study categorized the training by phase of work based on a typical residential construction project. Once these work phases were identified potential fall hazards and safe alternatives were added to the training curriculum. A minimum amount of content was 
delivered to the student in the form of rule or regulation that must be followed. Regulations are not written with the intent that they be developed into an outline for training or teaching; thus, the regulations should be translated into content that is digestible by the audience.

\section{Use of DVD Video for Interactive Training}

No studies were identified that utilized DVD-video as the delivery medium. There were two studies that used multi-media or computer based technology for delivery (Buch, 1989 and Kress, 1990). Neither study concluded or measured the importance of the technology on the outcome. This studies' training program took advantage of the DVD format for the large data capacity that allowed for the inclusion of a large amount of video and data. The DVD requires minimal financial investment to provide an interactive training component through the use of DVD authoring software. The DVD format is created through the use of video editing and DVD authoring software and may include subtitles and multiple audio tracks (languages). This research utilized this media to provide self-guided learning for those not able to attend group training. The cost was minimal and the technology (DVD players) is present in nearly all homes in the U.S. The use of the DVD increased the students' attention and acceptance.

There are limitations to consider when using this format to develop training. First, when developing the interactive DVD consider how the training curriculum will be sequenced in the classroom with the DVD as the primary delivery medium and ensure that the instructor is well versed in navigating the content. Second, develop the content to enhance the instructor's role in the classroom, not to act as a video player to replace the instructor. Finally, consider using the menu structure of the DVD to create activities to keep the students engaged in the learning experience. However, this study did validate the DVD as a viable medium to utilize to conduct training and as a means to disseminate a self-guided multi-media training program. 


\section{Use of Developmental Cycles for Training Programs}

A review of literature identified no studies involving construction workers or fall protection that utilized Type I developmental research. There were two studies identified that included industrial workers and some elements of Type I developmental research. Buch (1989) measured the effectiveness of training delivered to employees. This study only utilized the developmental research process during the design phase of the training curriculum. The study included a control group and concluded that there was a significant difference in knowledge gained by the intervention group compared to the control group. Kress (1990) conducted a study with industrial workers that compared the delivery of the same topic with one utilizing an instructional system design model and the other being delivered non-systematically. The study found no significant difference between the two courses in predicting achievement.

Industrial training is often done to meet regulatory requirements and company policy and is thus often delivered without the thought of continuous improvement. This study concluded that when the complete developmental cycle is implemented into a training program, redevelopment could occur after nearly every class. Frequent redevelopment is not always feasible, but this does identify the need to regularly evaluate the training delivery and curriculum as it is being delivered. It is also important to develop effective tools to measure the training programs effectiveness and acceptability to assist in re-development. Type I developmental research is a form of action research that is conducted by some trainers instinctively, but is not formalized. Trainers should educate themselves on the process to improve the training of workers in the area of safety and health.

Guidelines on Use of Developmental Cycles for Safety Trainers

The developmental research concept incorporates the active analysis of the process of 
developing, delivering and evaluating the training program while conducting these activities, with the results of this data collected being acted upon as the training content is being redeveloped. What follows are guidelines for utilizing these concepts for safety training.

Development. When initially developing a safety training curriculum, document the rationale for the curriculum design decisions. Additional documentation may also be kept for analysis, including notes from meetings with peer trainers and curriculum developers, draft versions of the training material while working toward a final version, regulatory documents, communication with others working on the development team and other pertinent documents.

During development of the training material, it is important to develop data collection tools that will provide the data back to curriculum developer and the trainer to be summarized and analyzed within each developmental phase. Determine what questions that need answered in regards to the training that is being developed. The questions could be specific to the content or to the instructional design method or both. This could include pre and posttests, pre questionnaires and post evaluations of curriculum and instruction. Consider developing an interview protocol that will allow the students to expand on their impressions on the curriculum and training. Post training jobsite checklists could also be developed that correlate with the major points addressed in the training.

Delivery of training. Ensure that the training is conducted as originally designed. Keep notes on changes that are needed in the curriculum as identified by the trainer and the students. Collect the required data using the instruments developed. This could include pre and posttests, demographic data, sign in sheets, and interviews. Although it is often difficult with the transient nature of construction workers, attempt to collect contact jobsite information from the students and to schedule follow up site visits to measure the effectiveness of the training on the worksite. 
The real impact of training that is least often documented is to what extent the knowledge is put to use in the workplace.

Evaluation. All data collected during the delivery of training must be evaluated and analyzed. This data is not limited to the quantitative data collected from the students but also includes qualitative data provided by the trainers and students that can be collected through interviews or document analysis of notes from the instructor.

The resulting collection of data can now be cross analyzed (triangulated) to identify emerging themes. This results in data that will be utilized in redeveloping or revising the training curriculum, which is the point at which the developmental cycle begins again with the Developmental cycle.

\section{Implications for Those Attempting to Reach Workers Through the Internet}

According to the Construction Chartbook (2007) in 2003, 57.1\% of construction workers had computers at home with $48.9 \%$ having Internet access. This study identified that of those that completed the instructor led classes, $94 \%$ had a computer at home with $85 \%$ reporting that they use the computer. Internet access was available to $83 \%$ of those students with $65 \%$ having high speed Internet access (DSL or cable). Ninety-three percent of those that requested the DVD through the website in this study reported that they had a computer with Internet access.

This study developed a website to deliver and market the training developed. When conducting a Google search for "residential construction fall protection" this website was the second search result of 216,000 results available. Even with this availability online no residential construction workers requested the DVD.

This study identified that nearly all construction workers have access to a computer and the Internet although those who needed the training did not seek it out. Those attempting to reach 
construction workers through the Internet should develop content that is compelling, easy to use, entertaining and easily accessible. This may be best achieved by connecting the safety content with web information or social networking sites that the specific worker demographic would most likely visit.

\section{Implications for the Residential Construction Industry}

The OSHA requirement for residential construction companies is to provide fall protection safety training to employees that are exposed to a fall to a lower level of 6 feet or more (OSHA, 2005). OSHA also requires the construction employer to provide the employee with fall protection equipment or other engineering control when exposed.

This study identified that residential construction workers, supervisors, owners and safety professionals scored, on average $55 \%$ on a basic residential fall protection pre-test. This lack of knowledge could lead to workers being exposed to falls, which could lead to an increased risk of injuries and death. This study validates that the training program developed for this study will significantly increase the knowledge of those attending. This gained knowledge will be retained and the attendees will utilize this knowledge on the construction site to work safer.

\section{Limitations of Study}

\section{Data Collection Varied by Course}

Due to the nature of the construction industry and the conditions under which the training courses were scheduled, the amount and type of data that was collected to evaluate the training varied. This was due to several reasons including time limitations of the workers attending the training and requests by employers to not conduct evaluations.

\section{Variability of Participants}

When offering publically held training courses the variability of participants are not in the 
control of the researcher. This study included participants that were typically non-union residential construction workers as well as supervisors, owners and others including college students, and commercial and heavy construction employees.

\section{Limited Feedback for Post-post Exams and Post Interviews from Construction Industry}

There were numerous attempts to contact the training attendees after the classes were completed. Communication attempts resulted in minimal success. The goal was to administer post posttests, post interviews, field observations and site inspections. The transient nature of construction work as well as the high rate of job change in the industry makes this a difficult group to study once they leave the training location. This limited the statistical strength of the tests and the amount of qualitative data that was collected throughout the study period.

\section{Limitation of Students Control Over Workplace Fall Hazard Conditions}

One basic foundation of a safe workplace is to have commitment to safety from the owners and management. The reality of residential construction is that many owners and supervision are not committed to ensuring a safe workplace. This then, leaves those workers that have attended this training with a jobsite to return to where they do not have the power to make the changes needed.

Additionally, individuals working for companies with a lack of commitment to safety may not seek out training because the company would not support the information from the training being implemented on site. The company may also be less likely to pay the employee wages for the time needed to complete training.

These same companies are also less likely to be inspected by an OSHA compliance officer based on the size of the company and on the limited number of OSHA compliance officers per region. This gives these companies less of an incentive to participate in the training 
as compared to larger companies that have a higher probability of being inspected and cited by OSHA.

No Feedback from Industry Experts

In the initial phase of the first training material development grant, WVUSHE held a focus group with experts. This group was very helpful in advising WVUSHE on developing the original training curriculum. Unfortunately, when the curriculum was completed and this expert panel was asked to review the material and complete an expert questionnaire, none of this group responded. Since this group was integral in the original development their feedback had the potential to lend vital recommendations for change in the upcoming developmental cycles. That did not happen due to lack of response from this group of experts.

\section{Future Research}

Evaluate the Effectiveness of the Addition of Hands-on Training to the Training Curriculum

The next iteration of this training will include the addition of a major hands-on component. Several students commented in evaluations and in interviews that hands-on or practical application of the safe alternatives demonstrated would be helpful in training construction workers. A hands-on portable sloped roof has been designed and will be built that will allow students to install and use the fall protection devices described in the classroom. Additionally, the training prop will allow training on the proper use and installation of ladders and scaffolds. This training will be evaluated similarly to the evaluation conducted in this study. Further Improvements of the DVD as a Delivery Medium

Further development of the DVD for use in classroom and self-guided training would benefit and inform the training professionals on best practices. For instance the DVD authoring software would allow for the DVD menu system to be used to conduct in classroom quizzes and 
interactive games.

Links to the website where the DVD is available for order should be linked to other popular worker safety websites such as www.osha.gov and www.cdc.gov/niosh. Many contractors, safety professionals and workers visit these sites for safety and health resources. Exploration of Other, More Current Delivery Mediums to More Effectively Reach Workers

The original concept for this training was conceived in 2003. At that time no other safety and health research group had proposed to develop and evaluate training for dissemination on a DVD. At the time the approach within the safety training community was unique. This research attempted to determine if residential construction workers would use the DVD or seek it out online. Since 2003, other delivery mediums have become more mainstream and should be considered for future dissemination.

Future research should disseminate the training material video segments on "YouTube" and on "iTunes" and evaluate the effectiveness. Universities can distribute podcast versions of the training through iTunesU. There are other video sharing sites that could be considered as well. Additionally, live (synchronous) classes being conducted could be shared through websites like "Ustream" and "Stickam." These websites offer free web video streaming of a wide variety of video content. The web streaming can be embedded on the trainer's website and training sessions can be recorded and streamed asynchronously.

Development of a Train-the-Trainer Program and a Field Based Developmental Cycle Toolkit

Based on the high response rate from safety professionals requesting the DVD training, a formal train-the-trainer program should be developed and delivered to those wanting to use the material to train others. This would better control the quality of the content that is being delivered by those other than the curriculum developers. 
Furthermore a practical toolkit should be developed that will guide industry trainers in developing appropriate evaluation tools to measure the effectiveness of the training delivered and provide instructions on how to redevelop the curriculum based on the outcomes of the training.

\section{Public Safety Outreach}

The ongoing question in the safety research community is "How do we reach the hard-to reach-worker?" Research should be conducted to measure the effectiveness of conducting a public outreach campaign to bring the issue of construction worker injuries and fatalities to the mainstream as other more mainstream public health campaign are conducted. Once the promotion occurs use this new awareness to increase training numbers.

Research should also be conducted on the effectiveness of reaching construction workers through marketing of the courses where they shop for their construction supplies. This could be in the form of traditional marketing through flyers as well as offering in-person demonstrations and training to these individuals at the builder supply stores themselves.

Due to the infrequency of falls on residential construction sites, the reality of the hazard is sometimes hard for the worker to realize. The addition of collecting anecdotal stories of falls from these workers and providing them back to the industry through the existing website may have more of a personal impact and increase attention on the problem.

\section{Development of More Effective Post Training Evaluation Tool}

Traditional worker training evaluation consists of pre and posttests as well as post instructor evaluations including tests, interviews, and site audits. The post data was effective in this training, but research should be conducted on the development of new post evaluative tools that more effectively measure the true impact of the training on the attendee's knowledge, acceptability and injury and hazard reduction. 


\section{Long-term Research to Measure Injury Rates and Site Condition Improvement}

The key to measuring injury and hazard reduction requires the need to conduct long-term research to measure the true effectiveness of training on worker safety. This would require a minimum of three years of post training regular site evaluation and data collection as well as access to injury data from prior to the training. The tracking of where training has been conducted by region as compared to the injury and fatality data for that region may be an additional measureable to determine if the training delivery has reduced injuries and fatalities. This long-term research could also provide a predictive model on the effectiveness of developmental cycles and establish a predicted gain in effectiveness based on the number of cycles implemented.

\section{An Evaluation of Cultural Barriers that Impact Worker Injures and Fatalities}

Research is needed to determine what other cultural barriers impact worker safety. For example, factors other than training material being available in Spanish impact whether or not the training is effective or attended. These factors could be immigration status or whether or not the employer has legally employed the worker. Beyond immigration status, the culture of construction workers in general needs more deeply explored. This would include an ethnographic study of a large group of residential construction workers seeking to identify how they selected residential construction as a career and how the truly feel about safety regulations, working safely, and the risks of being injured or killed. 


\section{REFERENCES}

Becker, P., Fullen, M., Akladios, M., \& Hobbs, G. (2001). Prevention of construction falls by organizational intervention. Injury Prevention, 7(Suppl. 1), 64-67.

Becker, P., Fullen, M., Akladios, M., Carr, M., Lundstrom, W. (2001, February). Use of a Hand Held Computer to Audit Construction Fall Prevention Effectiveness. International Journal of Computer Integrated Design and Construction, Special Issue: Computerized Integrated Safety Management. 3 (1), 16-24.

Becker, P., Morawetz, J. (2004). Impacts of health and safety education: Comparison of worker activities before and after training. American Journal of Industrial Medicine, 46(1), 63-70.

Becker, P., Takacs, B., Fullen, M. (2008, October). Fall Safe: A Management System Using Computerized Audits. Paper presented at the National Occupational Injury and Illness Symposium, Pittsburgh, PA.

Brunette, M. (2005). Development of Educational and Training Materials on Safety and Health Targeting Hispanic Workers in the Construction Industry. Family and Community Health, 28 (3), 253-266.

Buch, E.E. (1989). A systematically developed training program for microcomputer users in an industrial setting. (Doctoral dissertation, University of Pittsburgh, 1988.) Dissertation Abstracts International-A 49 (4), 750.

Census of Fatal Occupational Injuries. (n.d.) Retrieved December 16, 2005, from http://data.bls.gov/PDQ/outside.jsp?survey=fi

The Center to Protect Workers' Rights. (2007, September). The Construction Chart Book: The U.S. Construction Industry and Its Workers, 4th Edition. Silver Spring, MD. 
The Center to Protect Workers' Rights. (2002, September). The Construction Chart Book: The U.S. Construction Industry and Its Workers, $3^{\text {rd }}$ Edition. Silver Spring, MD.

Coyle and Spitzer, 1992 Technology News; Distance Education Project: Extending Extension Programming via Telecommunications Technology; [and] Fax for Library Services. Educational Technology, 32(8), 44,57-60.

Dabbagh, N.H., Jonassen, D.H., Yueh, H., \& Samouilova, M. (2000). Assessing a problem-based learning approach to an introductory instructional design course. A case study. Performance Improvement Quarterly, 13(2), 61-83.

Darragh, A., Stallones, L., Bigelow, P., \& Keefe, T. (2004). Effectiveness of the HomeSafe Pilot Program in Reducing Injury Rates Among Residential Construction Workers. American Journal of Industrial Medicine, 45, 210-217.

Denzin, N.K. (2006). Sociological Methods: A Sourcebook. New Brunswick, NJ. Aldine Transaction.

Dong, X., Entzel, P., Men, Y., Chowdhury, R., \& Schneider, S. (2004). Effects of Safety and Health Training on Work-Related Injury Among Construction Laborers. Journal of Occupational and Environmental Medicine, 46 (12), 1222-1228.

Dong, X., Yurong, M., \& Haile. (2005). Work-Related Fatal and Nonfatal Injuries among U.S. Construction Workers, 1992-2003. The Center to Protect Workers' Rights, Silver Spring, MD.

Dong, X., (2005, November). Safety and Health in Residential Construction. Paper presented at the Construction Economics Research Network meeting on Residential Construction, Silver Spring, MD. 
Fall Protection for Residential Construction. (n.d.). Retrieved December 16, 2005, from http://www.michigan.gov/documents/cis_wsh_12152005_Saginaw_140498_7.pdf

Forsyth, J.E. (1997). The construction and validation of an instructional systems design model for community based train-the-trainer instruction (Doctoral dissertation, Wayne State University), 238 pages

Fenton, B.C. (2003, July). Random Play. Sound \& Vision, 13-14.

Gilkey, D., Hautaluoma, J., Ahmed, T., Keefe, T., Herron, R., \& Bigelow, P. (2004). Construction Work Practices and Conditions Improved After 2-Years' Participation in the HomeSafe Pilot Program. AIHA Journal, 64, 346-351.

Goldenhar, L., Moran, S., \& Colligan, M. (2001). Health and safety training in a sample of openshop construction companies. Journal of Safety Research, 32, 237-252.

Kentucky Department of Labor Occupational Safety \& Health Program 2005 Training Schedule. (n.d.). Retrieved December 16, 2005, from http://www.labor.ky.gov/osh/training/

Kinn, S. (2000). Evaluation of safety orientation and training programs for reducing injuries in the plumbing and pipefitting industry. Journal of Occupational and Environmental Medicine, 42, 1142-1147.

Kress, C. (1990). The effects of instructional systems design techniques on varying levels of adult achievement in technical training (Doctoral dissertation, Wayne State University, 1989). Dissertation Abstracts International-A, 50(11), 3447.

Lipscomb, H., Dement, J., Nolan, J., Patterson, D., Leiming, L., \& Cameron, W. (2003). Falls in Residential Carpentry. Journal of Occupational and Environmental Medicine, 45 (8), 881-890. 
McKenney, S., \& van den Akker, J. (2005). Computer-based support for curriculum designers: A case of developmental research. Educational Technology Research and Development, 53(2), 41-66.

Merriam, S.B., (1998). Qualitative Research and Case Study Applications in Education. San Francisco, CA. Jossey-Bass.

Methner, M., McKernan, J., \& Dennison, J. (2000). Task-Based Exposure Assessment of Hazards Associated with New Residential Construction. Applied Occupational and Environmental Hygiene, 15 (11), 811-819.

Nonfatal cases involving days away from work: selected characteristics. (n.d.) Retrieved December 16, 2005, from http://data.bls.gov/PDQ/outside.jsp?survey=ch

O’Connor, T., Loomis, D., Runyan, C., Abboud dal Santo, J., \& Schulman, M. (2005). Adequacy of Health and Safety Training Among Young Latino Construction Workers. Journal of Occupational and Environmental Medicine, 7 (3), 272-277.

OSHA Awards More Than \$11 Million in Grants for Safety and Health Training Programs. (2002, September 22). Retrieved December 16, 2005, from http://www.osha.gov/pls/oshaweb/owadisp.show_document?p_table=NEWS_RELEASE S\&p_id=1881

Occupational Safety and Health Administration. (2005). 29 CFR 1926 OSHA Construction Industry Regulations. Davenport, IA. Mangan Communications.

Patton, M.Q. (2002). Qualitative Research \& Evaluation Methods (3 ${ }^{\text {rd }}$ ed). Thousand Oaks, CA. Sage. 
Presence of a Computer and the Internet for Households, by Selected Characteristics: October 2003. (n.d.). Retrieved December 16, 2005, from http://www.census.gov/population/socdemo/computer/2003/tab01A.xls

Richey, R.C., Klein, J. \& Nelson, W. (2004) Developmental Research: Studies of Instructional Design and Development. In D. Jonassen (Ed.) Handbook of Research for Educational Communications and Technology (2nd Ed.) (pp. 1099-1130). Bloomington, IN: Association for Educational Communications \& Technology.

Ross, K.R. (1998). Blending authentic work projects and instructional assignments. An adaptation process. Educational Technology Research and Development, 46(3), 67-79.

Shambaugh, N., Magliaro, S. (2001). A Reflexive Model for Teaching Instructional Design. Educational Technology Research and Development, 49(2), 69-92.

Tashakkori, A., \& Teddlie, C. (1998). Mixed methodology: Combining qualitative and quantitative approaches (Applied Social Research Methods Series, Vol. 46). Thousand Oaks, CA: Sage.

Washington State Department of Labor and Industries Training, Courses, Videos and Workshops. (n.d.). Retrieved December 16, 2005, from http:/www.Ini.wa.gov/Safety/TrainTools/default.asp

Wojcik, S., Kidd, P., Parshall, M., \& Struttmann, T. (2003). Performance and evaluation of small construction safety training simulations. Occupational Medicine, 53, 279-286.

Yin, R.K. (2003). Case Study Research: Design and Methods. (3 ${ }^{\text {rd }}$ ed. Applied Social Research Methods Series, Vol. 5). Thousand Oaks, CA. Sage. 


\section{APPENDICES}


Appendix A. Residential Fall Protection DVD Menu System 
Appendix A.
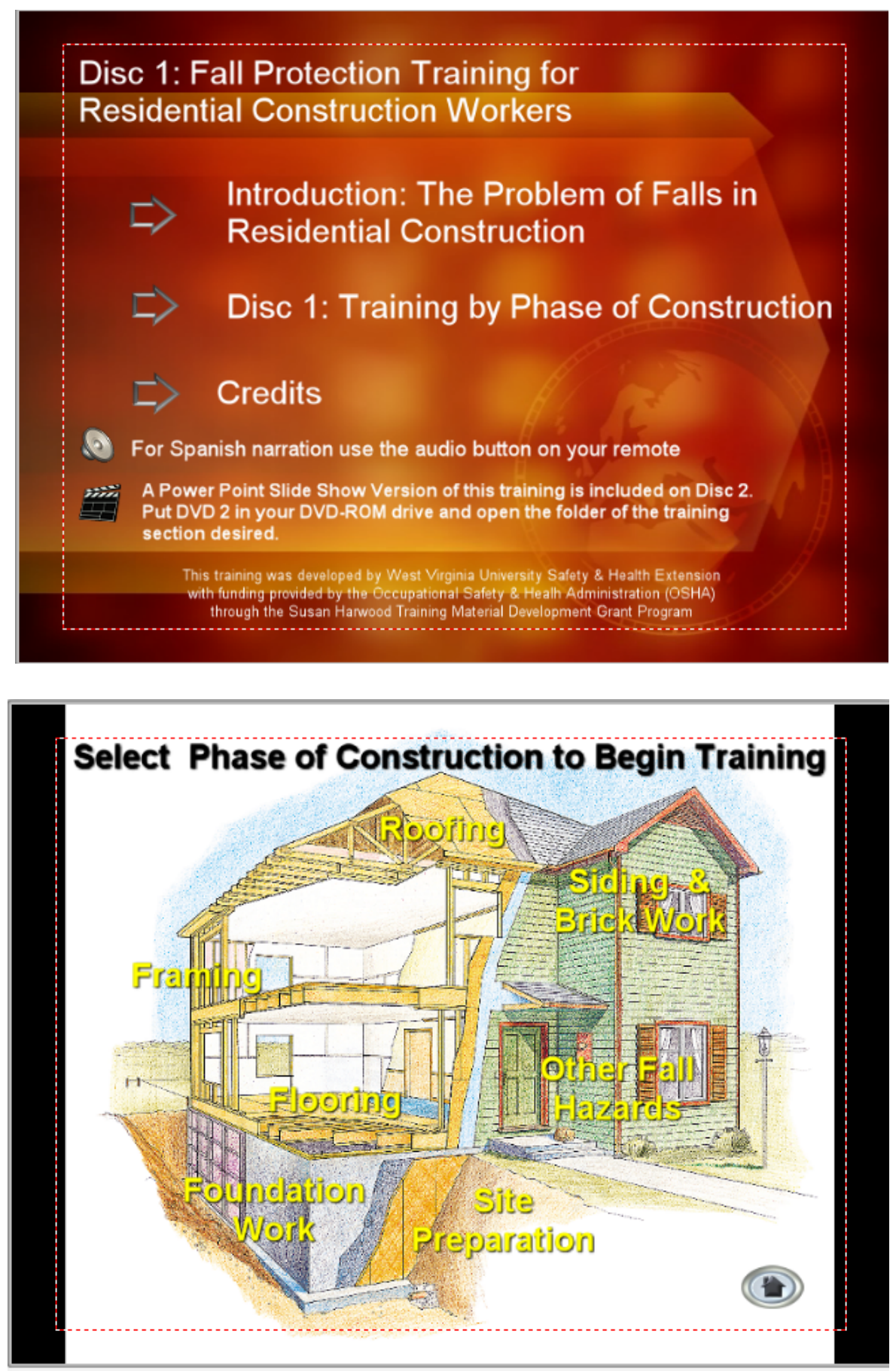
Appendix B. Human Subjects Approval Letter 


\section{Appendix B.}

\section{West VirginiaUniversity}

College of Human Resources and Education

December 21, 2006

\section{MEMORANDUM}
TO: $\quad$ Mark Fullen
FROM: Lynn Cartwright , Interim Associate Dean
RE: Human Resources \& Education H.S. \#2006-067

\section{Title: "The Development of a Task Based Fall Hazard Safety Training Program for Residential Construction Workers"}

Your Application for Exemption for the above-captioned research project has been reviewed under the Human Subjects Policies and has been approved. Attached are the originals of your cover letters with the signed stamp of approval. This must accompany your survey or questionnaire.

This exemption will remain in effect on the condition that the research is carried out exactly as described in the application.

Best wishes for the success of your research.

cc: Deans Office

Student Advising and Records

Neal Shambaugh, Advisor 
Appendix C. Pre Test Cycle I (Instructor Led Classes) 
Appendix C.

\section{Residential Fall Protection Training Pre Test}

1. The cause of the most fatalities on residential construction sites are:

a. Electrocutions

b. Excavation cave-ins

c. Falls

d. Motor Vehicle accidents

2. While working on a foundation wall higher than 6 feet from the ground below, what is the safest way to get from one location on the wall to another?

a. Climb down a nearby ladder and climb a ladder nearest to the work location.

b. Jump off the wall and climb a ladder nearest to the work location.

c. Walk around the top of the wall to the desired location.

d. Jump off the wall and pull yourself back up onto the wall.

3. At what height above the ground below is fall protection required when working along any unprotected edge?
a. 15 feet
b. 10 feet
c. 6 feet
d. 4 feet

4. If you are working on a ladder jack scaffold system and guardrails are not installed what would be the next best solution to prevent a fall?
a. Hook a lanyard off to the house and re hook as you move up or down.
b. Guardrails are not required on ladder jack scaffolds
c. Hook to a rope grab and vertical lifeline that is connected from the roof peak.
d. Hook your lanyard to the ladder rungs above you.

5. What is a safe fall distance from the anchor point to the ground / floor below when using a 6 foot lanyard to tie off?
a. 6 feet
b. 9.5 feet
c. 14 feet
d. 18.5 feet 
6. Select the photo below that shows improper use of a rope grab and vertical lifeline during roofing.

a.

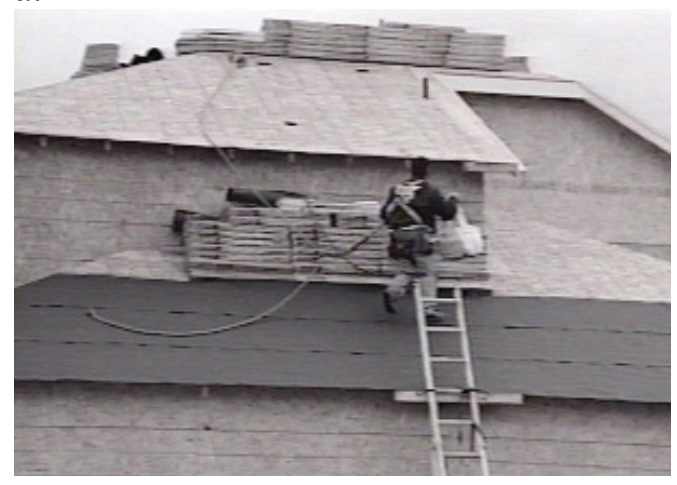

c.

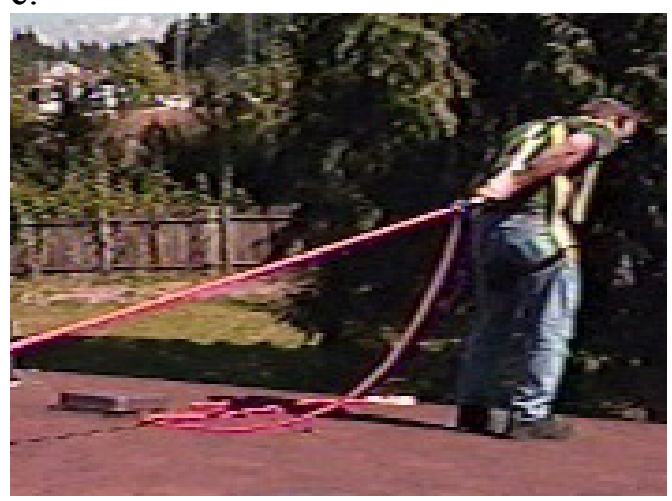

b.

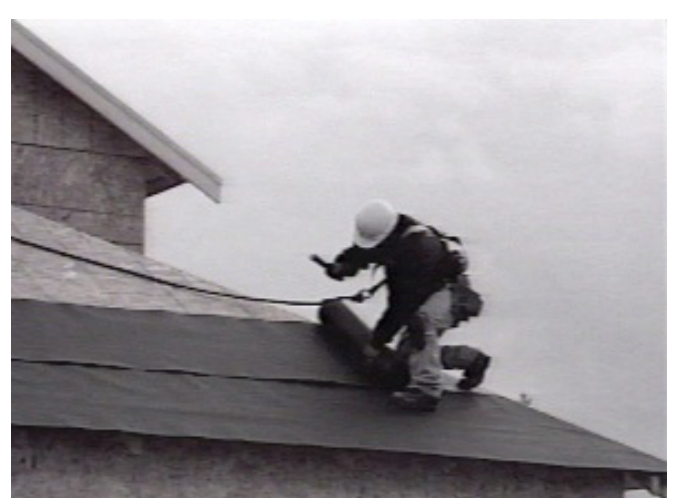

d.

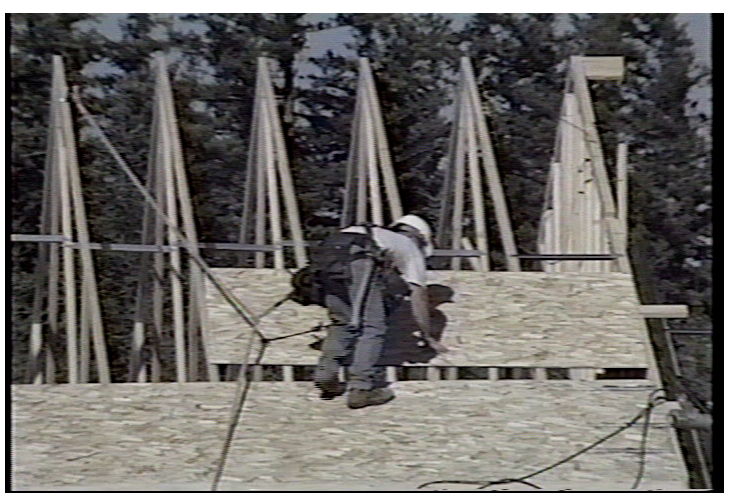


Appendix D. Post Test Cycle I 
Appendix D.

\section{Residential Fall Protection Post Test}

1. While working from a scaffold during foundation work, at what height above the ground are guardrails required to be installed on the scaffolding?
a. 4 feet
b. 6 feet
c. 9 feet
d. 10 feet

\section{True or False}

When working in an aerial lift (manlift) as shown here the guardrails around the basket replace the need for wearing a full body harness and tying off.

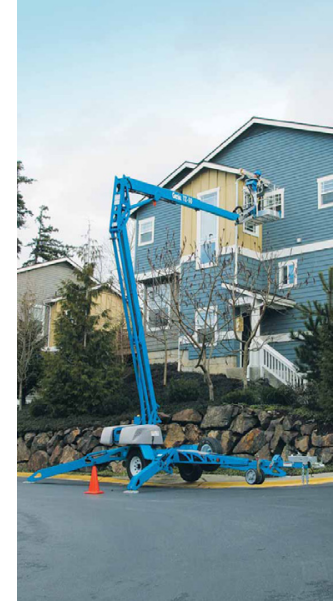

3. While standing up or raising wall sections during framing there is a risk of falling. What would be the preferred safe alternative to prevent a fall?
a. Be sure that there are no trip hazards on the floor that would cause you to trip and fall.
b. Hook a lanyard to the wall that is being raised and connect it to your full body harness.
c. Install an anchor point into the floor behind you and connect it to your harness.
d. Install kickers on the outside of the wall to keep the wall from falling outside the structure.

\section{What is the preferred method to protect you from falling while installing trusses?}

a. Stand on the top plate to receive and secure the trusses as they are hoisted into place.

b. Stand on a scaffold system inside the structure to receive and secure the trusses as they are being hoisted into place.

c. Stand on a ladder that is leaning against the top plate to receive and secure the trusses as they are hoisted into place.

d. Wear a harness, connect your lanyard to an anchor point while standing on the top plate to receive and secure the trusses. 


\section{True or False}

Residential roofers have nearly twice the percentage of fatal falls from ladders compared with all roofing workers.

6. While using a 5 foot wide scaffold (like the one shown here) at what height should this scaffold be secured to the house to ensure that it will not collapse?
a. 5 feet.
b. 10 feet.
c. 20 feet.
d. 30 feet.

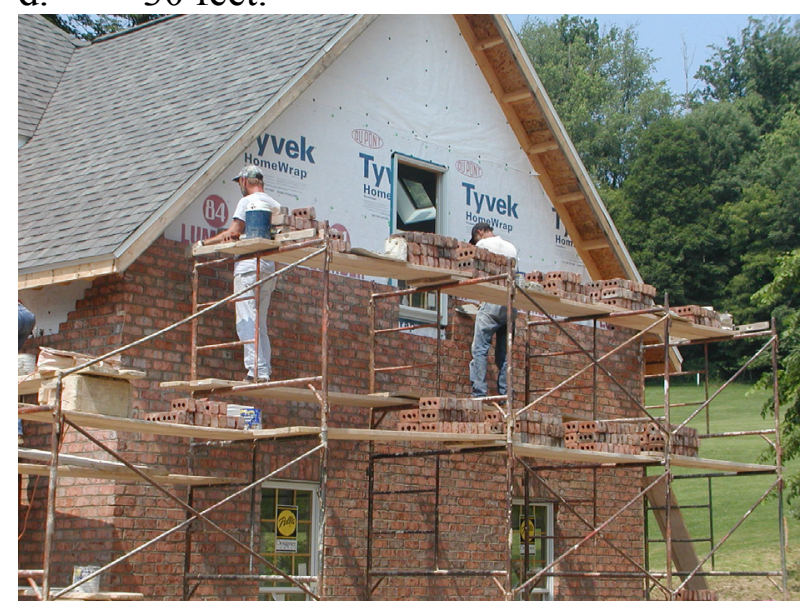


Appendix E. Pre Test Cycle III 
Appendix E.

\section{Residential Fall Protection Training Pre Test}

1. The cause of the most fatalities on residential construction sites are:

a. Electrocutions

b. Excavation cave-ins

c. Falls

d. Motor Vehicle accidents

2. While working on a foundation wall higher than 6 feet from the ground below, what is the safest way to get from one location on the wall to another?

a. Climb down a nearby ladder and climb a ladder nearest to the work location.

b. Jump off the wall and climb a ladder nearest to the work location.

c. Walk around the top of the wall to the desired location.

d. Jump off the wall and pull yourself back up onto the wall.

3. At what height above the ground below is fall protection required when working along any unprotected edge?
a. 15 feet
b. 10 feet
c. 6 feet
d. 4 feet

4. If you are working on a ladder jack scaffold system and guardrails are not installed what would be the next best solution to prevent a fall?

a. Hook a lanyard off to the house and re hook as you move up or down.

b. Guardrails are not required on ladder jack scaffolds

c. Hook to a rope grab and vertical lifeline that is connected from the roof peak.

d. Hook your lanyard to the ladder rungs above you.

5. What is a safe fall distance from the anchor point to the ground / floor below when using a 6 foot lanyard to tie off?
a. 6 feet
b. 9.5 feet
c. 14 feet
d. 18.5 feet 
Appendix F. Post Test Cycle III 
Appendix F.

\section{Residential Fall Protection Post Test}

1. While working from a scaffold of any type, at what height above the ground are guardrails required to be installed on the scaffolding?
a. 4 feet
b. 6 feet
c. 9 feet
d. $\quad 10$ feet

\section{True or False}

Which of the following conditions are not allowed when working on top of a foundation wall?

a. Adverse Weather

b. Impalement Hazards Below

c. Tools and Equipment out of reach of the worker

d. All of the Above

3. While standing up or raising wall sections during framing there is a risk of falling. What would be the preferred safe alternative to prevent a fall?

a. Be sure that there are no trip hazards on the floor that would cause you to trip and fall.

b. Hook a lanyard to the wall that is being raised and connect it to your full body harness.

c. Install an anchor point into the floor behind you and connect it to your harness.

d. Install kickers on the outside of the wall to keep the wall from falling outside the structure.

4. What is the preferred method to protect you from falling while installing trusses?

a. Stand on the top plate to receive and secure the trusses as they are hoisted into place.

b. Stand on a scaffold system inside the structure to receive and secure the trusses as they are being hoisted into place.

c. Stand on a ladder that is leaning against the top plate to receive and secure the trusses as they are hoisted into place.

d. Wear a harness, connect your lanyard to an anchor point while standing on the top plate to receive and secure the trusses.

5. What is the maximum platform height allowed for a Pump Jack Scaffold System?

a. 40 feet.

b. 10 feet.

c. 20 feet.

d. 30 feet. 
Appendix G. Pre Test Cycle V 
Appendix G.

\section{Residential Fall Protection Training Pre Test}

1. If you are working at or near a window opening on the second floor of a home what is the best fall protection solution to this hazard?

a. Install an anchor point and tie off when working around the window opening.

b. Install a guardrail in the window opening.

c. Install caution tape 6 feet back from the window opening.

d. Inform the workers to be careful when working around the window opening.

2. While working on a foundation wall higher than $\mathbf{6}$ feet from the ground below, what is the safest way to get from one location on the wall to another?

a. Climb down a nearby ladder and climb a ladder nearest to the work location.

b. Jump off the wall and climb a ladder nearest to the work location.

c. Walk around the top of the wall to the desired location.

d. Jump off the wall and pull yourself back up onto the wall.

3. At what height above the ground below is fall protection required when working along any unprotected edge?
a. 15 feet
b. 10 feet
c. 6 feet
d. 4 feet

4. If you are working on a ladder jack scaffold system and guardrails are not installed what would be the next best solution to prevent a fall?

a. Hook a lanyard off to the house and re hook as you move up or down.

b. Guardrails are not required on ladder jack scaffolds

c. Hook to a rope grab and vertical lifeline that is connected from the roof peak.

d. Hook your lanyard to the ladder rungs above you.

5. You are installing a hole cover to protect workers from falling through to the floor below during framing work. Which of the following is not a requirement of a hole cover?

a. Has to be able to withstand 2 times the intended load

b. Must be constructed of $3 / 4$ " plywood

c. Must be secured down

d. Must be marked as a "hole" or "cover" 
Appendix H. Post Test Cycle V 
Appendix H.

\section{Residential Fall Protection Training Post Test}

1. While working from a scaffold during foundation work, at what height above the ground are guardrails required to be installed on the scaffolding?
a. 4 feet
b. 6 feet
c. 9 feet
d. 10 feet

2. While standing up or raising wall sections during framing there is a risk of falling. What would be the preferred safe alternative to prevent a fall?
a. Be sure that there are no trip hazards on the floor that would cause you to trip and fall.
b. Hook a lanyard to the wall that is being raised and connect it to your full body harness.
c. Install an anchor point into the floor behind you and connect it to your harness.
d. Install kickers on the outside of the wall from falling outside the structure.

\section{At what height above the ground below is fall protection required when working along} any unprotected edge?
a. 15 feet
b. $\quad 10$ feet
c. 6 feet
d. 4 feet

\section{What is the preferred method to protect you from falling while installing trusses?}
a. Stand on the top plate to receive and secure the trusses as they are hoisted into place.
b. Stand on s scaffold system inside the structure to receive and secure the trusses as they are being hoisted into place.
c. Stand on a ladder that is leaning against the top plate to receive and secure the trusses as they are hoisted into place.
d. Wear a harness, connect your lanyard to an anchor point while standing on the top plate to receive and secure the trusses.

\section{On a steep sloped roof what is the required form of fall protection?}
a. Installation of roof jacks.
b. There is nothing required.
c. Tying off to an anchor point and using a rope grab.
d. Installing slide guards along the eaves. 
Appendix I. WVU Safety \& Health Extension Instructor / Course Evaluation 
Appendix I.

COURSE EVALUATION

\begin{tabular}{||l|l||}
\hline COURSE TITLE: & Residential Construction Fall Protection \\
\hline COURSE DATE: & \\
\hline INSTRUCTORS: & Mark Fullen \\
\hline LOCATION: & \\
\hline
\end{tabular}

1. Your overall appraisal of this course: Poor Excellent

$\begin{array}{lllllllll}\text { Handouts } & 1 & 2 & 3 & 4 & 5 & \text { NA }\end{array}$

$\begin{array}{lllllllll}\text { Audio visuals } & 1 & 2 & 3 & 4 & 5 & \text { NA }\end{array}$

$\begin{array}{lllllllll}\text { Meeting your needs and expectations } & 1 & 2 & 3 & 4 & 5 & \text { NA }\end{array}$

$\begin{array}{lllllllll}\text { Overall effectiveness } & 1 & 2 & 3 & 4 & 5 & \text { NA }\end{array}$

2. Your overall appraisal of the instructors:

$\begin{array}{lllllll}\text { Ability to communicate } & 1 & 2 & 3 & 4 & 5 & \text { NA } \\ \begin{array}{lllll}\text { Degree of preparedness } \\ \text { Organization of materials }\end{array} & 1 & 2 & 3 & 4 & 5 & \text { NA } \\ \text { Coverage of subject matter } & 1 & 2 & 3 & 4 & 5 & \text { NA } \\ \text { Responsive to class } & 1 & 2 & 3 & 4 & 5 & \text { NA } \\ \text { Overall effectiveness } & 1 & 2 & 3 & 4 & 5 & \text { NA } \\ & 1 & 2 & 3 & 4 & 5 & \text { NA }\end{array}$

3. To what extent will you make use of the materials presented in this session?

4. Additional comments \& suggestions for improvement:

5. What subjects/classes would you like to see included in the future? 
Appendix J. Residential Fall Protection Training Participant Interview Protocol 


\section{Appendix J.}
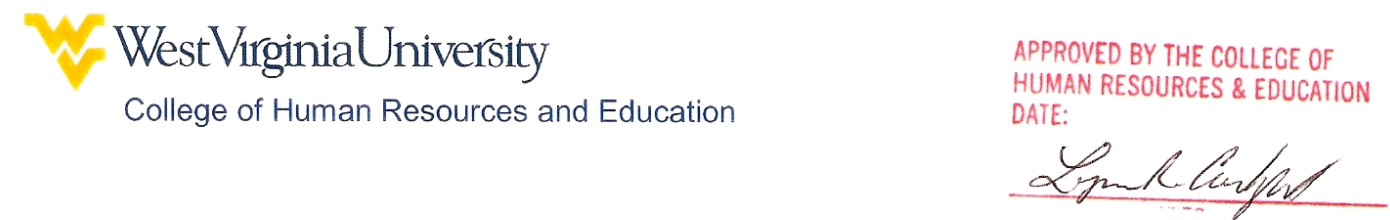

To: All Participating in a Residential Fall Protection Training Interviey

From: $\quad$ Mark Fullen, Principal Investigator $\quad$

Subject: $\quad$ Residential Fall Protection Interview Protocol

Date: $\quad$ November 30, 2006

This letter is to inform you of the following:

- This research is being conducted as part of the completion of a dissertation.

- The purpose of this study is to answer the following three questions:

- Does the training material developed bring about behavior change that could lead to a reduction in falls?

- Does the technology based availability and delivery of the training increase interest?

- Does including your feedback in the redesign of the training material impact the relevance and acceptability of the training material?

- All of your responses will be kept anonymous. The interview will be audio taped. The tapes will be stored in a locked filing cabinet in the Principal Investigators office.

- You do not have to answer every question.

- Your job status will not be affected by refusal to participate or by withdrawal from this study.

- Your participation in this study is voluntary.

If you have any questions or concerns feel free to contact Mark Fullen at (304) 293-3200. Thanks so much for your cooperation.

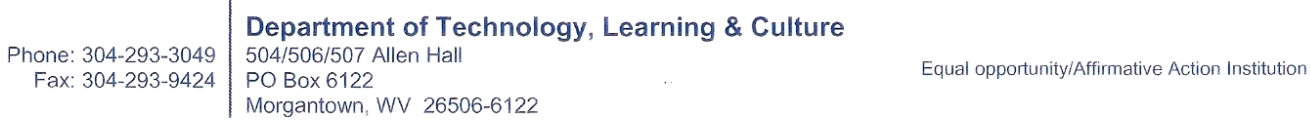




\section{Residential Fall Protection Participant Interview Protocol}

This interview is being conducted to determine the effectiveness and quality of the residential fall protection training developed by WVU Safety and Health Extension as part of an OSHA Susan Harwood Training Material Development Grant. This data is being collected as part of the requirements on my dissertation. Additionally, the information collected through these interviews will be used in the revision of the training material.

Your participation in this interview is entirely voluntary and you do not have to respond to every question. Your responses will remain anonymous. This interview is being audio recorded and will be transcribed. The recordings and transcripts will be kept in my office in a locked filing cabinet. If you do not feel comfortable with the audio taping I can take notes of the interview.

1. What is your occupation?

2. How many years have you worked in residential construction?

3. As you know, we have developed some training addressing fall hazards in residential construction.

4. Have you ever fallen from a height while working on a residential construction site?

5. Were you injured?

6. Have you ever seen or witnessed someone else falling?

7. Were they injured?

8. Do you think that fall hazards are a serious problem in the residential construction industry?

9. Have you ever participated in fall protection training, other than the training you received from us?

10. Do you think our training applies to "the real world" of construction?

11. What do think about the safe alternatives that were shown in the training? Do you think they would work?

12. In thinking about our training, what would you change?

13. Are there things that you would add to the training that we overlooked?

14. Are there items that you would remove from the training? 
15. Do you think training works in reducing falls?

16. If not, what is it that would have to take place that would help in reducing falls on residential construction sites?

17. Thanks so much for your time and insight. Before we wrap up is there anything else that you would like to add or do you have any questions for me? 
Appendix K. Residential Fall Protection Training Material Development Expert / User Interview 


\section{Appendix K.}

\section{West VirginiaUniversity}

College of Human Resources and Education

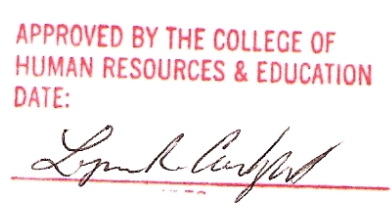

APPROVED BY THE COLLECE OF

DATE:

To: All Participating in a Residential Fall Protection Training Interview

From:

Subject:

Mark Fullen, Principal Investigator

Date:

Residential Fall Protection Interview Prótocol

November 30, 2006

This letter is to inform you of the following:

- This research is being conducted as part of the completion of a dissertation.

- The purpose of this study is to answer the following three questions:

- Does the training material developed bring about behavior change that could lead to a reduction in falls?

- Does the technology based availability and delivery of the training increase interest?

- Does including your feedback in the redesign of the training material impact the relevance and acceptability of the training material?

- All of your responses will be kept anonymous. The interview will be audio taped. The tapes will be stored in a locked filing cabinet in the Principal Investigators office.

- You do not have to answer every question.

- Your job status will not be affected by refusal to participate or by withdrawal from this study.

- Your participation in this study is voluntary.

If you have any questions or concerns feel free to contact Mark Fullen at (304) 293-3200.

Thanks so much for your cooperation. 


\section{Residential Fall Protection Training Material Development Expert / User Interview}

This interview is being conducted to determine the effectiveness and quality of the residential fall protection training developed by WVU Safety and Health Extension as part of an OSHA Susan Harwood Training Material Development Grant. This data is being collected as part of the requirements on my dissertation. Additionally, the information collected through these interviews will be used in the revision of the training material.

Your participation in this interview is entirely voluntary and you do not have to respond to every question. Your responses will remain anonymous. This interview is being audio recorded and will be transcribed. The recordings and transcripts will be kept in my office in a locked filing cabinet. If you do not feel comfortable with the audio taping I can take notes of the interview.

1. What is your job title?

2. How long have you worked in the residential construction field?

3. How did you hear about the available DVD training material?

4. Have you reviewed the DVD training material?

5. In developing this training material, we took a different approach to this training. How well did you like the design feature of this fall protection training (being able to receive or deliver training on a specific phase of residential construction related to fall hazards and being able to select appropriate safe alternatives)?

6. Are there changes that you would recommend to us to improve the quality and effectiveness of this training related to the DVD and instructional design features utilized (i.e., Menus, Narration, Ease of Use, etc)?

7. Do the fall hazards depicted in this training accurately depict real work fall hazards that you would see on residential construction site?

8. Were the safe alternatives offered in the training applicable to real world application on the job site?

9. Could you identify additional fall hazards that need to be addressed that were not included in the training from this list of construction phases?

- Site Preparation

- Foundation Work

- Flooring

- Framing

- Roofing

- Siding and Brickwork

- Other Fall Hazards During Residential Construction 
10. Could you identify in the following training modules other controls or safe methods for fall hazards that were not included in the training?

- Site Preparation

- Foundation Work

- Flooring

- Framing

- Roofing

- Siding and Brickwork

- Other Fall Hazards During Residential Construction

11. Could you make some suggestions to improve the quality and effectiveness of this training related to the content of the training developed?

12. To what extent have you or will you make use of the training material?

13. Have you used this material to conduct training? If so, how was it used?

14. How many students you have taught?

15. The DVD includes PowerPoint versions of the training material. These materials are purely image based with speaker notes. Could you comment on these materials?

16. Did you use these materials as well as the DVD based material?

17. The DVD and the PowerPoint Materials were available with Spanish narration. The PowerPoint's also included Spanish text. Have you used the training material to instruct Spanish speaking construction workers? If so, was the translation accepted and understood by the audience?

18. Do you think that training can help in the reduction of falls on construction sites?

19. If not, what is the solution to reducing falls in construction?

Thanks so much for your time and insight today. Before we wrap up is there anything else that you would like to add or do you have any questions for me? 
Appendix L. Residential Fall Protection Training Material Development Pre-Training Questionnaire 


\section{Appendix L.}
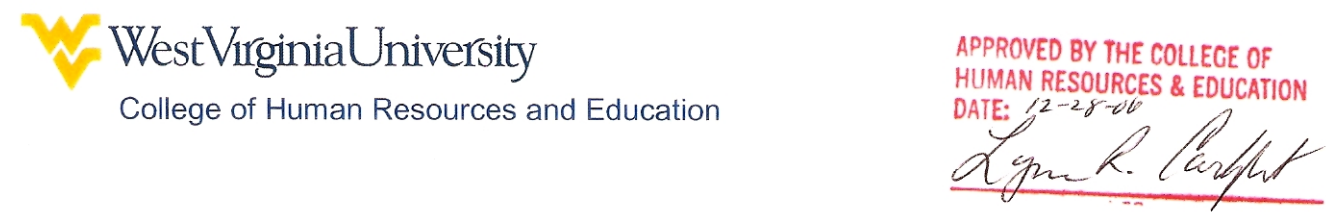

To: $\quad$ All Completing a Residential Fall Protection Training Questionnaire

From: $\quad$ Mark Fullen, Principal Investigator .

Subject: $\quad$ Residential Fall Protection Questionnaire

Date: $\quad$ November 30, 2006

This letter is to inform you of the following:

- This research is being conducted as part of the completion of a dissertation.

- The purpose of this study is to answer the following three questions:

- Does the training material developed bring about behavior change that could lead to a reduction in falls?

- Does the technology based availability and delivery of the training increase interest?

- Does including your feedback in the redesign of the training material impact the relevance and acceptability of the training material?

- All of your responses on the questionnaire will be kept anonymous.

- You do not have to answer every question.

- Your job status will not be affected by refusal to participate or by withdrawal from this study.

- Your participation in this study is voluntary.

If you have any questions or concerns feel free to contact Mark Fullen at (304) 293-3200.

Thanks so much for your cooperation. 


\section{Residential Fall Protection Training Material Development Pre-Training Questionnaire}

This questionnaire has been developed to determine the effectiveness of the residential fall protection training material developed by WVU Safety \& Health Extension as part of an OSHA Susan Harwood Training Material Development Grant. The data collected from the questionnaire is also being collected as part of the requirements for completion of a Mark Fullen's dissertation work. Additionally, the information collected through these interviews will be used in the revision of the training material.

Your participation is entirely voluntary. You do not have to complete this questionnaire or answer every question.

Your responses will be anonymous. The completed questionnaire will be kept in my office in a locked filing cabinet.

1. a. Age:

b. $\ulcorner$ Male $Г$ Female

c. Union $\Gamma$ Non-Union

2. Job title

$\begin{array}{llll}\Gamma & \text { Employee / Laborer } & \Gamma & \text { Employee / Skilled (electrician, plumber, carpenter) } \\ & \text { Supervisor / Foreman } & \ulcorner & \text { Contractor / Owner }\end{array}$

3. Type of construction your company performs (check all that apply)

\begin{tabular}{lllll}
\ulcorner & Residential & $\Gamma$ & Commercial & \\
\ulcorner & Heavy Construction & & Other \\
\hline
\end{tabular}

\section{Years worked in residential construction}

$\Gamma \quad$ Less than 1 year $\Gamma \quad 1-5$ years $\quad \Gamma \quad 5-10$ years
$\ulcorner\quad>10$ years

5. Current number of employees working in your company

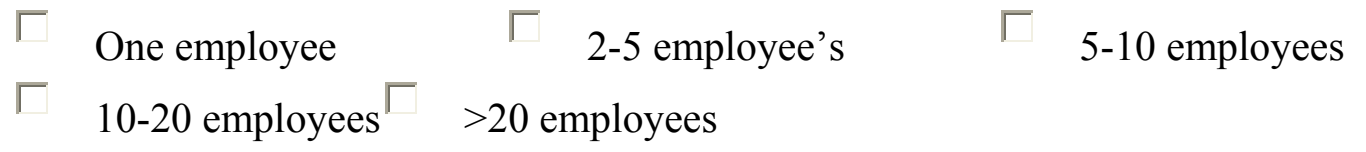

6. Have you ever fallen while working on a residential construction site?

$\ulcorner$ Yes $\ulcorner$ No

7. Have you ever been injured from falling while working on a residential construction site?

$\ulcorner$ Yes $\ulcorner$ No

8. Do you work at heights (roofs, wall and window openings, and stairs)?

$\ulcorner$ Yes $\Gamma$ No


9. Do you or have you used fall protection equipment while working on residential jobsites?

Yes $\quad$ No

10. How many DVD players do you have at home?

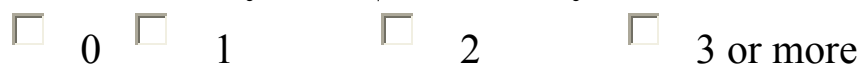

11. Do you own a portable DVD player?

$\Gamma$ Yes $\Gamma$ No

12. Have you ever accessed special features on a movie DVD such as the Director's Commentary or Deleted Scenes?

$\Gamma$ Yes $\Gamma$ No

13. Do you have a computer at home?

Yes $\Gamma$ No

14. Do you have a computer w/ web access at home?

$\Gamma$ Yes $\Gamma$ No

15. Check which internet connection speed that you have at home.

$\Gamma$ Dial Up $\Gamma$ DSL $\quad \Gamma$ Cable $\Gamma \quad$ No Internet Connection

16. Do you have access to a computer at work?

$\ulcorner$ Yes $\Gamma$ No

17. Do you have access to a computer w/ web access at work?

$\Gamma$ Yes $\Gamma$ No

18. Do you use the computer at home or work?

$\Gamma$ Yes $\Gamma$ No

19. Have you ever participated in web-based safety training?

$\Gamma$ Yes $\Gamma$ No

20. What best describes your computer usage skills?

$\ulcorner$ Advanced $\Gamma$ Intermediate $\Gamma$ Beginner $\Gamma$ First-time user

21. Have you participated in instructor led safety training previously?

$\ulcorner$ Yes $\Gamma$ No 
22. Have you had safety training on other safety topics previously?

Yes $\Gamma \quad$ No 
Appendix M. Residential Fall Protection Training Material Development Post-Training Questionnaire 


\section{Appendix M.}

West VurginiaUniversity
College of Human Resources and Education

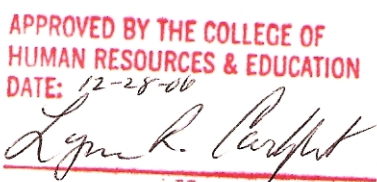

To:

From:

Subject:

All Completing a Residential Fall Protection Training Questionnaire

Date:

en, Principal Investigator

Residential Fall Protection Questionnarre

November 30, 2006

This letter is to inform you of the following:

- This research is being conducted as part of the completion of a dissertation.

- The purpose of this study is to answer the following three questions:

- Does the training material developed bring about behavior change that could lead to a reduction in falls?

- Does the technology based availability and delivery of the training increase interest?

- Does including your feedback in the redesign of the training material impact the relevance and acceptability of the training material?

- All of your responses on the questionnaire will be kept anonymous.

- You do not have to answer every question.

- Your job status will not be affected by refusal to participate or by withdrawal from this study.

- Your participation in this study is voluntary.

If you have any questions or concerns feel free to contact Mark Fullen at (304) 293-3200.

Thanks so much for your cooperation. 


\section{Residential Fall Protection Training Material Development Post-Training Questionnaire}

This questionnaire has been developed to determine the effectiveness of the residential fall protection training material developed by WVU Safety \& Health Extension as part of an OSHA Susan Harwood Training Material Development Grant. The data collected from the questionnaire is also being collected as part of the requirements for completion of a Mark Fullen's dissertation work. Additionally, the information collected through these interviews will be used in the revision of the training material.

Your participation is entirely voluntary. You do not have to complete the questionnaire or answer every question.

Your responses will be anonymous. The completed questionnaire will be kept in my office in a locked filing cabinet.

1. How was this training delivered?

$\Gamma$

$\Gamma$

Instructor Led with PowerPoints

Instructor-Led with DVD

\section{Self-Guided DVD}

Web-Based

2. How well did you like the design feature of this fall protection training (being able to receive training on a specific phase of residential construction related to fall hazards and being able to select appropriate safe alternatives)?

$\ulcorner$ Excellent $\Gamma$ Good $\Gamma$ Satisfactory $\Gamma$ Unsatisfactory

3. Does this Residential Fall Protection Training Material address fall hazards that you see on your residential worksites?

$\ulcorner$ Always $\ulcorner$ Often $\ulcorner$ Sometimes $\ulcorner$ Rarely $\ulcorner$ Never

4. Were the safe alternatives offered in the training applicable to real work applications on your job site?

$\ulcorner$ Yes $\ulcorner$ No

5. To what extent will you make use of the material developed as part of the Residential Fall Protection Training Material Development Grant?

$\ulcorner$ Always $\ulcorner$ Often $\ulcorner$ Sometimes $\ulcorner$ Rarely $\ulcorner$ Never

6. How does this training rate compared to other types of safety training you have received?

$\ulcorner$ Excellent $\ulcorner$ Good $\ulcorner$ Satisfactory $\ulcorner$ Unsatisfactory $\ulcorner$ N/A 
Appendix N. Web Requested Residential Fall Protection Training Material Development Questionnaire 


\section{Appendix N.}
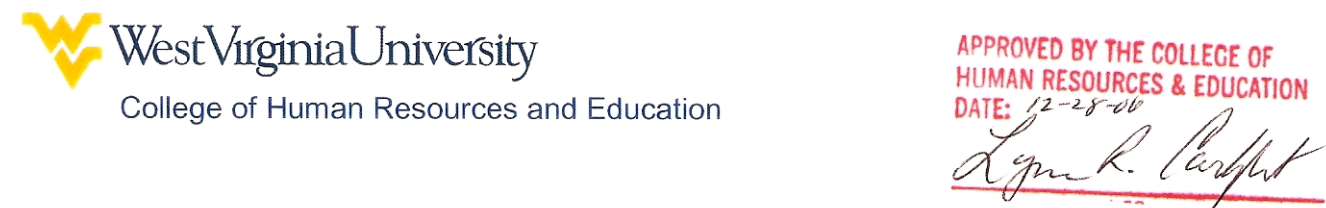

To: $\quad$ All Completing a Residential Fall Protection Training Questionnaire

From: $\quad$ Mark Fullen, Principal Investigator

Subject: $\quad$ Residential Fall Protection Questionnaire

Date: $\quad$ November 30, 2006

This letter is to inform you of the following:

- This research is being conducted as part of the completion of a dissertation.

- The purpose of this study is to answer the following three questions:

- Does the training material developed bring about behavior change that could lead to a reduction in falls?

- Does the technology based availability and delivery of the training increase interest?

- Does including your feedback in the redesign of the training material impact the relevance and acceptability of the training material?

- All of your responses on the questionnaire will be kept anonymous.

- You do not have to answer every question.

- Your job status will not be affected by refusal to participate or by withdrawal from this study.

- Your participation in this study is voluntary.

If you have any questions or concerns feel free to contact Mark Fullen at (304) 293-3200.

Thanks so much for your cooperation. 


\section{Web Requested Residential Fall Protection Training Material Development Questionnaire}

This questionnaire has been developed to determine the effectiveness of the residential fall protection training material developed by WVU Safety \& Health Extension as part of an OSHA Susan Harwood Training Material Development Grant. The data collected from the questionnaire is also being collected as part of the requirements for completion of a Mark Fullen's dissertation work. Your comments and suggestions will be considered in revising and improving the next version of this training material.

Your participation is entirely voluntary. You do not have to complete the questionnaire or answer every question. Your responses will be anonymous. The completed questionnaire will be kept in my office in a locked filing cabinet.

1. Age:

2. Male

Female

3. Job Title

Employee / Laborer

Employee / Skilled (Electrician, Plumber, etc.)

Supervisor / Forman Contractor / Owner

Safety Director

Safety Trainer/Consultant

Other

4. Years worked in residential construction related work

Less than 1 year 1-5 years 5-10 years >10 years

5. Current number of employees working in your company

One employee 2-5 employee's 5-10 employees

10-20 employees $>20$ employees Individual, not a company

6. How did you hear about the available DVD training material?

Web Search OSHA WVU Safety \& Health Extension class

Colleague Received material as an OSHA office or OTI Education Center

Received Material as a member of the original focus group

Other

7. Have you reviewed the DVD training material?

Yes No

If Yes, please answer the following questions, if No, go to Question 20.

8. How well did you like the design feature of this fall protection training (being able to receive or deliver training on a specific phase of residential construction related to fall hazards and being able to select appropriate safe alternatives)?

Excellent Good Satisfactory Unsatisfactory

9. Are there changes that you would recommend to improve the quality and effectiveness of this training related to the DVD and instructional design features utilized (i.e., Menus, Narration, Ease of Use, etc)? 
10. Do the fall hazards depicted in this training accurately depict real work fall hazards that you would see on residential construction site?
All
The majority
About Half
A few
None

11. Were the safe alternatives offered in the training applicable to real world application on the job site?
All
The majority
About Half
A few
None

12. Could you identify in the following training modules additional fall hazards that need to be addressed that were not included in the training?

Site Preparation:

Foundation Work:

Flooring:

Framing:

Roofing:

Siding and Brickwork:

Other Fall Hazards During Residential Construction:

13. Could you identify in the following training modules other controls / safe methods for fall hazards that were not included in the training?

Site Preparation:

Foundation Work:

Flooring:

Framing:

Roofing:

Siding and Brickwork:

Other Fall Hazards During Residential Construction:

14. Could you describe suggested changes that you would recommend to improve the quality and effectiveness of this training related to the content of the training developed?

15. To what extent will you make use of the material developed as part of the Residential Fall Protection Training Material Development Grant?

16. If you have conducted training with this material could you estimate how many students you have taught?

17. The DVD set included PowerPoint versions of the training material. Did you use these materials as well as the DVD based material?

Yes No 
18. The DVD and the PowerPoint Materials were available with Spanish narration. The PowerPoint's also included Spanish text. Have you used the training material to instruct Spanish speaking construction workers?

Yes No

19. If yes to 18 , was the translation accepted and understood by the audience?

Yes No

20. Have you ever fallen while working on a residential construction site?

Yes No

21. Have you ever been injured from falling while working on a residential construction site?

Yes No

22. Do you currently work at heights (roofs, wall and window openings, and stairs)?

Yes No

23. Do you or have you used fall protection equipment while working on residential jobsites?

Yes No

24. Do you own a DVD player?

Yes No

25. Have you ever accessed special features on a movie DVD such as the Director's Commentary or Deleted Scenes?

Yes No

26. Have you previously completed safety training using a DVD?

Yes No

27. Do you have a computer with web access at home?

Yes No

28. Have you ever participated in web-based safety training?

Yes No

29. Have you ever participated in traditional instructor led safety training?

Yes No 
Appendix O. Worksite Fall Hazards Audit Reports 


\section{Appendix O1.}

$\underline{\text { Fall-Safe Program Management and Related Functions }}$

Company: Bill Thompson Company

Site:

Hurricane, WV

Contact:

Bill Thompson

Address:

WV
Visits Date:

$4 / 3 / 2008$

Workers Managed: 3

Print Date:

2/9/2009
Location: First Floor

Exposure: Ladder Intervention:

1 Correct size for the job.

2 Fully opened and spreader bars locked.

3 Firm foundation for ladder feet.

NA 44 Proper climbing procedures being used.

NA 5 Three point contact rule being followed.

NA $\quad 7 \quad$ Worker not standing on top 2 steps.

8 Being used properly and not being bypassed.

9 Adequate access/egress.

\section{Raw Score: $\quad 100.00 \%$}

Exposure: Aisles, passageways and work areas.

Intervention: Aisles, Passageways and Work Areas

1 Free from trip hazards and debris.

2 Free from slip hazards and liquids.

3 Location is $25 \%$ free of slip and trip hazards.

4 Location is $50 \%$ free of slip and trip hazards.

5 Location is $75 \%$ free of slip and trip hazards.

6 Location is $100 \%$ free of slip and trip hazards

\begin{tabular}{|c|c|c|}
\hline \multirow{2}{*}{\multicolumn{3}{|c|}{ Exposure: $\quad$ Ladder }} \\
\hline & & \\
\hline \multicolumn{2}{|c|}{ Intervention: } & $\underline{\text { Ladder }}$ \\
\hline & 1 & Correct size for the job. \\
\hline & 2 & Fully opened and spreader bars locked. \\
\hline & 3 & Firm foundation for ladder feet. \\
\hline NA & 4 & Proper climbing procedures being used. \\
\hline NA & 5 & Three point contact rule being followed. \\
\hline & 6 & Free from obvious defects. \\
\hline NA & 7 & Worker not standing on top 2 steps. \\
\hline & 8 & Being used properly and not being bypassed. \\
\hline & 9 & Adequate access/egress. \\
\hline
\end{tabular}

Exposure: Aisles, passageways and work areas.

Intervention: Aisles, Passageways and Work Areas

1 Free from trip hazards and debris.

2 Free from slip hazards and liquids.

3 Location is $25 \%$ free of slip and trip hazards.

4 Location is $50 \%$ free of slip and trip hazards.

5 Location is $75 \%$ free of slip and trip hazards.

6 Location is $100 \%$ free of slip and trip hazards.

\begin{abstract}
Raw Score: $\quad \mathbf{8 3 . 3 3 \%}$
\end{abstract}
Adjusted Score: $\quad \mathbf{8 3 . 3 3 \%}$
Adjusted Score: $\quad \mathbf{1 0 0 . 0 0} \%$

Possible : $\quad 100 \%$

Possible : $\quad 100 \%$

Adjusted Score: $\quad \mathbf{1 0 0 . 0 0 \%}$
Possible : $\quad 100 \%$

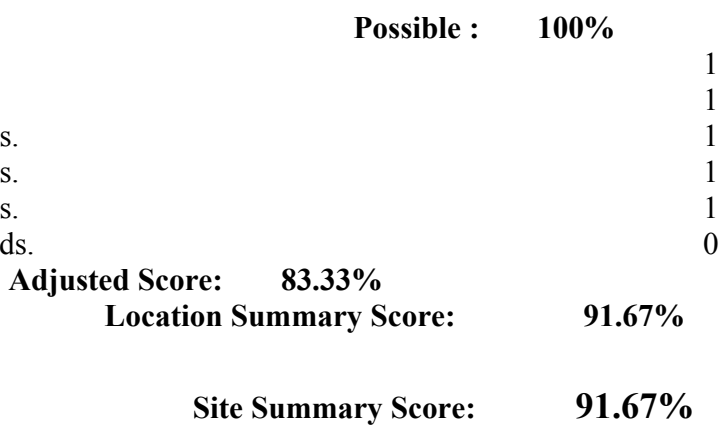




\section{Appendix O2.}

\section{$\underline{\text { Fall-Safe Program Management and Related Functions }}$}

$\begin{array}{lllr}\text { Company: } & \text { RC General Contractors } & \text { Visits Date: } & 4 / 3 / 2008 \\ \text { Site: } & \text { Home Site, Charleston, WV } & \text { Workers Managed: } & 5 \\ \text { Contact: } & & \text { Print Date: } & 2 / 9 / 2009 \\ \text { Address: } & \text { Charleston } \quad \text { WV } & \end{array}$

\section{Location: Exterior of Home}

\section{Number Exposed: $\quad 0$}

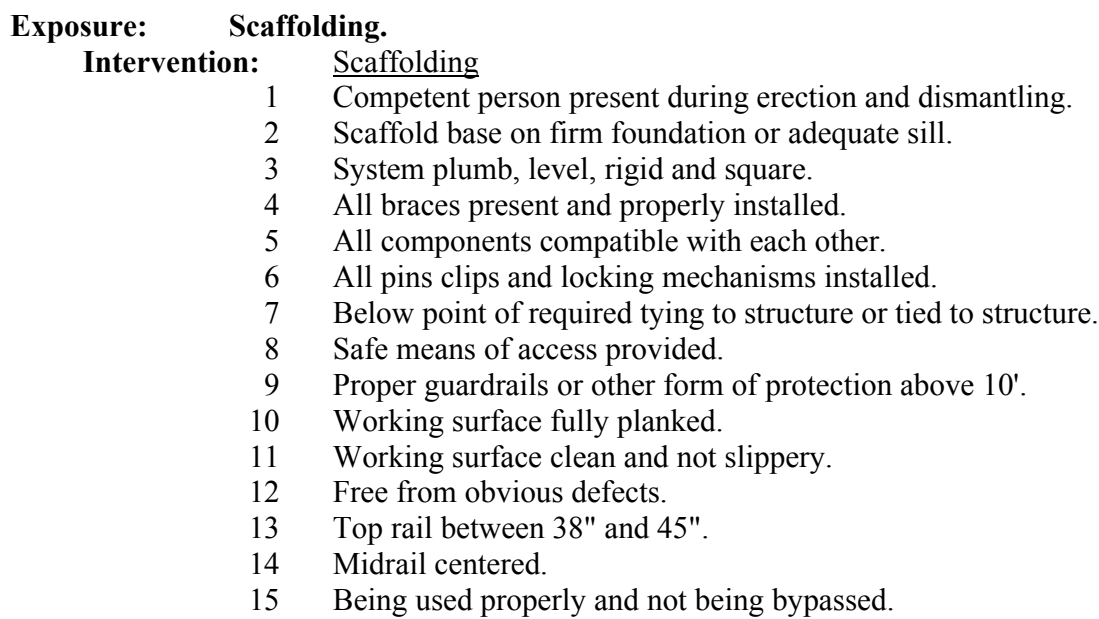

Adjusted Score: $\quad 100.00 \%$ 


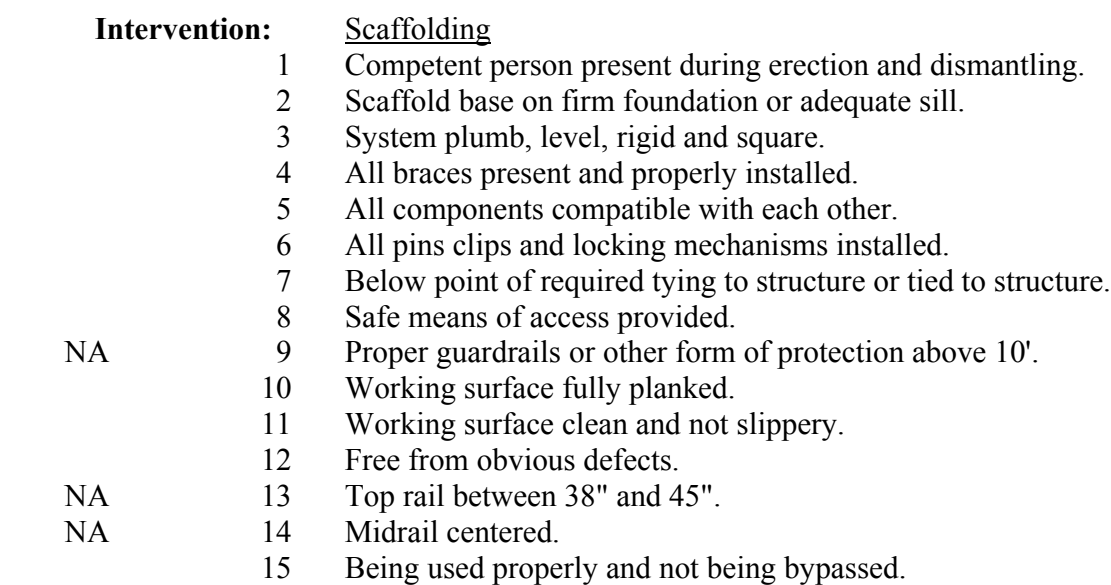

Possible : $\quad 100 \%$

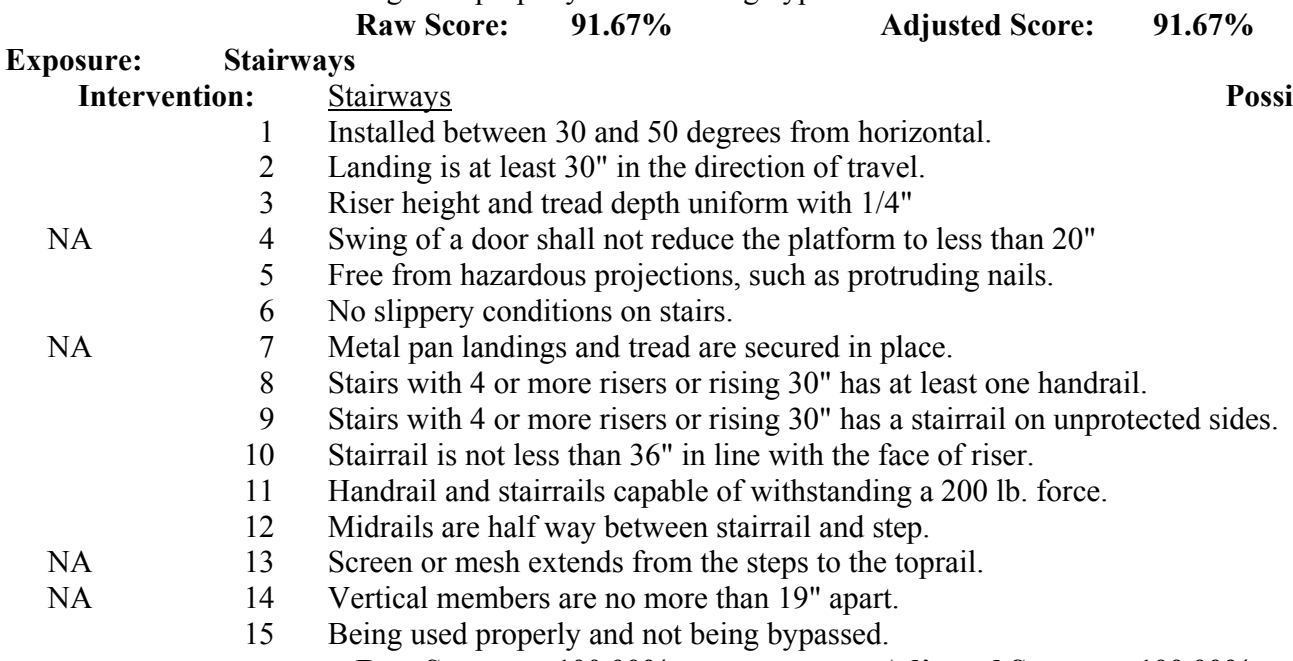

Possible : $\quad 100 \%$
Raw Score:
$100.00 \%$
Adjusted Score:
$100.00 \%$

Exposure: Wall openings $+6 \mathrm{ft}$

Intervention: Guardrail System

Possible : $\quad \mathbf{8 5 \%}$

1 Top edge between $39 "$ and 45" and at least $2 " \mathrm{x} 4$ " construction.

2 Midrail centered and at least $1 " \mathrm{x} 6 "$ or $2 " \mathrm{x} 4$ " construction.

3 Guardrail capable of withstanding $200 \mathrm{lb}$. force.

4 Midrails capable of withstanding $150 \mathrm{lb}$. force.

5 Toeboards installed and structurally sound.

6 Posts no more than 8' apart and at least 2"x4" construction.

7 Smooth and free from defects.

8 Being used properly and not being bypassed.
Raw Score:
$100.00 \%$
Adjusted Score:
$85.00 \%$

Exposure: Wall openings $+6 \mathrm{ft}$

Intervention: Guardrail System

1 Top edge between $39 "$ and 45" and at least $2 " x 4 "$ construction.

2 Midrail centered and at least 1"x6" or 2"x4" construction.

Guardrail capable of withstanding $200 \mathrm{lb}$. force.

$4 \quad$ Midrails capable of withstanding $150 \mathrm{lb}$. force.

5 Toeboards installed and structurally sound.

6 Posts no more than $8^{\prime}$ apart and at least $2 " \mathrm{x} 4$ " construction.

7 Smooth and free from defects.

8 Being used properly and not being bypassed.
Raw Score:
$\mathbf{5 0 . 0 0 \%}$
Adjusted Score:

Exposure: Wall openings $+6 \mathrm{ft}$

Intervention: Guardrail System

1 Top edge between $39 "$ and $45^{\prime \prime}$ and at least $2 " \mathrm{x} 4$ " construction.

2 Midrail centered and at least 1"x6" or 2"x4" construction.

3 Guardrail capable of withstanding $200 \mathrm{lb}$. force.

Possible : $\quad \mathbf{8 5} \%$

$42.50 \%$

Possible : $\quad \mathbf{8 5} \%$ 
$4 \quad$ Midrails capable of withstanding $150 \mathrm{lb}$. force.

Toeboards installed and structurally sound.

Posts no more than 8 ' apart and at least 2"x4" construction.

Smooth and free from defects.

Being used properly and not being bypassed.

Raw Score: $\quad \mathbf{5 0 . 0 0 \%}$

Adjusted Score: $\quad 42.50 \%$

Location Summary Score:

$72.33 \%$

\section{Location: $\quad$ Interior Second Floor $\quad$ Number Exposed: 3}

Exposure: $\quad$ Unprotected sides and edges 6' or more above lower level.

Intervention: Guardrail System

Possible : $\quad \mathbf{8 5} \%$

1 Top edge between $39 "$ and $45 "$ and at least $2 " x 4 "$ construction.

2 Midrail centered and at least 1 "x6" or $2 " \mathrm{x} 4$ " construction.

3 Guardrail capable of withstanding $200 \mathrm{lb}$. force.

4 Midrails capable of withstanding $150 \mathrm{lb}$. force.

5 Toeboards installed and structurally sound.

6 Posts no more than 8 ' apart and at least 2"x4" construction.

7 Smooth and free from defects.

8 Being used properly and not being bypassed.
Raw Score: $\quad \mathbf{8 7 . 5 0 \%}$
Adjusted Score:
$74.38 \%$

Exposure: $\quad$ Unprotected sides and edges 6' or more above lower level.

Intervention: Guardrail System

1 Top edge between 39" and 45" and at least 2"x4" construction.

2 Midrail centered and at least $1 " \mathrm{x} 6 "$ or $2 " \mathrm{x} 4$ " construction.

3 Guardrail capable of withstanding $200 \mathrm{lb}$. force.

4 Midrails capable of withstanding $150 \mathrm{lb}$. force.

5 Toeboards installed and structurally sound.

6 Posts no more than 8' apart and at least 2"x4" construction.

$7 \quad$ Smooth and free from defects.

8 Being used properly and not being bypassed.

Raw Score: $\quad \mathbf{1 0 0 . 0 0 \%}$

Adjusted Score: $\quad \mathbf{8 5 . 0 0 \%}$

Location Summary Score:

Possible : $\quad \mathbf{8 5 \%}$

1
1
1
1
1
1
1
1

$79.69 \%$

Site Summary Score:

$80.12 \%$ 


\section{Appendix O4.}

$\underline{\text { Fall-Safe Program Management and Related Functions }}$

Company: $\quad$ OC Cluss - Post Training Hazard Inspection

Visits Date:

$6 / 7 / 2007$

Site:

Greensburg, PA

Workers Managed: 3

Contact:

Print Date:

$2 / 15 / 2009$

Address: $\quad$ Uniontown $\quad$ PA

Location: $\quad$ Rear of House Gutter Install

Number Exposed: $\quad 2$

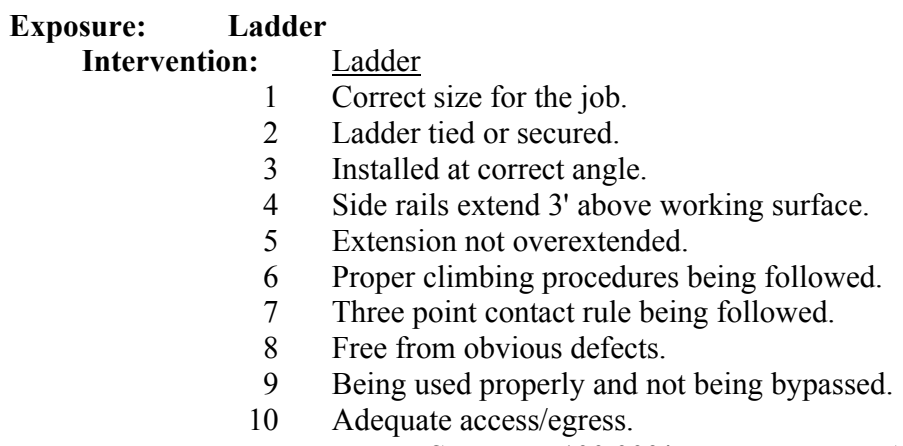


Exposure: Ladder

Intervention: $\quad \underline{\text { Ladder }}$

Possible : $\quad 100 \%$

1 Correct size for the job.

2 Ladder tied or secured.

NA $\quad 4 \quad$ Side rails extend 3' above working surface.

Extension not overextended.

Proper climbing procedures being followed.

Three point contact rule being followed.

Free from obvious defects.

9 Being used properly and not being bypassed.

10 Adequate access/egress.
Raw Score:
$77.78 \%$
Adjusted Score: $\quad \mathbf{7 7 . 7 8 \%}$

Exposure: $\quad$ Steep sloped roof work.

Intervention: Personal Fall Arrest

Possible :

$85 \%$

1 Anchor point proper and capable of withstanding 5000 lbs.or 2 times the intended load.

2 Life line limited to one worker.

3 Free fall limited to 6 ' or less.

4 Sufficient total fall clearance.

$5 \quad$ Rigged to avoid swing fall.

6 Attachment point to worker in center of back.

7 Snaphook and connector are locking type.

8 System free from obvious defects.

9 Being used properly and not being bypassed.

\section{Exposure: Ladder}

Raw Score: $\quad \mathbf{1 0 0 . 0 0 \%}$

Adjusted Score: $\quad \mathbf{8 5 . 0 0 \%}$

Intervention: Ladder

Possible : $\quad 100 \%$

1 Correct size for the job.

2 Ladder tied or secured.

NA $\quad 4 \quad$ Side rails extend 3' above working surface.

Side rails extend 3 ' above wo
Extension not overextended.

Proper climbing procedures being followed.

Three point contact rule being followed.

Free from obvious defects.

9 Being used properly and not being bypassed.

10 Adequate access/egress.

Raw Score: $\quad \mathbf{8 8 . 8 9 \%}$

Adjusted Score: $\quad \mathbf{8 8 . 8 9} \%$

Location Summary Score:

$83.89 \%$

Site Summary Score:

$83.80 \%$ 


\section{Appendix O5.}

$\underline{\text { Fall-Safe Program Management and Related Functions }}$

$\begin{array}{lllr}\text { Company: } & \text { Northern VA Roofing } & \text { Visits Date: } & 6 / 24 / 2008 \\ \text { Site: } & \text { Townhouse } & \text { Workers Managed: } & 8 \\ \text { Contact: } & & \text { Print Date: } & 2 / 9 / 2009\end{array}$

Address: Washington $\quad$ DC

Location: Exterior Roof

Exposure: Ladder Intervention:

$1 \quad$ Correct size for the job.

2 Ladder tied or secured.

3 Installed at correct angle.

NA 4 Side rails extend 3' above working surface.

5 Extension not overextended.

6 Proper climbing procedures being followed.

7 Three point contact rule being followed.

8 Free from obvious defects.

9 Being used properly and not being bypassed.

10 Adequate access/egress.

\section{Raw Score: $\quad \mathbf{8 8 . 8 9 \%}$}

\section{Exposure: Scaffolding.}

Intervention: $\quad$ Scaffolding

1 Competent person present during erection and dismantling.

2 Scaffold base on firm foundation or adequate sill.

3 System plumb, level, rigid and square.

$4 \quad$ All braces present and properly installed.

5 All components compatible with each other.

$6 \quad$ All pins clips and locking mechanisms installed.

7 Below point of required tying to structure or tied to structure.

8 Safe means of access provided.

NA

9 Proper guardrails or other form of protection above 10'.

10 Working surface fully planked.

11 Working surface clean and not slippery.

12 Free from obvious defects.

NA $\quad 13$ Top rail between 38" and 45".

NA $14 \quad$ Midrail centered.

15 Being used properly and not being bypassed.

Exposure: Ladder

Intervention:

$$
\text { Raw Score: } \quad 41.67 \%
$$

Ladder

Correct size for the job.

2 Ladder tied or secured.

3 Installed at correct angle.

NA 4 Side rails extend 3' above working surface.

5 Extension not overextended.

6 Proper climbing procedures being followed.

7 Three point contact rule being followed.

8 Free from obvious defects.

9 Being used properly and not being bypassed.

10 Adequate access/egress.
Number Exposed: $\quad 8$

Possible : $\quad 100 \%$

$\mathbf{8 8 . 8 9 \%}$

Possible : $\quad 100 \%$

Adjusted Score: $\quad 41.67 \%$

Possible : $\quad 100 \%$ 


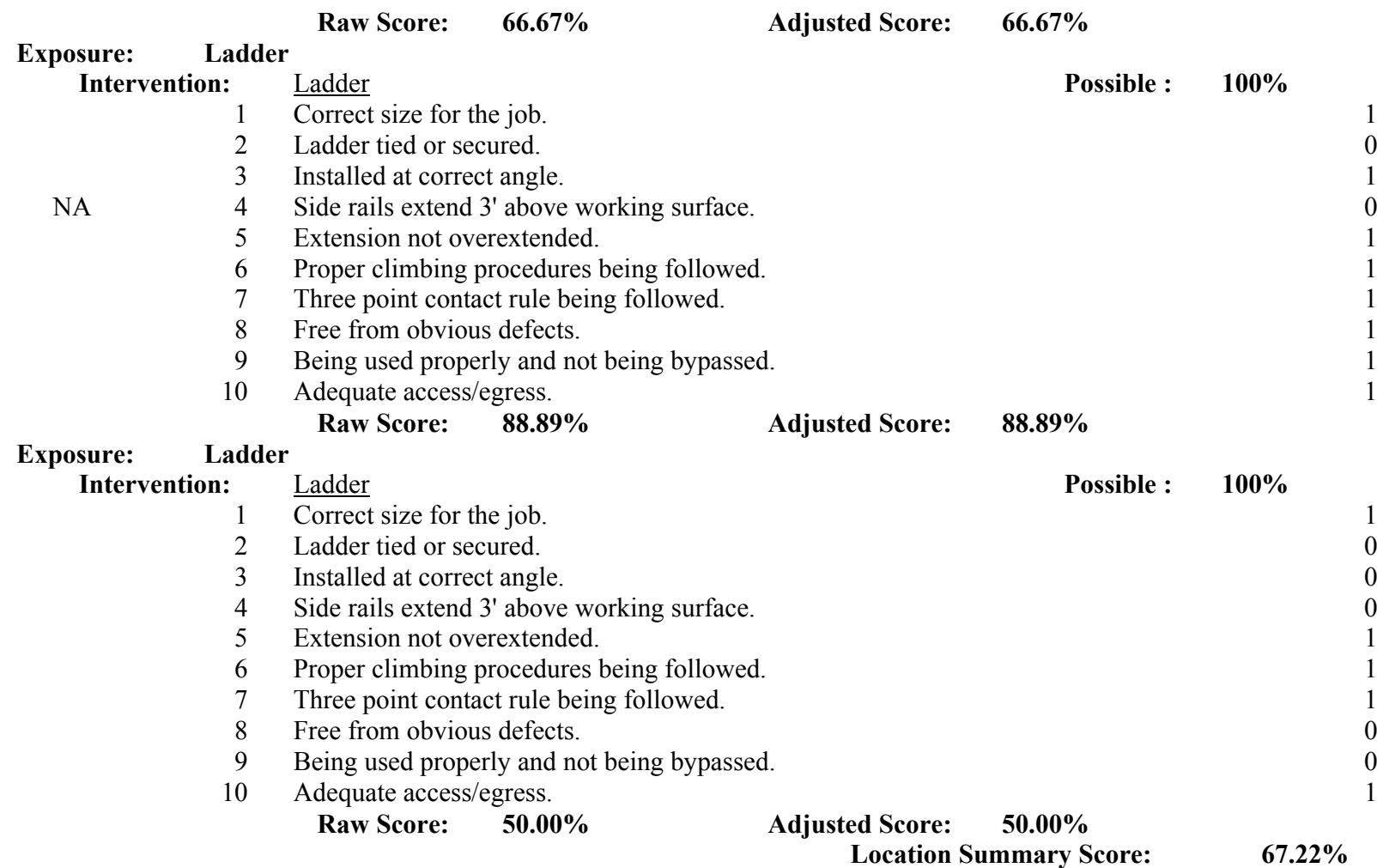

Site Summary Score:

$67.22 \%$ 